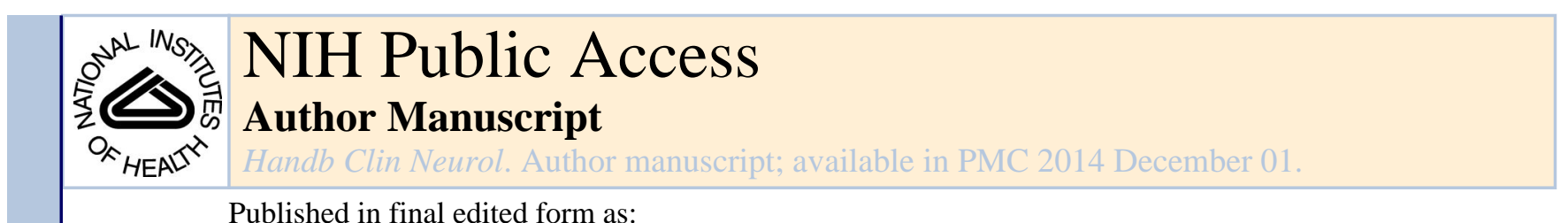

Published in final edited form as:

Handb Clin Neurol. 2013 ; 116: 693-737. doi:10.1016/B978-0-444-53497-2.00055-3.

\title{
Learning and memory
}

ANNA-KATHARINE BREM ${ }^{1}$, KATHY RAN ${ }^{1}$, and ALVARO PASCUAL-LEONE ${ }^{1,2,{ }^{*}}$

${ }^{1}$ Berenson-Allen Center for Noninvasive Brain Stimulation, Division of Cognitive Neurology, Department of Neurology, Beth Israel Deaconess Medical Center, Harvard Medical School, Boston, MA, USA

${ }^{2}$ Institut Guttman de Neurorehabilitació, Universitat Autonoma, Barcelona, Spain

\section{INTRODUCTION}

A fairly large number of studies to date have investigated the nature of learning and memory processes in brain-injured and healthy subjects with noninvasive brain stimulation (NBS) methods. NBS techniques, such as transcranial magnetic stimulation (TMS) and transcranial direct current stimulation (tDCS), can alter brain activity in targeted cortical areas and distributed brain networks. The effects depend on the stimulation parameters. TMS and tDCS can be used to interfere with ongoing brain activity ("virtual lesion") and thus help to characterize brain-behavior relations, give information about the chronometry of cognitive processes, and reveal causal relationships. Particularly in real-time combination with electroencephalography (EEG) or functional magnetic resonance imaging (fMRI), TMS and tDCS are valuable tools for neuropsychological research. They offer the combination of interference methods (TMS, tDCS) with techniques to record ongoing brain activity with high temporal (EEG) and spatial (MRI) resolution. This can: (1) shed unique insights into physiological and behavioral interactions, and (2) test, refine, and improve cognitive models; and (3) might ultimately lead to better neurorehabilitative methods.

The main goals of research with NBS in learning and memory have been to: (1) identify underlying neuropsychological processes and neurobiological components; (2) find out how this knowledge can be used to diagnose and restore dysfunctions of learning and memory in various patient populations; and (3) assess the use of NBS for enhancement purposes in healthy subjects.

In the present chapter, we first review and define memory and learning processes from a neuropsychological perspective. Then we provide a systematic and comprehensive summary of available research that investigates the neurobiological substrates of memory and aims to improve memory functions in patient populations, as well as in healthy subjects. Finally, we discuss methodological considerations and limitations, as well as the promise of the approach.

(C) 2013 Elsevier B.V. All rights reserved

"Correspondence to: Alvaro Pascual-Leone, M.D., Berenson-Allen Center for Noninvasive Brain Stimulation, Beth Israel Deaconess Medical Center, 330 Brookline Ave, Kirstein Building KS 158, Boston, MA 02215, USA. Tel: 617-667-0203,

apleone@bidmc.harvard.edu. 


\section{FRAMING APPLICATION OF NONINVASIVE BRAIN STIMULATION IN THE CONTEXT OF NEUROPSYCHOLOGICAL DEFINITIONS}

Learning and memory are cognitive functions that encompass a variety of subcomponents. These components can be structured in different ways. For example, we can focus on their temporal dimension, or differentiate various forms of memory by virtue of their content or mechanisms of acquisition (Fig. 55.1). It seems clear that the cognitive structure of learning and memory is complex, and that, given the many interactions and overlaps between key subcomponents, neither neuropsychological nor neurobiological models can give us a fully satisfying taxonomy.

A key advance in the study of the neurobiological substrates of memory was Squire's (1987, 2004) distinction between declarative and nondeclarative memory functions related to their differential reliance on distinct neural structures (Cohen and Squire, 1980). Declarative memory incorporates semantic and episodic memory, and refers to everyday memory functions, which are typically impaired in amnesic patients. Declarative memory is thought to rely primarily on medial temporal lobe structures, including the hippocampus.

Nondeclarative memory includes various subcomponents, of which procedural memory or formation of motor memories is the most prominent. Nondeclarative memory is thought to depend mostly on striatum, cerebellum, and cortical association areas (Cohen and Squire, 1980). However, procedural memory also includes associative learning forms, such as classical and operant conditioning, and nonassociative learning forms such as priming, habituation, and learning of perceptual and cognitive routines. Notably, motor learning has been regarded as a less cognitive form of memory functions, and most research makes a clear distinction between motor and nonmotor memory functions. Thus, it seems clear that declarative and nondeclarative memory processes are interactive and partly overlapping domains.

Historically, the distinction between explicit and implicit memory has been associated with declarative and nondeclarative memory. It is often argued that declarative memory (semantic and episodic memory) corresponds to explicit memories that are conscious and verbally transmittable. On the other hand, nondeclarative memory is thought to represent an implicit and nonverbal type of memory that is acquired subconsciously. Although most declarative memory contents seem to be acquired explicitly, and most nondeclarative memory contents appear to be acquired implicitly, this dichotomy is an oversimplification and ultimately not accurate. For example, declarative memories can be acquired subconsciously (e.g., memories of an emotionally intense event or subliminal priming effects), and nondeclarative memories can be acquired with conscious engagement (e.g., learning of motor movements playing sports or a musical instrument).

Another important dichotomy, first proposed by William James (1890), differentiates memory subcomponents along a temporal dimension of duration (short-versus long-term memory, STM versus LTM). Since then researchers have proposed that STM and LTM are dependent on different neural substrates. More recently, however, it has been argued that the same representations that are active during encoding are also active during STM or during retrieval from LTM. According to these models, medial temporal lobe structures are 
responsible for the establishment of new representations independent of their duration, and the same binding processes are active in both STM and LTM (Wheeler et al., 2000; Jonides et al., 2008). A related temporal dichotomy separates retrograde and anterograde memory processes (Hartje and Poeck, 2002; Markowitsch and Staniloiu, 2013). Access to memories of the past enables us to improve current decisions, while mental time traveling and the imagination of future experiences helps us to follow long-term goals (Boyer, 2008).

These are some of the complex and not mutually exclusive dichotomies of memory processes that NBS could help link to specific neural substrates. For example, one can conceive of experiments aimed at assessing whether disruption of specific brain regions affects one type of memory process and not another (e.g., Basso et al., 2010), or experiments evaluating the time at which disruption of a given brain region interferes with a specific memory step (e.g., Oliveri et al., 2001). One can use NBS to explore the nature of the relation between different processes within or across different dichotomies. Finally, one can compare the effects of NBS in healthy individuals and those with deficits in specific memory processes, and evaluate the impact on the deficit or even on other, apparently unaffected, memory and learning types.

It is also apparent that memory is tightly connected to time perception, attention, and emotional valence of memory contents, and there is evidence that brain circuits implicated with these functions are overlapping with areas involved in processing of memory functions. For example, with an increasing load of varying experiences stored in memory, time intervals are perceived to be longer (Bailey and Areni, 2006), and the subjective perception of a long time interval recruits areas such as the medial temporal cortex, which is known to be involved in binding episodic memory features (Noulhiane et al., 2007). State-dependent models have proposed that there is no "centralized clock," but that there are time-dependent neural changes, such as short-term synaptic plasticity, accounting for the decoding of temporal information (Karmarkar and Buonomano, 2007). It has been suggested that there is no linear metric of time, but that short time intervals are rather encoded in the context of (memory) events and therefore a state of local neural networks. In the same way as longterm plasticity may provide a memory of a learning experience (Martin et al., 2000), statedependent networks may use short-term plasticity to provide a memory trace of the recent stimulus history of a network (Buonomano, 2000). These are further examples of questions that NBS can help address. Pharmacological experimental interventions suggest that affecting working memory (WM) also interferes with temporal processing (Rammsayer et al., 2001). However, NBS offers a promise of spatial and temporal precision that pharmacological agents lack.

Currently, researchers are trying to integrate findings in the memory domain into comprehensive models aiming to account for the wealth of data on functional characteristics of memory networks. There are debates over the implication of attention functions to memory and specifically, for example, of the role of parietal regions to retrieval of episodic memory. For instance, the Attention to Memory (AtoM) model postulates that the dorsal parietal cortex mediates top-down attention processes guided by retrieval goals (orienting), while ventral parietal cortex mediates automatic bottom-up attention processes captured by retrieved memory output (detection) (Ciaramelli et al., 2008; Cabeza et al., 2011). Cabeza 
and colleagues (2011) have proposed that parietal regions control attention in a similar way to perception processes. While orienting-related activity for memory and perception are thought to overlap in dorsoparietal cortex (DPC), detection-related activity is believed to overlap in ventroparietal cortex (VPC). Furthermore, both DPC and VPC show strong connectivity with medial-temporal lobe (MTL) during a memory task, which can, however, shift to strong connectivity with visual cortex during a perception task. Accordingly, the DPC appears to be collaborating with the prefrontal cortex (PFC) to induce top-down attention to salient retrieval paths, while the VPC seems to be involved in the activation of episodic features in alliance with the MTL. Thus, current models of memory processes integrate dynamic concepts of distributed network interactions and plasticity. These and other conclusions are derived from brain imaging studies, which, although extremely valuable, cannot offer insights into causality (Silvanto and Pascual-Leone, 2012). Here again, NBS offers the promise of a transformative approach.

\section{Procedural memory}

Motor learning and the formation of motor memories can be defined as an improvement of motor skills through practice, which are associated with long-lasting neuronal changes. They rely primarily on the primary motor cortex, premotor and supplementary motor cortices, cerebellum, thalamus, and striatal areas (Karni et al., 1998; Muellbacher et al., 2002; Seidler et al., 2002; Ungerleider et al., 2002). As learned from patients with apraxia, the parietal cortex is furthermore implicated in accessing long-term stored motor skills and contributes to visuospatial processing during motor learning (Halsband and Lange, 2006). Frontoparietal networks may become important after learning has been established, and play key roles in consolidation and storage of skill (Wheaton and Hallett, 2007).

Motor learning and memory take a special place within the memory domain and have been studied extensively. However, procedural memories build on subprocesses similar to those of nonmotor memories: they are divided into encoding, consolidation and long-term stability, retrieval (Karni et al., 1998; Robertson et al., 2005), and even a short-term memory system has been suggested to exist in the primary motor cortex (Classen et al., 1998). Robertson (2009) has further proposed that motor and nonmotor memory processes may be fully or partially supported by the same neuronal resources during wakefulness, but not during sleep. Indeed, the MTL - which is known to support declarative memory formation also contributes to implicit procedural learning (Schendan et al., 2003; Robertson, 2007; Albouy et al., 2008). During sleep, motor and nonmotor memory systems may be functionally disengaged, which may promote independent offline consolidation within systems (Robertson, 2009). As we shall see, key aspects of such insights have been derived from recent studies using NBS.

\section{Short-term memory}

STM is an essential component of cognition and is defined as the maintenance of information over a short period of time (seconds). Multistore models differentiate between STM and LTM. STM can remain unimpaired in amnesic patients who show distinct LTM impairments (Scoville and Milner, 1957; Cave and Squire, 1992). However, STM can be impaired while LTM functions remain intact (Shallice and Warrington, 1970). According to 
William James (1890), STM (primary memory) involves a conscious maintenance of sensory stimuli over a short period of time after which they are not present anymore. On the other hand, LTM (secondary memory) involves the reactivation of past experiences that were not consciously available between the time of encoding and retrieval. This led to the assumption, going back to Hebb (1940s), that STM and LTM are based on separate neural systems. While STM engages repeated excitation of a cellular compound, LTM leads to structural changes on the synaptic level, which are preceded by consolidation processes that are thought to be highly dependent on hippocampal functions. NBS, particularly TMS combined with EEG, MRI, or other brain imaging methods, has provided valuable insights on such neurobiological questions.

Baddeley also proposed a multistore architecture of STM and LTM (Baddeley and Hitch, 1974; Baddeley, 1986). In his model, STM consists of a "verbal buffer" (phonological loop) and a "visuospatial sketchpad" (maintenance of visual information). He later added an "episodic buffer" that is supposed to draw on the other buffers and LTM (Baddeley, 2000). Finally, a "central executive" is argued to be responsible for orchestrating all components. As we shall see, such cognitive models lend themselves exquisitely well to hypothesis testing with NBS.

Unitary store models assume that the MTL is engaged in both STM and LTM, and that its function is the establishment of new representations independent of their duration. Accordingly, information that does not require binding processes can be preserved in amnesic patients, which might also explain often preserved retrieval of consolidated preinjury memories. In a comprehensive review, Jonides and colleagues (2008) concluded that STM and LTM are not separable, but that STM consists of temporarily activated LTM representations. Several studies have confirmed these assumptions (Ranganath and D'Esposito, 2001; Hannula et al., 2006; Olson et al., 2006a, b). According to their assumptions, initial neural representations are also the repository of long-term representations, as they are active during encoding, as well as during STM, or the retrieval from LTM into STM (Wheeler et al., 2000). Chronometric brain stimulation experimental designs can be applied to explore such questions (e.g., Mottaghy et al., 2003a).

\section{Long-term memory}

LTM refers to the mechanism by which acquired memories gain stability or are strengthened over time, and become resistant to interference (Brashers-Krug et al., 1996; McGaugh, 2000; Dudai, 2004). Consolidation is assessed as a change in performance between testing and retesting (Robertson et al., 2004; Walker, 2005) and provides a direct measure of "offline" changes.

Mainly two components of LTM are described in the literature and frequently included under the term "declarative memory" - episodic and semantic memory. They rely mostly on MTL structures. Episodic memory refers to contents that can be located within a spatiotemporal context, such as holiday memories or autobiographical events. On the other hand, semantic memories are independent of context and are not personally relevant. They consist of general and factual world knowledge, such as "Dakar is the capital city of 
Senegal." However, "nondeclarative" memory functions, such as procedural memory (see above), also involve LTM consolidation processes, such as knowing how to ride a bike.

Successful long-term storage includes several steps starting with the encoding of information, followed by short-term storage and consolidation from STM to LTM, as well as repeated reconsolidation. Consolidation is thought to occur in a structured way allowing for prompt and precise retrieval. Elegant work from Muellbacher and colleagues (2002) pioneered the use of NBS approaches to explore the neurobiology of such processes in humans. During consolidation, memories can undergo changes that can be quantitative (enhancement, strengthening) as well as qualitative in nature (e.g., awareness of underlying sequences) (Wagner et al., 2004; Walker, 2005; Robertson and Cohen, 2006). Chronometric brain stimulation paradigms are contributing to clarify some of these issues. Consolidation mechanisms may depend on neuronal reactivation (signal increase), on the removal of noiseinducing synaptic changes (noise decrease), or their combination, all of which can be examined with NBS. For example, offline performance changes seem to be causally associated with neuronal reactivation (Rasch et al., 2007). However, it remains to be shown that disruption of reactivation would impair consolidation processes, a problem that seems experimentally approachable with TMS.

It has been shown that sleep plays an important role in the consolidation of memories (Walker et al., 2002; Korman et al., 2007), and it has been argued (synaptic homeostasis hypothesis) that a net increase in the efficacy and number of synapses during wakefulness may add noise to the network. The reduction of noise would therefore improve the signal-tonoise ratio. Slow-wave sleep is thought to be responsible for downscaling synaptic strength and therefore noise reduction (Tononi and Cirelli, 2003, 2006), and has been associated with learning and the induction of brain plasticity (Huber et al., 2004, 2006; De Gennaro et al., 2008). NBS, in this case, particularly tDCS, is being elegantly employed to test some of these notions, while TMS-EEG studies are providing experimental support for the underlying hypotheses (e.g., Marshall et al., 2004, 2011).

\section{Encoding and retrieval}

During encoding, various event features distributed across neocortical areas are held actively online through processes guided by the PFC (Miller and Cohen, 2001; D'Esposito, 2007). TMS and tDCS lend themselves well to experimentally test such notions and evaluate precise spatial and temporal aspects of the hypothesized neural substrates.

The MTL is thought to be responsible for binding these representations in a highly structured way to enable optimal retrieval at a later timepoint (Cohen and Eichenbaum, 1991; Squire and Zola, 1998), and activity in PFC and MTL during encoding is correlated with successful retrieval (Paller and Wagner, 2002). Moreover, intermediate processes such as additional encoding or consolidation processes, are relevant for further stabilization of memories (Squire, 1984; Nadel et al., 2000; Paller, 2002). Critical encoding components include bottom-up sensory processes as well as top-down processes that select/engage, maintain, and update relevant features (Shimamura, 2011). Here again, NBS is a valuable experimental tool, thanks to the opportunity of interference with ongoing neural activity in a spatially and temporally controlled manner. 
Retrieval of episodic memories depends on the recollection of encoded contextual features of a past event, such as time, place, people, sights, thoughts, and emotions (Mitchell and Johnson, 2009). Source memory is therefore an important element of episodic memory (Tulving, 2002; Shimamura and Wickens, 2009). MTL plays its part in memory retrieval by reinstating these features (Eldridge et al., 2005; Moscovitch et al, 2006). Successful retrieval has also been associated with the PFC (Buckner et al., 1998; Dobbins et al., 2002; Simons and Spiers, 2003), which is involved in top-down executive control. The HERA (Hemispheric Encoding/Retrieval Asymmetry) model proposed by Tulving and colleagues (1994) postulates that both prefrontal lobes subserve memory processes, but play different roles. While the left PFC is believed to be more involved in encoding and semantic retrieval, the right $\mathrm{PFC}$ is thought to be more important in episodic memory retrieval. Early functional imaging studies proposed an asymmetry in memory processes irrespective of modality, with encoding and retrieval being associated with left and right/bilateral PFC respectively (Cabeza and Nyberg, 2000; Haxby et al., 2000; Fletcher and Henson, 2001). The HAROLD (Hemispheric Asymmetry Reduction in OLDer adults) model suggests that prefrontal activity during cognitive performance becomes less lateralized with advancing age (Cabeza, 2002). In particular, the role of the PFC can be evaluated with TMS or tDCS, as the PFC is easily accessible to modulation with NBS (e.g., Gagnon et al., 2010, 2011).

Besides MTL, PFC, and cortical sites that store contextual features, brain imaging studies suggest that parietal areas also play an important role in episodic memory retrieval (Wagner et al., 2005; Cabeza et al., 2008). For instance, according to a recently proposed theory ("COrtical Binding of Relational Activity", CoBRA), the VPC acts as a binding zone for episodic features and linking these to long-term memory networks (Shimamura, 2011). Both the CoBRA model and the AtoM model (see above) share some similarities, as both suggest that MTL and VPC are linked. Although the role assigned to the VPC differs between the AtoM model (bottom-up processes) and the CoBRA model (integration of event-related activity), they might complement each other. Paired-pulse TMS and the combination of TMS with brain imaging are well suited to examine such notions of corticocortical interactions.

\section{Prospective memory}

Prospective memory involves an intention to carry out a psychological or physical act and is related to future-oriented behaviors. In order to realize a goal in the future, it is necessary to retain intentions and activate them at the right time and/or in the appropriate context (Ellis et al., 1999). Depending on the time that passes in between the creation of the intention and the action, and depending on whether the action is triggered externally (context feature) or internally (internal pacemaker), prospective memory involves working and long-term memory processes, as well as attentional processes (Wittmann, 2009). Within this context it has been proposed that, during encoding, prospective memory contents obtain a special status, where they are tagged as not being achieved yet. During the presentation of prospective memory cues, temporal areas are active, possibly representing stimulus-driven attentional processes (Reynolds et al., 2009). The delay period between encoding the intention and the actual act is filled with cognitive activity that prevents active and conscious rehearsal, which differentiates prospective memory from WM or vigilance 
(Reynolds et al., 2009; Burgess et al., 2011). Prospective memory and WM take a special place within the memory domain as they rely strongly on executive processes. However, prospective memory and WM engage different brain areas. Whereas WM demands dorsolateral prefrontal cortex (DLPFC) activity, prospective memory has been associated mainly with activation in the rostral PFC (Okuda et al., 1998, 2007; Reynolds et al., 2009), which is implicated in “future thinking" (Atance and O'Neill, 2001). Such, largely theoretical, considerations derived from careful task analysis and psychological and cognitive model formation can be tested experimentally using NBS.

\section{Working memory}

WM refers to the temporary, active maintenance and manipulation of information necessary for complex tasks, while ignoring irrelevant information. It involves the temporary manipulation of external (experienced) or internal (retrieved) stimuli. Like other memory components, it also involves an encoding and retrieval stage. The PFC is an integral component for successful WM performance (Missonnier et al., 2003, 2004; Jaeggi et al., 2007), and NBS offers experimental approaches that were previously limited to animal models.

WM takes a special place within the memory functions, as it is highly dependent on topdown processing and selective attention. Top-down modulation allows us to focus attention on relevant stimuli and ignore irrelevant distractors. This is achieved through an improvement of the signal-to-noise ratio by increasing sensory activity for relevant items and decreasing activity for irrelevant items (Gazzaley and Nobre, 2012). Successful manipulation of information is necessary for encoding as well as the integration of memory functions with other so-called higher cognitive functions associated with conscious processing, such as decision-making, mental imagery, interference control, or language functions. State-dependency experimental designs with NBS (Silvanto and Pascual-Leone, 2008) might allow selective modulation of different items of information and thus shifting of the signal-to-noise ratio. This offers intriguing promises for translational applications of such NBS to populations with WM deficits, such as the elderly or patients with attentiondeficit disorders, Parkinson's disease, or schizophrenia.

\section{UNDERSTANDING THE NEURAL MECHANISMS OF LEARNING AND MEMORY}

Learning and memory processes are investigated with a wealth of methods. In the literature we find studies that use brain imaging during memory tasks, analyze the number of remembered items correlated with EEG activity, look at the influence of state changes as captured by various brain imaging and neurophysiological measures, or "borrow patients' illnesses" to investigate the impact of serendipitous lesions. The application of all these methods has led to valuable information about the neural mechanisms of memory. However, cause-effect relationships are difficult to establish. NBS is uniquely suited to provide this (Silvanto and Pascual-Leone, 2012). 
Although TMS and tDCS both promote changes in excitability, they do not rely on the same processes (Wagner et al., 2007; Nitsche et al., 2008) and behavioral effects can be different. Neuronavigated TMS can serve to probe the spatio-temporal contribution of certain structures and processes important for learning and memory. It can reveal where and when certain memory processes happen and can shed light on the interplay of multiple processes. On the other hand, the temporal and spatial resolution is lower for tDCS, which is a reason why the utility of tDCS to study spatiotemporal properties of learning and memory is limited. In the following section we concentrate on studies applying TMS as a means to induce so-called "virtual lesions" in the healthy brain (Pascual-Leone et al., 2000). In recent years, research in this field has grown immensely.

\section{Assessing memory functions by induction of virtual lesions in healthy subjects}

The first systematic investigation of the contribution of certain brain areas to cognitive functions took place during World War I. Soldiers with circumscribed brain lesions after gunshots provided information about how certain brain regions are associated with cognitive functions (Lepore, 1994). Later, Luria's work with brain-damaged war veterans contributed strongly to rekindling of the interest in neuropsychology during World War II (Luria, 1972).

Although lesion studies with patients have been widely used since then to investigate learning and memory, they have some disadvantages. Important variables, such as, for example, lesion size, comorbidities, and age, cannot be controlled easily. On the other hand, modern brain imaging methods, such as positron emission tomography (PET) and fMRI, are able to detect regional activation changes with an excellent spatial resolution, and allow for controlled, test-retest experimental designs, but their low temporal resolution does not allow investigation of the organization of distributed memory networks, and they cannot provide information on facilitatory or inhibitory effects or cause-effect relationships. EEG offers a direct measure of brain activity with exquisite temporal resolution, but spatial resolution is in turn limited.

Many of these disadvantages can be overcome when using TMS to induce a "virtual lesion" in an otherwise healthy brain (Pascual-Leone et al., 1999; Walsh and Pascual-Leone, 2003). Instead of studying cognitive functions in patients with brain lesions, we can use TMS as a means to induce virtual lesions in healthy subjects and, therefore, reproduce neurobehavioral patterns of patients with brain lesions. TMS is a method that interferes with brain activity and thereby allows probing the chronological contribution of underlying cortical areas. However, it is important to note that our understanding on the neural mechanisms underlying such "virtual lesions" is rather limited, and that a functional disruption is not simply dependent on a mere modification of cortical excitability in the targeted brain area, but appears to involve a complex interplay of inhibitory and excitatory mechanisms, disruption of oscillators, and modification of functional connectivity and synaptic efficacy across distributed neural networks.

TMS has been used in a vast number of studies investigating mechanisms of motor learning and memory (Bütefisch et al., 2004; Censor and Cohen, 2011), whereas studies looking at nonmotor memory functions are less numerous. However, recent technical advances allowing the combination of TMS with EEG and fMRI are promising and will allow further 
exploration of nonmotor memory processes (Miniussi and Thut, 2010; Thut and PascualLeone, 2010). The combination of methods has, furthermore, the advantage of helping to unravel local and distant effects of brain stimulation and give us insights into functional connectivity.

Most research groups that study WM or STM with NBS methods have focused on the DLPFC or the parietal cortex, believed to be core cortical structures for memory processes. Typically, these studies have used delayed response tasks or $n$-back tasks to measure STM or WM performance, respectively. A classical example of a delayed match-to-sample task is the Sternberg task (Sternberg, 1966), where the subject is shown a list of numbers or letters and is asked to memorize them. After the delay period, a probe number or letter is shown and the subject has to indicate whether the probe was in the list. Researchers have used several versions of this test using different stimuli and parameters. In " $n$-back tasks" a string of visual or auditory stimuli is presented, and subjects have to compare each new stimulus with a stimulus presented $n$ trials back. $n$-back tasks with $n=1$ involve a continuous maintenance and matching of stimuli, whereas $n$-back tasks with $n>1$ furthermore require concurrent engagement of manipulation processes. The reallocation of attention and processing capacity away from mere matching to actual WM processes (by increasing $n$ ) is reflected in decreasing P300 amplitudes (Watter et al., 2001). As these tasks draw on different processes, we will address them in separate sections. Studies using delayed matchto-sample tasks will therefore be summarized under the STM section, whereas studies using the $n$-back task, or other tasks requiring the online manipulation and integration of stimuli, will be summarized under the WM section. Another major section gives an overview for studies that have investigated encoding, consolidation, and retrieval.

The number of studies that apply TMS and tDCS to address questions regarding the underlying neurobiological structure and modulation of memory functions has grown rapidly in past years. The studies presented in Table 55.1 have applied single-pulse TMS, paired-pulse TMS, repetitive TMS (rTMS), and theta-burst stimulation (TBS). The tasks that were used draw on various processes (attentional, sensory, motor, verbal/nonverbal, spatial/ nonspatial, maintenance/manipulation) and stimulation parameters, such as pattern, timing, duration, intensity, and location, vary across studies. It is important to realize that memory tasks vary greatly regarding their specific cognitive demands. In addition, it is important to recognize TMS methodological factors. For example, online stimulation differs from offline stimulation in that underlying brain areas are concomitantly activated through TMS as well as through task performance. This combined activation may affect stimulation outcome. Finally, note that some studies report effects on accuracy, whereas others focus on response times (see Table 55.1). It is important to note, though, that the amount of time it takes to recognize an already encountered stimulus or to recall a memorized representation is far less important than the accuracy of this process. Finally, we have to keep in mind that the act of receiving TMS may have an influence on attentional processes that should be carefully controlled for.

Despite the many differences between studies, the growing literature summarized in Table 55.1 is providing important novel insights in the neurobiology of human learning and memory, and illustrates the power of NBS in this area of cognitive neuroscience. 
Prefrontal areas undoubtedly play an important role in STM processes. However, one of the questions that NBS studies are helping address relates to the organization of information processing streams. Is processing of STM supported through a domain-specific segregation (spatial, object, verbal processing) or rather through a processing segregation (encoding, maintenance, storage)?

Processing segregation-Most studies examining this question have used a delayed match-to-sample task and applied stimulation during either the delay period or the decision period (Fig. 55.2). High-frequency TMS applied over the parietal cortex during the delay period can improve STM function (Kessels et al., 2000; Kirschen et al., 2006; Luber et al., 2007; Yamanaka et al., 2010), but some studies found it to impair STM (Koch et al., 2005; Postle et al., 2006). In either case, the effects seem specific to the delay period, since parietal TMS during the decision phase has not been found to impact STM (Luber et al., 2007; Hamidi et al., 2009). The question whether DLPFC also plays a role during the delay phase has not been answered yet. Although some TMS studies support DLPFC participation (Pascual-Leone and Hallett, 1994; Koch et al., 2005), others have found no impact when stimulating DLPFC during the delay phase (Herwig et al., 2003; Postle et al., 2006; Hamidi et al., 2008; Sandrini et al., 2008). On the other hand, high-frequency TMS over the DLPFC during the decision period impairs STM functions (Koch et al., 2005; Hamidi et al., 2009). Therefore, although further studies are needed, findings suggest a dissociation between parietal and prefrontal areas, playing primary roles in delay and decision phases, respectively. These findings are supportive of the notions of posteroanterior temporal gradient in memory processing: parietal regions coming online first and prefrontal regions contributing to later subprocesses. Chronometric TMS experimental designs enable such notions to be directly tested further.

Mottaghy et al. (2003a) conducted the first such experiment (Fig. 55.3), albeit focusing on verbal WM. They used single-pulse TMS to explore the temporal dynamics of left and right inferior parietal and DLPFC involvement in verbal WM in six healthy volunteers. TMS was applied at 10 different time points $140-500 \mathrm{~ms}$ into the delay period of a 2-back verbal WM task. Precise and consistent targeting of a given cortical brain region was assured by using frameless stereotactic neuronavigation. A choice reaction task was used as a control task. Interference with task accuracy was induced by TMS earlier in the parietal cortex than in the PFC, and earlier over the right than the left hemisphere. This suggests a propagation of information flow from posterior to anterior cortical sites, converging in the left PFC. Significant interference with reaction time was observed after $180 \mathrm{~ms}$ with left PFC stimulation. These effects were not observed in the control task, underlining the task specificity of our results. Hamidi and colleagues (2009) also examined the roles of right and left DLPFC in recall and recognition. They found that right DLPFC stimulation impaired accuracy in delayed recall, while enhancing accuracy in delayed recognition. On the other hand, left DLPFC stimulation impaired delayed recognition. Therefore, it seems clear that TMS, in repetitive and chronometric single-pulse experimental designs, can provide valuable insights into the functional segregation of core subprocesses of STM. 
Domain-specific segregation-Mottaghy et al. (2002b), in another pioneering study (Fig. 55.4) used TMS to show that functional and modality-specific segregation need not be mutually exclusive. They applied low-frequency rTMS to explore the functional organization of STM by selectively disrupting the left dorsomedial PFC (DMPFC), DLPFC, or ventral PFC (VPFC). They applied a 10-min 1-Hz rTMS train before assessing spatial or nonspatial (face recognition) delayed-response performance. Spatial task performance was impaired after rTMS to DMPFC, whereas nonspatial task performance was impaired after rTMS to VPFC. Disruption of the DLPFC affected the performance in both tasks. This finding reveals a task-related segregation of processing streams along prefrontal structures. More recent studies have confirmed the utility of TMS to offer empirical support for modality-specific segregation. For example, Soto et al. (2012) combined evidence from fMRI and rTMS to demonstrate that verbal and nonverbal memories interact with attention functions independently: whereas rTMS to the superior frontal gyrus disrupted STM effects from colored shapes, rTMS to the lateral occipital cortex disrupted effects from written words. Finally, Morgan and colleagues (2013) used TMS to reveal the neural substrates for integration of segregated features of STM processes. They investigated STM for colors, orientations, and combinations of these, and found that continuous TBS (cTBS) over the right parietal cortex or left inferior frontal gyrus selectively impaired STM for combinations but not for single features. Therefore, functional coupling between frontal and parietal areas appears to be critical to bind modality-specific segregated processes.

Frontoparietal binding-Frontoparietal interactions in memory formation and maintenance appear to be dynamic and NBS studies - particularly studies combining TMS with MRI or EEG - help gaining critical insights in this regard.

In the motor domain, frontoparietal interactions seem to be particularly important in the early phase of learning, as has been shown in a recent study combining TMS and EEG (Karabanov et al., 2012). In the nonmotor domain, a recent TMS-fMRI study (Feredoes et al., 2011) found that DLPFC contribution to maintenance of stimuli in STM is highly dynamic depending on the presence or absence of distractors. In the presence of distractors, DLPFC changes its communication with posterior regions to support maintenance. These results are supported by tDCS studies that assign the DLPFC an important role in STM in the presence of distractors (Gladwin et al., 2012; Meiron and Lavidor, 2013). Zanto and colleagues (2011) combined EEG with 1-Hz rTMS to the right inferior frontal junction to investigate the contribution of the prefrontal cortex in top-down modulation of visual processing and STM in a delayed-match-to-sample task. They found that EEG patterns from posterior electrodes, which are associated with the distinction of task-relevant and irrelevant stimuli during early encoding, were diminished after TMS, which again predicted a subsequent decrease in STM accuracy. Subjects with stronger frontoposterior functional connectivity furthermore showed greater disruption. Higo and colleagues (2011) combined offline TMS over the frontal junction with subsequent fMRI to explore the same question. They also observed a TMS-induced decrease of effects in posterior regions depending on task relevance/irrelevance. The inferior frontal junction may therefore control the causal connection between early attentional processes and subsequent STM performance, and may 
regulate the level of activity of representations in posterior brain areas depending on their relevance/irrelevance for response selection.

It could be hypothesized that the interaction between frontal and posterior areas during the delay period secures the maintenance of information, especially if this information needs to be protected from distracting information. These processes may be related to the regulation and reactivation of patterns that were active during encoding. Accordingly, frontal areas might recruit neuronal assemblies and regulate their activity in posterior areas in order to protect and actively maintain information. Such activations may be most prominent at the beginning of the delay period and decrease gradually.

Other brain regions involved in STM-Frontal and parietal areas are undoubtedly the most explored areas in STM. Although it has been debated in the literature, there is some evidence that the cerebellum may also be involved in STM. When Desmond and colleagues (2005) applied single-pulse TMS (at 120\% resting motor threshold) over the right superior cerebellum at the beginning of the delay phase, they found an increased reaction time but no change in accuracy for correct trials in the Sternberg task. This is in agreement with a tDCS study that probed the cerebellum and found an abolishment of practice-dependent improvements in reaction time after anodal as well as cathodal tDCS in a Sternberg task (Ferrucci et al., 2008).

Last, but not least, cortical areas implied in sensory processing are also believed to be involved in STM of sensory information, which may be guided through attentional processes. A number of TMS studies have shown a role of visual cortex with visual STM and WM (see review by Postle et al., 2006). A few studies have furthermore investigated the tactile domain. Application of TMS to the visual cortex during the delay phase of STM tasks results in a decrease of accuracy in the targeted visual field for high memory loads (Van de Ven et al., 2012) or a decrease in memory scanning rates (Beckers and Hömberg, 1991). The effect of TMS was furthermore shown to be different if applied at the beginning (inhibitory) or at the end (facilitatory) of the delay period in both a visual STM task and imagery (Cattaneo et al., 2009). This is an elegant application of state-dependency TMS experimental designs (Silvanto and Pascual-Leone, 2008). Although neurons implicated in encoding are highly active at the onset of the retention period, TMS might preferentially activate neurons not involved in encoding, thereby reducing the signal-to-noise ratio of the memory trace, and impair behavior.

In the tactile domain, a TMS study using single-pulse stimulation over the middle frontal gyrus (MFG) during the early maintenance period led to a decrease in reaction time in a tactile STM task, even in the presence of a distracting stimulus (Hannula et al., 2010). In a follow-up study, the same group investigated whether this improvement only occurs when the interference is tactile, or whether MFG creates a more general top-down suppression (Savolainen et al., 2011). Their results showed that TMS did not lead to facilitation when a visual interference was presented, but only when the interfering stimulus was also tactile.

These and other findings (e.g., Silvanto and Cattaneo, 2010) suggest that sensory brain areas involved in early, modality-specific, processing of perceptual stimuli contribute to the 
formation and maintenance of STM representations through an interaction with the attentional system. In this context, TMS can help elaborate the chronology of memory processes and contributions of state-dependent processes.

WoRKING MEMORY

WM has been investigated with NBS in a growing number of studies. As for STM, most of these studies have explored the roles of DLPFC and parietal areas, trying to find an answer to the question of whether information is separately processed with regard to domain or functional subprocess (Fig. 55.5). In addition, some studies have examined the question of whether the same areas that participate in STM are also active in WM tasks.

Verbal and nonverbal WM in DLPFC_Again building on pioneering work from Mottaghy et al. (2000), most researchers have found an impairment of verbal WM after stimulation of the left DLPFC (Mull and Seyal, 2001; Mottaghy et al., 2000, 2003a; Postle et al., 2006; Osaka et al., 2007) and after stimulation of the right DLPFC (Mottaghy et al., 2003a; Postle et al., 2006; Sandrini et al., 2008). However, some studies failed to find such effects (Mull and Seyal, 2001; Rami et al., 2003; Imm et al., 2008; Sandrini et al., 2008).

The role of DLPFC in nonverbal WM has been studied much less ( Oliveri et al., 2001; Imm et al., 2008; Sandrini et al., 2008). Sandrini and colleagues (2008) tried to clarify domainand process-specific contributions of the DLPFC. They presented physically identical stimuli (letters in different spatial locations) in a 1-back task (STM) and a 2-back task (WM). Furthermore, they presented the 2-back task with stimuli of both or just one domain. A short train of 10-Hz rTMS was applied at the end of the delay period between stimuli. They found interference only during the 2-back task, and only when stimuli from both domains were presented. Interestingly, performance in the letter task was impaired after rTMS over the right DLPFC, whereas performance in the location task was impaired after rTMS over the left DLPFC. These results were interpreted as an interference effect on control mechanisms (central executive) in the sense of the suppression of task-irrelevant information. The same hypothesis has been put forward with regard to the protection of memory contents in STM (Feredoes et al., 2011; Higo et al., 2011; Zanto et al., 2011), according to which an interaction between frontal and posterior areas during the delay period secures the maintenance of information, especially in the presence of distractors.

Further experiments have aimed at dissecting the role of DLPFC in WM in order to find out whether domain- or process-specific models should be favored, and others have examined the role of interactions between DLPFC and other brain areas. Combination of TMS with brain imaging has proven quite valuable in this context. Mottaghy and colleagues (2000) found that performance in a verbal WM (2-back) task was significantly diminished after rTMS (30-second train of 4-Hz rTMS) to the left but also the right DLPFC (F3/F4). Importantly, by combining TMS with PET, they showed that TMS-altered performance in the WM task was associated with a reduction in regional cerebral blood flow $(\mathrm{rCBF})$ at the stimulation site and in distant areas as assessed with PET. In an elegant follow-up TMSPET study, the same authors (Mottaghy et al., 2003b) showed that at baseline (in the absence of TMS) there was a negative correlation between $\mathrm{rCBF}$ in the left (but not the 
right) DLPFC and WM task performance. Application of rTMS to the left or the right DLPFC could disrupt WM performance, but appeared to do so on the basis of different distributed impact on a bihemispheric network of frontal and parietal regions: whereas rTMS over the left DLPFC led to changes in rCBF in the directly targeted left DLPFC and the contralateral right PFC, rTMS over the right DLPFC led to more distributed changes involving not only bihemispheric prefrontal, but also parietal areas (Fig. 55.6B). Regardless of the differential network impact of the right or left stimulation, the behavioral consequences of rTMS were always related to the impact onto left DLPFC rCBF. This study highlights a number of important findings of relevance for future studies on NBS in memory and learning. First, it shows that rTMS to different nodes of a given brain network can exert differential impact onto said brain network. More recently, Eldaief et al. (2011) have expanded on this line of inquiry combining resting-state fMRI with TMS to examine brain network dynamics. Second, the study shows that network dynamics are modified by behavioral engagement. In other words, it might be possible to learn about mechanisms of memory and learning by examining how the impact of TMS onto a given brain network is modulated by the behavioral state. Finally, the study illustrates that brain stimulation can affect behavior by disrupting a computation in the targeted brain region (as in the case of left DLPFC rTMS) or by disrupting function of a brain regions reached via trans-synaptic network impact (as in the case of rTMS to the right DLPFC altering left DLPFC via interhemispheric connections). This later finding is important in the interpretation of brain stimulation results in general, and illustrates the power of studies integrating brain stimulation with neuroimaging in exploring causal relations between brain activity and behavior (Fig. 55.6A). In a later study, Mottaghy and colleagues (2003a) applied singlepulse TMS at different time points after stimulus presentation to probe the temporal dynamics of parietal and prefrontal contributions in verbal WM. With this approach they were able to add chronometric information to their prior findings. They showed that singlepulse TMS could interfere with task accuracy earlier in the parietal than in the PFC, and earlier over the right than left hemisphere. This indicates an information flow from posterior to anterior converging in the left PFC. These series of studies reveal that both hemispheres contribute to WM, but that the computation performed by the left PFC is critical in verbal WM.

Interestingly, involvement of DLPFC, regardless of stimulus modality, has been shown in an often-cited study using bilateral single-pulse stimulation during a 2-back task (Oliveri et al., 2001). Early temporal stimulation (300 ms) increased reaction time for object-related WM, whereas early parietal stimulation and late stimulation $(600 \mathrm{~ms})$ over the superior frontal gyrus increased reaction time for spatial WM. However, late DLPFC stimulation interfered with both tasks and not only with RT, but also with accuracy. These results relate to the discrimination of a dorsal ("where") and ventral ("what") pathway and again information flow from parietotemporal to frontal areas. They indicate that there might not only exist a bilateral involvement of the DLPFC in verbal WM, but that DLPFC might be active irrespective of stimulus material, unlike other prefrontal regions that may be segregated (see e.g., Mottaghy et al., 2002b). Segregation in posterior areas seems to be easier to pinpoint, and is concordant with the view that both hemispheres are implicated in spatial and object WM tasks (Smith and Jonides, 1997). The research that has been done up to date generally 
points into the direction of favoring a process-specific model for DLPFC, whereas other areas of the prefrontal or parietal cortex may be modality-based. Possibly, WM operations relying on DLPFC, such as selective attention and other executive processes (e.g., the inhibition of task-irrelevant stimuli), are independent of modality (Smith and Jonides, 1999) and play a role in both STM and WM. The combination of fMRI and EEG with TMS may help us to disentangle further the interactions of DLPFC and other prefrontal and parietal areas to WM functions.

Prospective memory

Prospective memory is tightly connected with other memory subcomponents (see Fig. 55.1), which makes it difficult to single out its processes. Perhaps this challenge accounts for the fact that few studies to date have explored prospective memory using NBS. One study (Basso et al., 2010) investigated whether verbal WM and prospective memory are based on common or separate processes. In a first experiment participants had to accomplish tasks with low, medium, or high WM load. In the prospective condition, subjects had to react whenever a specific word appeared. In a second experiment the prospective conditions included 1 or 3 prospective words. A higher prospective memory demand interfered with the WM task only at higher loads, whereas WM activity did not affect prospective memory performance. If both processes were part of the same system one might expect a trade-off. In a third experiment single-pulse TMS was applied to the left and right DLPFC in order to test the notion that WM and prospective memory rely on distinct systems. TMS to the DLPFC increased error rates in the prospective memory task, whereas the effect on the WM task was only marginal. No difference between hemispheres was detected. The authors concluded that WM and prospective memory may not be based on the same memory system. However, it is hard to rule out that prospective memory may require resources (including in part WM resources) and may thus be easier to disrupt with TMS. More complex TMS designs, such as input-output designs with TMS applied at various intensity and timings, seem necessary to explore this issue further.

Costa and coworkers (2011) investigated the effects of cTBS (80\% active motor threshold) on prospective memory. Stimulation over left Brodmann area (BA) 10 (frontal pole) resulted in impaired accuracy as compared with stimulation over $\mathrm{Cz}$. In a second experiment they did not find a significant difference after cTBS over left BA46 (DLPFC) and Cz. They concluded that the left BA10 is important for prospective memory processes. This is in accordance with a neuroimaging study (Koechlin et al., 1999) that tried to dissociate the roles of frontopolar and DLPF cortices in prospective memory. Costa and colleagues employed a fairly novel TMS paradigm (cTBS) and tackled a complicated memory construct (prospective memory). However, this important, innovative study also illustrates one important challenge for all studies using NBS in memory: it is ultimately critical to have separate empirical demonstration of the impact of brain stimulation on brain function, and on behavior. In fact, ideally, one would want to apply TMS, measure the behavioral impact and the impact on brain physiology, and then correlate one with the other (see Fig. 55.6A). Costa and coworkers (like most investigators using TMS or tDCS in studies of memory) placed the TMS coil over the scalp overlaying the brain regions they wanted to target (frontal pole or DLPFC). They then assumed that the TMS impact on brain activity would 
be maximal in the underlying cortex. They assessed the impact of TMS onto prospective memory and assumed that said impact must reflect the consequence of TMS-induced change in activity in the targeted brain region. There is a risk of circular logic in this approach: "If TMS over a given region has a predicted impact onto a given memory process, then I have shown that said brain region was affected by TMS and that it plays said role in memory." Obviously, independent empirical demonstration of these two steps would be important and the use of NBS in studies of memory, or studies of cognitive functions in general, should aim to achieve such experimental discrimination.

Encoding, Consolidation, Retrieval

Some studies have applied rTMS during the encoding phase and support the critical role of the PFC in such memory processes. Stimulation of the left DLPFC during the encoding phase has been found to affect both verbal (Grafman et al., 1994; Rami et al., 2003; Sandrini et al., 2003; Flöel et al., 2004; Skrdlantová et al., 2005; Blanchet et al., 2010; Gagnon et al., 2010, 2011) and nonverbal (Rossi et al., 2001, 2004; Blanchet et al., 2010; Gagnon et al., $2010,2011)$ memory. However, a few studies have reported an impact on memory functions after stimulating right frontal areas during the encoding phase of verbal (Grafman et al., 1994; Sandrini et al., 2003; Kahn et al., 2005; Blanchet et al., 2010; Machizawa et al., 2010) or nonverbal (Epstein et al., 2002; Flöel et al., 2004; Blanchet et al., 2010) memory functions. Some investigators did not find any effects after stimulating right frontal cortex (Rami et al., 2003; Köhler et al., 2004). No effects have been found after stimulating parietal (Köhler et al., 2004; Rossi et al., 2006) or occipital cortex (Grafman et al., 1994). Only one study reported impairment after stimulating the temporal cortex (Grafman et al., 1994).

Fewer studies have applied TMS during the retrieval phase of memories. Stimulation of the right DLPFC during the retrieval phase appears to be associated with an impact on both verbal (Sandrini et al., 2003; Gagnon et al., 2010, 2011) and nonverbal (Rossi et al., 2001, 2004; Gagnon et al., 2010, 2011) memory. No studies have reported an effect after stimulation of the left hemisphere during the retrieval phase.

Several studies have used NBS to reveal the important role of the ventrolateral PFC (VLPFC) in the formation of long-term memory (Grafman et al., 1994; Flöel et al., 2004; Köhler et al., 2004; Machizawa et al., 2010), and it has been suggested that VLPFC may be material-specific whereas DLPFC is not. Further studies are needed to shed light on these mechanisms.

Recent studies by Gagnon and colleagues explicitly addressed the assumptions of the HERA model (Blanchet et al., 2010; Gagnon et al., 2010, 2011) and tried to shed light on the contribution of left and right DLPFC in encoding and retrieval of verbal as well as nonverbal information. These are particularly important studies as they illustrate the value of TMS in the systematic testing of key aspects of a well formulated cognitive conceptual model. It is this type of experimental approach that can fully leverage the advantages of TMS in studies of memory and learning. In a first study, Gagnon et al. (2010) applied paired-pulse TMS (interstimulus interval (ISI) $3 \mathrm{~ms}$ ) over the left or right DLPFC during encoding or retrieval of verbal (words) and nonverbal stimuli (random shapes). They found that left and right DLPFC play different roles in encoding and retrieval irrespective of stimulus type: 
stimulation of the left DLPFC during encoding resulted in discrimination deficits, whereas stimulation of the right DLFPC during retrieval resulted in a reduced hit and disrimination rate. In a follow-up study they applied paired-pulse TMS with a longer ISI (15 ms) to promote facilitation (rather than cortical suppression) to the left and right DLPFC during encoding or retrieval of verbal (words) and nonverbal stimuli (random shapes) (Gagnon et al., 2011). They found a facilitation of reaction times during encoding (left DLPFC) and retrieval (right DLPFC) regardless of the type of material presented. These results are consistent with other TMS studies (Rossi et al., 2001, 2006; Rami et al., 2003) and provide experimental support for the HERA model, which proposes that the left PFC is more involved in semantic retrieval and episodic encoding than the right PFC, whereas the right PFC is involved in episodic retrieval (Tulving et al., 1994). This hemispheric asymmetry seems to uphold for both verbal and nonverbal material (Haxby et al., 2000; Blanchet et al., 2010).

\section{USING NONINVASIVE BRAIN STIMULATION AS A DIAGNOSTIC TOOL}

In addition to uses in cognitive neuroscience, it is worth considering the potential utility of NBS in clinical neuroscience as a diagnostic tool. Diagnostic applications of NBS are appealing as they are noninvasive and can be applied safely to various patient populations across the lifespan, if appropriate precautions are taken and guidelines are followed (Rossi et al., 2009). TMS has an excellent temporal resolution and its spatial resolution is superior to tDCS, which are important advantages in diagnostic applications and make TMS a superior tool to probe brain reactivity and brain connectivity.

To date, TMS has not been established as a diagnostic tool. However, if we define carefully the areas of need in specific patient populations, we may be able to complement currently used test measures, which rely mainly on behavioral assessments (Rost et al., 2008; Sigurdardottir et al., 2009; Gialanella, 2011; Wagle et al., 2011).

As for motor dysfunctions, nonmotor memory functions could be characterized by changes in the excitation/inhibition (E/I) balance and cortical plasticity in specific brain areas, which could be assessed with TMS-EEG measures (Thut and Pascual-Leone, 2010). Changes of such neurophysiological measures over the time-course of cognitive rehabilitation, during normal and pathological aging, or in response to treatment of disease could help us establishing neurophysiological biomarkers indicative of functional improvements. Such measures could not only be helpful to differentiate across pathological entities, but may also disentangle underlying causes of memory dysfunctions on an individual level. Finally, this information could help develop novel and improve existing interventions in order to improve memory functions.

In the memory domain there are several questions worth exploring with TMS as a diagnostic tool: (1) What is the pathogenesis of present memory problems? (2) Who is at risk of developing memory problems and what kind of memory problems? (3) Who is likely to benefit from a given behavioral/physiologic/pharmacological intervention? 


\section{Identify the pathogenesis of memory problems}

Depending on the etiology, the pathogenesis of an individual patient's memory problem can be vastly different and be affected by many factors including age, environmental, and genetic predispositions. Regardless of etiology, though, one can also aim to identify the proximal, neural dysfunction that accounts for a given memory deficit. TMS can be applied to gain insights at both these levels of inquiry.

Single- and paired-pulse TMS measures may reveal changes in connectivity or altered network dynamics and link those to specific memory functions. Advanced combined technologies such as TMS-EEG or TMS-MRI allow us to utilize TMS-induced cortical evoked potentials or TMS-induced blood oxygen level-dependent (BOLD) fMRI changes as neural measures of brain activity in specific brain regions or networks to relate to behavioral memory measures.

rTMS paradigms, for example intermittent and continuous TBS stimulation (iTBS and cTBS), can be used to obtain indices of cortical plasticity that appear related to long-term potentiation and depression (LTP and LTD)- like induction of synaptic plasticity. Such paradigms can be used to evaluate cortical plasticity in neural structures thought to support memory processes and may allow us to draw conclusions regarding the pathogenesis of a memory problem. For example, a cortical lesion within a widespread memory network could not only have a direct impact on memory functions caused by this particular lesion but could also lead to indirect deficits due to disconnection of the lesioned area with another memory hub. TMS measures could inform us about acute processes as well as adaptive or maladaptive changes characteristic of chronic processes that lead to memory dysfunctions (Pascual-Leone et al., 2011).

\section{Identify risk for developing memory problems}

Another major area of interest lies in the possible use of TMS as a physiological biomarker, which could indicate the individual risk of developing memory dysfunctions with age and predict what kind of memory problems could be expected in certain populations. Cognitive decline including memory functions presents a critical hallmark of aging (Morrison and Baxter, 2012). Early changes in neuroplasticity and neurophysiological circuits indicated by TMS measures, such as short-latency afferent inhibition (SAI), could constitute biomarkers for the development of neurodegenerative disorders (Freitas et al., 2011b). Risk identification with this approach requires the integration of numerous factors associated with causal and formal pathomechanisms, including age-related changes, but also, for example, changes related to systemic diseases, such as diabetes mellitus, that may indirectly have an impact on brain physiology and plasticity. TMS could be a valuable tool to identify these factors and consequently help guide and implement early interventions in populations at risk.

Another approach is using TMS measures to identify risks related to interventions that could result in brain lesions or dysfunctions. For example, consider neurosurgical interventions: presurgical detailed knowledge about functional contributions of brain areas to be resected can critically inform surgical approaches and minimize the risk. In this context, the Wada 
test can be used to determine hemispheric language dominance prior to brain surgery (Wada and Rasmussen, 1960). However, this test has a non-negligible risk of complications and discomfort for the patient and does not allow precise functional localization. Neuronavigated TMS can provide detailed information regarding functional anatomy of the targeted brain area and is potentially valuable for presurgical planning not only in regard to language dominance (Pascual-Leone et al., 1991; Devlin and Watkins, 2007), but also in regard to memory (Grafman et al., 1994). Such noninvasive neuronavigated TMS cortical mapping appears to correlate well with direct cortical stimulation (DCS) results and seems to be more precise than fMRI, which is the most widely used technique today (Krieg et al., 2012). As DCS is limited to intraoperative use, presurgical TMS might also save operation time by guiding intraoperative DCS.

\section{Predicting benefit from a given intervention/medication}

Cognitive rehabilitation consists in assessment-based therapeutic interventions aiming to reduce disability and promote functional recovery. Functional changes are achieved through various intervention methods targeting restitution, compensation, and adaptation (Cicerone et al., 2000). But how can we determine whether a given therapeutic intervention will have a beneficial effect for an individual patient?

TMS measures may be used not only to track but also to predict intervention-related neuroplastic changes within memory networks. Moreover, TMS measures can inform us about the functionality of specific neurophysiological circuits implicated in memory functions and may be indicative of how well an individual will profit from a given pharmacological intervention. For instance, acetylcholine (ACh) is a neurotransmitter that plays a crucial role in synaptic plasticity and memory functions, and ACh imbalances have been associated with memory deficits in patients with Alzheimer's disease (AD) (Davies and Maloney, 1976; Coyle et al., 1983). Deficits in cholinergic circuits can be counteracted with pharmacological interventions involving acetylcholine esterase (AChE) inhibitors. SAI is a TMS measure that is indicative of cholinergic circuits in the motor cortex (Di Lazzaro et al., 2000) and is altered in patients with AD (for a review see Freitas et al., 2011a). SAI may even be useful to differentiate dementia subtypes (Di Lazzaro et al., 2006, 2008) and may be used as an indicator of who will profit from AChE inhibitors. Short-latency intracortical inhibition (SICI) and the cortical silent period (cSP) are thought to reflect the excitability of inhibitory $\gamma$-aminobutyric acid (GABA)ergic circuits (Hallett, 2000) and were also found to be abnormal in patients with AD. However, the relationship of these TMS measures with specific memory dysfunctions is less clear (Freitas et al., 2011a). Notably, studies up to date have relied on TMS measures from the motor cortex. However, the combination of TMS with EEG may enable us to find more precise TMS biomarkers by exploring neurophysiological changes outside the motor cortex.

\section{MODULATING LEARNING AND MEMORY}

The interest in the augmentation of cognitive functions reaches far back into the history of modern humanity. The use of memory techniques, for instance in order to improve rhetorical skills, was already promoted by Marcus Tullius Cicero ("De Oratore", Book II, 55 вс). One of these methods, the "Cicero Memory Method" (Method of loci), a simple memory 
enhancement method that uses visualization to structure information, is still in use today. The pursuit of cognitive augmentation has since led researchers to take advantage of technical developments in order to achieve a better outcome. In the past decade, scientists have therefore started investigating the impact of various NBS techniques on memory functions.

Learning is a prerequisite for the formation of memory traces and is thought to be dependent on synaptic plasticity mediated by LTP and LTD, which also represent key mechanisms in the effects of NBS on brain functions. This has not only rendered NBS valuable for the investigation of neuroplastic processes associated with learning and memory but also promotes it as a valuable tool to enhance memory functions.

Although TMS is used mostly for diagnostic purposes and the investigation of brain structures contributing to specific functions, tDCS is more often applied to enhance brain functions.

\section{Healthy subjects}

Working memory-In the past decade, researchers have begun examining the effects of WM training on neural correlates and concomitant performance (Jaeggi et al., 2008). These studies have shown that not only can WM capacity be increased via constructive training but also that said training increases the density of cortical D1 dopamine receptors in prefrontal regions (McNab et al., 2009). The neurobiological substrate of WM is an ongoing topic of research; however, prefrontal regions are believed to be critically involved. Consistent with such notions, studies exploring the potential for NBS to enhance WM have focused on the prefrontal cortex, generally the DLPFC, and the majority have used verbal WM tasks. In most studies subjects were asked to practice STM or WM tasks concurrently to tDCS, and their WM abilities were assessed either during or afterwards.

Compared with sham stimulation, tDCS with the anode over the left DLPFC (and the cathode right supraorbitally) has been repeatedly reported to enhance WM in healthy subjects (Fregni et al., 2005; Ohn et al., 2008; Mulquiney et al., 2011; Teo et al., 2011; Zaehle et al., 2011). Some researchers have suggested that increasing stimulation intensity (Teo et al., 2011) or duration (Ohn et al., 2008) might lead to more robust effects. Only one study has reported no memory improvement following tDCS with the anode over the left DLPFC (Mylius et al., 2012), and one study reported improvement in STM but not in WM (Andrews et al., 2011). The only study applying tDCS with the anode over the right DLPFC showed no WM effect (Mylius et al., 2012). On the other hand, tDCS with the cathode over the left DLPFC (and the anode right supraorbitally) yielded diverse results in different studies, ranging from memory benefits (Mylius et al., 2012), to no effects (Fregni et al., 2005), and even negative effects (Zaehle et al., 2011). The study by Zaehle et al. (2011) is of particular interest as the authors reported that the negative effects of tDCS with the cathode over the left DLPFC were associated with decreased electroencephalographic power in theta and alpha bands over posterior (parietal) regions. On the other hand, the authors found that improved WM following tDCS with the anode over the left DLPFC was associated with increased power in alpha and theta EEG bands over parietal regions. This study illustrates the potential of studies combining behavioral and neurophysiological outcome measures, 
and suggests the critical role of corticocortical interactions in memory enhancement. It has been proposed that a more distributed network may subserve WM functions with the posterior parietal cortex (PPC) playing an important role (Mottaghy et al., 2002a; Collette et al., 2006). Stimulation might disrupt activity in a given cortical region and thus release activity in a distant connected node, resulting in paradoxical facilitation (Najib and PascualLeone, 2011). The specific nature of the stimulation seems important, although, for example, random noise stimulation over the left DLPFC showed no effects (Mulquiney et al., 2011).

In order to explore further the role of parietal structures in WM, Sandrini and colleagues (2012) applied bilateral stimulation over the PPC during a 1-back (STM) or a 2-back (WM) task. They found a double dissociation, with STM being impaired after left-anodal/rightcathodal and WM being impaired after left-cathodal/right-anodal stimulation. They concluded that this dissociation might be due to differential processing strategies in STM and WM. However, the effects might have been mediated by impact on attentional (rather than memory) processes given the fact that only response time, and not accuracy, was affected. Future studies will need to investigate further the contribution of parietal areas and their interaction with prefrontal areas to WM enhancement.

Further studies could examine the duration of effects, the likely synergistic effect of cognitive training with tDCS, or the applicability of tDCS or other NBS methods to enhance WM across the age span, from children to elderly. However, all such studies need carefully to weigh risk-benefit considerations, and should be informed by a thoughtful discussion of the ethical connotations of such enhancement approaches (Rossi et al., 2009; Hamilton et al, 2011; Horvath et al., 2011).

Short-тевм mемову-Whether NBS can enhance STM in normal subjects is less clear. Studies show less consistent results. This could in part be due to the fact that basic STM tasks are easy for healthy subjects, which leads to ceiling effects. More recent studies have applied adapted tasks, which, however, makes it difficult to compare across studies. Most studies, similar to the literature on WM, have targeted the DLPFC. Two recent studies reported beneficial effects of tDCS with the anode over the DLPFC for an STM task with additional distractors (Gladwin et al., 2012; Meiron and Lavidor, 2013). One study found a genderdependent improvement in accuracy, with male subjects profiting more from left DLPFC stimulation and female subjects profiting more from right DLPFC stimulation, but only if distractor loads were high (Meiron and Lavidor, 2013). The other study used a modified Sternberg task, which introduced additional distractor stimuli during the delay period (Gladwin et al., 2012). These workers found significant reaction time improvements after stimulation of the left DLPFC. Compared with these studies, Marshall et al. (2005) applied tDCS with either two anodes or two cathodes over DLPFC, with the reference electrodes positioned over the mastoids, and found deleterious effects of STM. This may indicate that the introduction of distractors to an STM task changes underlying neurobiological processes and enables enhancement effects. Improvements after tDCS may be due to either improved selective attention or more successful inhibition of distracting information. Indeed, a recent TMS study has shown that the role of the DLPFC in STM tasks seems to be dependent on the presence of distractors. The stronger the distraction, the more prominent the 
frontoparietal interactions become, in order to protect relevant memory representations (Feredoes et al., 2011).

Studies in which investigators stimulated parietal areas have yielded partly opposing results. This is true of studies using tDCS and those employing TMS. Regarding TMS experiments, some show worsened STM (Koch et al., 2005; Postle et al, 2006), while the other report improved STM (Hamidi et al., 2008; Yamanaka et al., 2010) after high-frequency parietal stimulation during the delay period. As for tDCS experiments, Berryhill et al. (2010) found impairment in recognition, but not free recall, after tDCS with the cathode over the right parietal cortex (and the anode over the left cheek), whereas Heimrath and coworkers (2012), positioning the cathode over the right parietal cortex (and the anode over the contralateral homologous area), found an improved capacity in a delayed match-to-sample task after tDCS when stimuli were presented in the left visual hemifield (STM for stimuli presented in the left hemifield decreased). Interestingly, Heimrath et al. used concurrent tDCS and EEG, and found a decrease in oscillatory power in the alpha band after cathodal stimulation. As alpha activity is assumed to reflect inhibition of distractors (Klimesch, 1999), the authors suggested that this measure might indicate memory performance. This study again illustrates the potential of experiments combining behavioral and neurophysiological outcome measures with NBS.

Finally, one study probed the cerebellum and found an abolishment of practice-dependent improvements in response time in a Sternberg task, regardless of whether the anode or the cathode was placed over the cerebellum (and the other electrode over the vertex) (Ferrucci et al., 2008). The contribution of the cerebellum to STM was also probed with single-pulse TMS by Desmond and colleagues (2005), who also found a negative effect on response time in the Sternberg task. Whether other cerebellar stimulation paradigms can induce an enhancement of STM remains unexplored.

General memory and learning-Researchers attempting to enhance learning processes have targeted various neural regions. Such diverse approaches again render it difficult to single out a pattern regarding stimulatory condition, mechanisms, and outcome. Most studies have applied tDCS during the learning phase, and most have targeted the left DLPFC or other left prefrontal areas. Generally, studies report memory improvement following tDCS with the anode over DLPFC (Kincses et al., 2004; Javadi and Walsh, 2012; Javadi et al., 2012) or other prefrontal areas (De Vries et al., 2010), and worsening memory after tDCS with the cathode over DLPFC (Elmer et al., 2009; Hammer et al., 2011; Javadi and Walsh, 2012; Javadi et al., 2012) or other prefrontal areas (Vines et al., 2006). However, in interpreting their results, investigators have often made the overly simplistic assumption that the effects of tDCS can be accounted for by the neurobiological effect of one of the electrodes, the anode enhancing and the cathode suppressing activity in the brain area under them. Yet, it is important to remember that tDCS is not monopolar and that all electrodes are active. Thus the brain is exposed to a flow of current with opposite faradizing effects of the anode and the cathode. Therefore, to speak of anodal tDCS or cathodal tDCS is inaccurate.

Few studies have targeted right prefrontal areas. One study reported no effects in an episodic verbal memory task after tDCS with either anode or cathode over the right prefrontal region 
(Elmer et al., 2009). Two studies showed that the learning process of threat detection in a virtual reality environment and the time required to learn this skill can be improved following tDCS with the anode over the right prefrontal (Bullard et al., 2011; Clark et al., 2012) or right parietal region (Clark et al., 2012). Furthermore, Bullard and colleagues (2011) found that applying tDCS at the beginning of the learning phase significantly enhanced learning in comparison with findings in experienced learners (after 1 hour of training).

Bilateral stimulation (anode and cathode over homologous areas of either hemisphere) has been applied in a few studies (Marshall et al., 2004, 2011; Boggio et al., 2009; Chi et al., 2010; Cohen Kadosh et al., 2010; Penolazzi et al., 2010; Jacobson et al., 2012). Jacobson and coworkers (2012) applied bilateral tDCS (anodal left, cathodal right, or vice versa) over the parietal lobe during encoding. They found improved verbal memory only when the anode was placed over the left hemisphere and the cathode over the right hemisphere. Another study investigating the contribution of the parietal cortex to numerical learning applied bilateral tDCS during a training phase of 6 days (Cohen Kadosh et al., 2010). While right-anodal/left-cathodal stimulation improved learning significantly, right-cathodal/leftanodal stimulation decreased learning compared with sham tDCS.

Penolazzi and colleagues (2010) applied bilateral tDCS (anode left and cathode right, or vice versa) over the frontotemporal cortex during encoding and found facilitated recall of pleasant images after right-anodal/left-cathodal tDCS, whereas left-anodal/right-cathodal tDCS facilitated recall of unpleasant images. These results support a theoretical model (specific valence hypothesis) according to which the right and left hemispheres are specialized in the processing of unpleasant and pleasant stimuli respectively. Another group applying bilateral stimulation (anodal left, cathodal right, or vice versa) over the anterior temporal lobe assessed visual memory (Chi et al., 2010) and also reported an improvement in memorizing different types of shape after right-anodal/left-cathodal stimulation, but no effects when applying an inverse stimulation pattern.

One set of studies has investigated effects of bilateral anodal stimulation over DLPFC during sleep and wakefulness. In their first study, Marshall and colleagues (2004) reported an improvement of memory consolidation when applying intermittent (on/off 15 seconds) anodal tDCS simultaneously over both DLPFCs during slow-wave (nonrapid eye movement, non-REM) sleep but not during wakefulness. In a second study they investigated statedependent effects, and found enhanced theta activity when transcranial slow oscillation stimulation (tSOS) was applied during wakefulness (Kirov et al., 2009). Memory enhancement occurred only when tSOS was applied during learning, but not after learning. In their third study, Marshall and colleagues (2011) applied anodal theta-tDCS (tDCS oscillating at $5 \mathrm{~Hz}$ ) during REM sleep and non-REM sleep, which led to increased gammaband activity and decreased memory consolidation respectively. The data from these studies illustrate the potential of transcranial current stimulation at specific stimulation frequencies selectively to modulate specific brain oscillations. This NBS method provides an interesting approach for investigating the relation between cortical brain rhythms, sleep-related processes, and memory functions. 
Some studies have reported apparently contradictory results, highlighting the need for further investigation of the mechanisms of action underlying tDCS and TMS. Boggio et al. (2009) found decreased "false memories" utilizing anodal tDCS over the left anterior temporal lobe, or bilateral (left-anodal/right-cathodal) tDCS. However, the same researchers reported a nearly identical effect after applying 1-Hz rTMS over the same region, a protocol that is believed to suppress activity of the targeted brain area (Gallate et al., 2009). Of course, it is possible that the behavioral effect might be related to trans-synaptic network effects, rather than being mediated by the targeted brain region. Indeed, a study using singlepulse TMS reported a facilitatory effect on verbal memory after stimulating the right inferior PFC (Kahn et al., 2005), presumably due to interhemispheric paradoxical facilitation effects. This would be consistent with another study that found an improvement in verbal memory after stimulating the left inferior PFC with 7-Hz rTMS bursts (Köhler et al., 2004). Furthermore, a paired-pulse protocol known to induce facilitatory effects led to memory improvements after stimulation of the left and right DLPFC in verbal as well as nonverbal episodic memory. The combination of stimulation techniques and other methods, such as EEG and fMRI, allows their inherent advantages to be combined to help answer these open questions.

\section{Elderly healthy subjects}

Basic memory research includes mostly young and healthy subjects. However, one of the key topics in the domain of NBS research concerns the changes of interhemispheric balance and the increased compensatory recruitment of brain areas with aging. As memory represents an overarching topic for the elderly, it is crucial to promote research that investigates these changes and provides information as to how to enhance memory functions. Furthermore, research with healthy elderly subjects is vital if we want to translate it into the clinical setting, as patients with memory deficits are mostly older. A newly emerging field has started to investigate memory enhancement in elderly subjects and underlying models (Rossi et al., 2004; Solé-Padullés et al., 2006; Manenti et al., 2011; Flöel et al., 2012).

The "Hemispheric Asymmetry Reduction in Older Adults" (HAROLD) model states that prefrontal activity during cognitive performance becomes less lateralized with advancing age (Cabeza, 2002). Manenti and colleagues investigated the differential assumptions of the HERA model (young subjects) and the HAROLD model (elderly subjects), suggesting that hemispheric asymmetry is reduced with age. Interestingly, they could show that lowperforming elderly subjects continue showing prefrontal asymmetry, whereas highperforming elderly individuals show reduced asymmetry indicative of compensatory mechanisms (Manenti et al., 2011).

Although lateralized activations within the PFC can be observed in younger subjects during episodic memory tasks (Rossi et al., 2001), this asymmetry vanishes progressively with advancing age, as indicated by bilateral interference effects (Rossi et al., 2004).

Conversely, the predominance of left DLPFC effect during encoding was not abolished in older subjects, indicating its causal role for encoding along the lifespan. However, this study did not differentiate between high- and low-performing subjects. Another study supported 
the assumption that higher performance is associated with more bilateral recruitment of brain areas and that stimulation may be able to promote the recruitment of additional brain areas to compensate for age-related decline. Solé-Padullés and colleagues (2006) found improved performance in associative learning after $5-\mathrm{Hz}$ offline rTMS, which was accompanied by additional recruitment of right prefrontal and bilateral posterior brain regions.

A tDCS study showed improvements in spatial learning and memory in elderly subjects (mean 62 years) when stimulating during encoding (Flöel et al., 2012). Anodal stimulation over the right temporoparietal cortex improved free recall 1 week later compared with sham stimulation. No immediate learning differences were observed, which indicates that retention (less decay) rather than encoding was affected by the stimulation.

To summarize, several studies have found different results following the stimulation of the DLPFC in young and elderly healthy subjects in accordance with the HAROLD model (Cabeza, 2002). These differences could be due to changes in interhemispheric balance and recruitment of different brain areas for the same tasks, which could arise due to compensatory mechanisms. It remains to be further elucidated whether these changes reflect local or distributed mechanisms, whether compensatory recruitment of additional brain areas is associated with higher performance levels and could be enhanced by NBS.

\section{Patients}

Compared with the wealth of studies that have been done with healthy and mostly young subjects, studies on patients are rather sparse (see Table 55.1). The evidence is encouraging and calls for further investigation of the combined application of NBS and neuropsychological therapy. Besides behavioral measures, these studies should ideally include other measurements, such as assessment of brain plasticity or memory-specific neurophysiological outcomes. The work on patients with stroke is very preliminary, and more studies with larger patient numbers and better control of lesion location are needed. In one crossover, sham-controlled study, Jo et al. (2009) applied tDCS with the anode over the left DLPFC (and the cathode over the contralateral supraorbital area) in a 2-back task to 10 patients with unilateral, right-hemispheric, ischemic, or hemorrhagic strokes (1-4 months poststroke). After a single stimulation session, performance accuracy but not reaction time improved significantly. Enhancement of memory functions has been more extensively investigated in patients with $\mathrm{AD}$ and Parkinson's disease (PD). These findings provide evidence that NBS could be a safe and useful tool in restoring/compensating brain functions through activation of primary and compensatory networks that underlie memory functions.

Alzhemer's disease-A few studies have demonstrated effects of NBS on cognitive functions in AD (6 TMS, 3 tDCS). The first studies that used NBS in AD looked primarily at language and not memory functions. Cotelli and colleagues used rTMS $(20 \mathrm{~Hz})$ over the left and right DLPFC and reported positive effects for both hemispheres. They applied a single online session of rTMS in two crossover, sham-controlled studies (Cotelli et al., 2006, 2008). In the first study they reported improved accuracy in action naming, but not object naming, for all patients (Cotelli et al., 2006). In the second study they could replicate the positive results for 
action naming; however, object naming also improved significantly, although only in moderately to severely impaired patients (Cotelli et al., 2008). The authors hypothesized that the lack of improvement in object naming may be due to a ceiling effect. Furthermore, the bilateral effect could have been due to compensatory activation of right hemispheric resources.

In a third placebo-controlled study the same authors tested various functions, including memory, executive functions, and language in patients with moderate AD (Cotelli et al., 2011). This study entailed 4 weeks of daily sessions of 20-Hz rTMS to the left DLPFC. Although they found significant improvements in sentence comprehension after 10 sessions (with no further improvement after 20 sessions), they did not find any improvements in memory and executive functions (Cotelli et al., 2011). This lack of improvement could be due to the fact that the patients were not doing any specific concomitant cognitive training. Alternatively, the lack of memory effects could be related to the targeted brain region.

Bentwich and colleagues (2011) interleaved cognitive training and rTMS (10 Hz) during 30 sessions while stimulating six different brain regions (Broca, Wernicke, right and left DLPFC and parietal cortices). During each session three of these regions were stimulated while patients did cognitive tasks that were developed to fit each of these regions. Improvements in cognitive functions were significant, as measured using the cognitive subscale of the Alzheimer's Disease Assessment Scale (ADAS-Cog), and were maintained for 4.5 months after the training. A case report (Haffen et al., 2012) showed an improvement in episodic memory (free recall) and processing speed following 10 sessions of rTMS (10 $\mathrm{Hz}$ ) over the left DLPFC. These are open trials and, obviously, sham-controlled interventions are needed. However, the results are promising and warrant follow-up. In a sham-controlled trial, Ahmed and colleagues (2012) assigned 45 patients with AD to three different treatment groups to study the effects of high- or low-frequency rTMS $(20 \mathrm{~Hz}, 1$ $\mathrm{Hz}$ ), or sham stimulation. Patients received treatment on 5 consecutive days without combined cognitive training. Mildly to moderately impaired patients receiving highfrequency rTMS improved significantly on all scales (Mini Mental State Examination (MMSE), Instrumental Daily Living Activity Scale, Geriatric Depression Scale), and maintained these improvements for 3 months. However, severely impaired patients did not respond to the treatment.

Two crossover studies applied tDCS for one session and reported improvements in visual recognition memory following stimulation of the left DLPFC and temporoparietal cortex (TPC) (Boggio et al., 2009), and in word recognition following stimulation of the bilateral TPC (Ferrucci et al., 2008). In the first study, the authors applied 15 minutes of anodal, cathodal, and sham stimulation over bilateral TPC on three different sessions in patients with mild AD. While anodal tDCS led to an improvement, cathodal stimulation led to impairments in word recognition. No effects were observed in a visual attention task (Ferrucci et al., 2008). In the second study, mildly to moderately impaired AD patients received anodal tDCS over the left DLPFC, the left TPC, or sham stimulation. Stimulation over both DLFPC and TPC resulted in a significant improvement in visual recognition. No effects were observed on selective attention or a visual delayed match-to-sample task. 
Possibly, tDCS-induced changes in cholinergic activity contributed to these improvements. A recent study reported a significant change of SAI (ISI $2 \mathrm{~ms}$ ) in the motor cortex of healthy subjects after anodal stimulation, while the resting motor threshold and amplitudes of motor evoked potentials did not change (Scelzo et al., 2011). This could explain the positive impact of tDCS on memory functions in the above-mentioned studies. Future studies measuring behavioral along with neurophysiological effects and exploring correlations between them would be desirable.

Parkinson's disease-Two studies have applied TMS or tDCS with the aim of improving cognitive functioning in PD. The first study compared the effects of active or sham rTMS and fluoxetine or placebo in patients with PD with concurrent depression (Boggio et al., 2005). The authors applied 15-Hz rTMS over the left DLPFC for 10 daily sessions, and assessed cognitive functions at baseline, and 2 and 8 weeks after the treatment. Treatments were not combined with cognitive training or psychotherapy. After 2 weeks both interventions led to similar improvements in the Stroop Test and the Wisconsin Card Sorting Test (executive functions), and the Hooper (visuospatial functions). Furthermore, depression rates improved significantly in both groups. However, no improvements were reported in STM or WM (digits forward and backward). Eight weeks after treatment, these improvements declined slightly but remained significant.

The second study found improved accuracy in a 3-back task during a single session of anodal tDCS over the left DLPFC. Improvement was significant at a stimulation intensity of $2 \mathrm{~mA}$ but not at $1 \mathrm{~mA}$ (Boggio et al., 2006).

Cognitive impairments in PD are often associated with depression symptoms, which occur in about $35 \%$ of patients. Furthermore, dementia is common in these patients with a point prevalence of 30\% (Aarsland and Kurz, 2010). Further studies are needed to investigate underlying processes leading to cognitive impairments. Moreover, studies should evaluate the efficacy of repetitive NBS in combination with cognitive training for this patient population.

\section{CONCLUSION}

A quickly growing number of studies is using NBS applications to study the underlying neurobiological substrates of memory functions, to investigate the use of TMS as a diagnostic tool, and the application of NBS to enhance memory functions. To date, most studies have used TMS to probe underlying memory processes and their causal and temporal relationships, whereas TMS, tDCS, and other forms of transcranial current stimulation are being used to enhance memory functions in healthy as well as patient populations. The combination of NBS with other methods, such as EEG and fMRI, enables the measurement of behavioral along with neurophysiological effects; the exploration of correlations between them is desirable to advance our neurobiological understanding and optimize future interventions. 


\section{Acknowledgments}

A.P.-L. serves on the scientific advisory boards for Nexstim, Neuronix, Starlab Neuroscience, Neosync, and Novavision, and is listed as an inventor on several issued and pending patents on the real-time integration of transcranial magnetic stimulation (TMS) with electroencephalography (EEG) and magnetic resonance imaging (MRI). Work on this study was supported by grants from the National Center for Research Resources: Harvard Clinical and Translational Science Center/Harvard Catalyst (UL1 RR025758), and investigator-initiated grants from Nexstim Inc. and Neuronix. A.-K.B. was supported by the Young Academics Support of the University of Zurich, Switzerland. K.R. was supported by the Dean's Summer Research Award Grant, Harvard University.

\section{$\boldsymbol{R}_{\text {EFERENCES }}$}

Aarsland D, Kurz MW. The epidemiology of dementia associated with Parkinson disease. J Neurol Sci. 2010; 289:18-22. [PubMed: 19733364]

Ahmed MA, Darwish ES, Khedr EM, et al. Effects of low versus high frequencies of repetitive transcranial magnetic stimulation on cognitive function and cortical excitability in Alzheimer's dementia. J Neurol. 2012; 259:83-92. [PubMed: 21671144]

Albouy G, Sterpenich V, Balteau E, et al. Both the hippocampus and striatum are involved in consolidation of motor sequence memory. Neuron. 2008; 58:261-272. [PubMed: 18439410]

Andrews SC, Hoy KE, Enticott PG, et al. Improving working memory: the effect of combining cognitive activity and anodal transcranial direct current stimulation to the left dorsolateral prefrontal cortex. Brain Stimul. 2011; 4:84-89. [PubMed: 21511208]

Atance CM, O’Neill DK. Episodic future thinking. Trends Cogn Sci. 2001; 5:533-539. [PubMed: 11728911]

Baddeley, AD. Working Memory. Clarendon; Oxford: 1986.

Baddeley AD. The episodic buffer: a new component of working memory? Trends Cogn Sci. 2000; 4:417-423. [PubMed: 11058819]

Baddeley, AD.; Hitch, G. Working memory. In: Bower, GA., editor. Recent Advances in Learning and Motivation. Vol. 8. Academic Press; New York: 1974. p. 47-90.

Bailey N, Areni CS. Background music as a quasi clock in retrospective duration judgments. Percept Mot Skills. 2006; 102:435-444. [PubMed: 16826665]

Basso D, Ferrari M, Palladino P. Prospective memory and working memory: asymmetrical effects during frontal lobe TMS stimulation. Neuropsychologia. 2010; 48:3282-3290. [PubMed: 20637788]

Beckers G, Hömberg V. Impairment of visual perception and visual short term memory scanning by transcranial magnetic stimulation of occipital cortex. Exp Brain Res. 1991; 87:421-432. [PubMed: 1769392]

Bentwich J, Dobronevsky E, Aichenbaum S, et al. Beneficial effect of repetitive transcranial magnetic stimulation combined with cognitive training for the treatment of Alzheimer's disease: a proof of concept study. J Neural Transm. 2011; 118:463-471. [PubMed: 21246222]

Berryhill ME, Wencil EB, Branch Coslett $\mathrm{H}$, et al. A selective working memory impairment after transcranial direct current stimulation to the right parietal lobe. Neurosci Lett. 2010; 479:312-316. [PubMed: 20570713]

Blanchet S, Gagnon G, Schneider C. The contribution of the dorsolateral prefrontal cortex in full and divided encoding: a paired-pulse transcranial magnetic stimulation study. Behav Neurol. 2010; 23:107-115. [PubMed: 21098964]

Boggio PS, Fregni F, Bermpohl F, et al. Effect of repetitive TMS and fluoxetine on cognitive function in patients with Parkinson's disease and concurrent depression. Mov Disord. 2005; 20:1178-1184. [PubMed: 15895421]

Boggio PS, Ferrucci R, Rigonatti SP, et al. Effects of transcranial direct current stimulation on working memory in patients with Parkinson's disease. J Neurol Sci. 2006; 249:31-38. [PubMed: 16843494]

Boggio PS, Khoury LP, Martins DC, et al. Temporal cortex direct current stimulation enhances performance on a visual recognition memory task in Alzheimer disease. J Neurol Neurosurg Psychiatry. 2009; 80:444-447. [PubMed: 18977813] 
Boggio PS, Ferrucci R, Mameli F, et al. Prolonged visual memory enhancement after direct current stimulation in Alzheimer's disease. Brain Stimul. 2012; 5:223-230. [PubMed: 21840288]

Boyer P. Evolutionary economics of mental time travel? Trends Cogn Sci. 2008; 12:219-224. [PubMed: 18468941]

Brashers-Krug T, Shadmehr R, Bizzi E. Consolidation in human motor memory. Nature. 1996; 382:252-255. [PubMed: 8717039]

Buckner RL, Koutstaal W, Schacter DL, et al. Functional-anatomic study of episodic retrieval using fMRI. I. Retrieval effort versus retrieval success. Neuroimage. 1998; 7:151-162. [PubMed: 9597657]

Bullard LM, Browning ES, Clark VP, et al. Transcranial direct current stimulation's effect on novice versus experienced learning. Exp Brain Res. 2011; 213:9-14. [PubMed: 21706300]

Buonomano DV. Decoding temporal information: a model based on short-term synaptic plasticity. $\mathrm{J}$ Neurosci. 2000; 20:1129-1141. [PubMed: 10648718]

Burgess PW, Gonen-Yaacovi G, Volle E. Functional neuroimaging studies of prospective memory: what have we learnt so far? Neuropsychologia. 2011; 49:2246-2257. [PubMed: 21329712]

Bütefisch CM, Khurana V, Kopylev L, et al. Enhancing encoding of a motor memory in the primary motor cortex by cortical stimulation. J Neurophysiol. 2004; 91:2110-2116. [PubMed: 14711974]

Cabeza R. Hemispheric asymmetry reduction in older adults: the HAROLD model. Psychol Aging. 2002; 17:85-100. [PubMed: 11931290]

Cabeza R, Nyberg L. Neural bases of learning and memory: functional neuroimaging evidence. Curr Opin Neurol. 2000; 13:415-421. [PubMed: 10970058]

Cabeza R, Ciaramelli E, Olson IR, et al. The parietal cortex and episodic memory: an attentional account. Nat Rev Neurosci. 2008; 9:613-625. [PubMed: 18641668]

Cabeza R, Mazuz YS, Stokes J, et al. Overlapping parietal activity in memory and perception: evidence for the attention to memory model. J Cogn Neurosci. 2011; 23:3209-3217. [PubMed: 21568633]

Cattaneo Z, Vecchi T, Pascual-Leone A, et al. Contrasting early visual cortical activation states causally involved in visual imagery and short-term memory. Eur J Neurosci. 2009; 30:1393-1400. [PubMed: 19788574]

Cave CB, Squire LR. Intact verbal and nonverbal short-term memory following damage to the human hippocampus. Hippocampus. 1992; 2:151-163. [PubMed: 1308180]

Censor N, Cohen LG. Using repetitive transcranial magnetic stimulation to study the underlying neural mechanisms of human motor learning and memory. J Physiol. 2011; 589:21-28. [PubMed: 21041531]

Chi RP, Fregni F, Snyder AW. Visual memory improved by non-invasive brain stimulation. Brain Res. 2010; 1353:168-175. [PubMed: 20682299]

Ciaramelli E, Grady CL, Moscovitch M. Top-down and bottom-up attention to memory: a hypothesis (AtoM) on the role of the posterior parietal cortex in memory retrieval. Neuropsychologia. 2008; 46:1828-1851. [PubMed: 18471837]

Cicerone KD, Dahlberg C, Kalmar K, et al. Evidence-based cognitive rehabilitation: recommendations for clinical practice. Arch Phys Med Rehabil. 2000; 81:1596-1615. [PubMed: 11128897]

Clark VP, Coffman BA, Mayer AR, et al. TDCS guided using fMRI significantly accelerates learning to identify concealed objects. Neuroimage. 2012; 59:117-128. [PubMed: 21094258]

Classen J, Liepert J, Wise SP, et al. Rapid plasticity of human cortical movement representation induced by practice. J Neurophysiol. 1998; 79:1117-1123. [PubMed: 9463469]

Cohen NJ, Eichenbaum H. The theory that wouldn't die: a critical look at the spatial mapping theory of hippocampal function. Hippocampus. 1991; 1:265-268. [PubMed: 1669304]

Cohen NJ, Squire LR. Preserved learning and retention of pattern-analyzing skill in amnesia: dissociation of knowing how and knowing that. Science. 1980; 210:207-210. [PubMed: 7414331]

Cohen Kadosh R, Soskic S, Iuculano T, et al. Modulating neuronal activity produces specific and longlasting changes in numerical competence. Curr Biol. 2010; 20:2016-2020. [PubMed: 21055945]

Collette F, Hogge M, Salmon E, et al. Exploration of the neural substrates of executive functioning by functional neuroimaging. Neuroscience. 2006; 139:209-221. [PubMed: 16324796] 
Costa A, Oliveri M, Barban F, et al. Keeping memory for intentions: a cTBS investigation of the frontopolar cortex. Cereb Cortex. 2011; 21:2696-2703. [PubMed: 21515712]

Cotelli M, Manenti R, Cappa SF, et al. Effect of transcranial magnetic stimulation on action naming in patients with Alzheimer disease. Arch Neurol. 2006; 63:1602-1604. [PubMed: 17101829]

Cotelli M, Manenti R, Cappa SF, et al. Transcranial magnetic stimulation improves naming in Alzheimer disease patients at different stages of cognitive decline. Eur J Neurol. 2008; 15:12861292. [PubMed: 19049544]

Cotelli M, Calabria M, Manenti R, et al. Improved language performance in Alzheimer disease following brain stimulation. J Neurol Neurosurg Psychiatry. 2011; 82:794-797. [PubMed: 20574108]

Coyle JT, Price DL, DeLong MR. Alzheimer's disease: a disorder of cortical cholinergic innervation. Science. 1983; 219:1184-1190. [PubMed: 6338589]

Davies P, Maloney AJ. Selective loss of central cholinergic neurons in Alzheimer's disease. Lancet. 1976; 2:1403. [PubMed: 63862]

De Gennaro L, Fratello F, Marzano C, et al. Cortical plasticity induced by transcranial magnetic stimulation during wakefulness affects electroencephalogram activity during sleep. PLoS One. 2008; 3:e2483. [PubMed: 18575583]

Desmond JE, Chen SHA, Shieh PB. Cerebellar transcranial magnetic stimulation impairs verbal working memory. Ann Neurol. 2005; 58:553-560. [PubMed: 16178033]

de Vries MH, Barth ACR, Maiworm S, et al. Electrical stimulation of Broca's area enhances implicit learning of an artificial grammar. J Cogn Neurosci. 2010; 22:2427-2436. [PubMed: 19925194]

De Weerd P, Reithler J, van de Ven V, et al. Posttraining transcranial magnetic stimulation of striate cortex disrupts consolidation early in visual skill learning. J Neurosci. 2012; 32:1981-1988. [PubMed: 22323712]

D'Esposito M. From cognitive to neural models of working memory. Philos Trans R Soc Lond B Biol Sci. 2007; 362:761-772. [PubMed: 17400538]

Devlin JT, Watkins KE. Stimulating language: insights from TMS. Brain. 2007; 130:610-622. [PubMed: 17138570]

Di Lazzaro V, Oliviero A, Profice P, et al. Muscarinic receptor blockade has differential effects on the excitability of intracortical circuits in the human motor cortex. Exp Brain Res. 2000; 135:455-461. [PubMed: 11156309]

Di Lazzaro V, Pilato F, Dileone M, et al. In vivo cholinergic circuit evaluation in frontotemporal and Alzheimer dementias. Neurology. 2006; 66:1111-1113. [PubMed: 16606932]

Di Lazzaro V, Pilato F, Dileone M, et al. In vivo functional evaluation of central cholinergic circuits in vascular dementia. Clin Neurophysiol. 2008; 119:2494-2500. [PubMed: 18829384]

Dobbins IG, Foley H, Schacter DL, et al. Executive control during episodic retrieval: multiple prefrontal processes subserve source memory. Neuron. 2002; 35:989-996. [PubMed: 12372291]

Dudai Y. The neurobiology of consolidations, or, how stable is the engram? Annu Rev Psychol. 2004; 55:51-86. [PubMed: 14744210]

Eldaief MC, Halko MA, Buckner RL, et al. Transcranial magnetic stimulation modulates the brain's intrinsic activity in a frequency-dependent manner. Proc Natl Acad Sci U S A. 2011; 108:2122921234. [PubMed: 22160708]

Eldridge LL, Engel SA, Zeineh MM, et al. A dissociation of encoding and retrieval processes in the human hippocampus. J Neurosci. 2005; 25:3280-3286. [PubMed: 15800182]

Ellis J, Kvavilashvili L, Milne A. Experimental tests of prospective remembering: the influence of cueevent frequency on performance. Br J Psychol. 1999; 90:9-23. [PubMed: 10085543]

Elmer S, Burkard M, Renz B, et al. Direct current induced short-term modulation of the left dorsolateral prefrontal cortex while learning auditory presented nouns. Behav Brain Funct. 2009; 5:29. [PubMed: 19604352]

Epstein CM, Sekino M, Yamaguchi K, et al. Asymmetries of prefrontal cortex in human episodic memory: effects of transcranial magnetic stimulation on learning abstract patterns. Neurosci Lett. 2002; 320:5-8. [PubMed: 11849750] 
Feredoes E, Heinen K, Weiskopf N, et al. Causal evidence for frontal involvement in memory target maintenance by posterior brain areas during distracter interference of visual working memory. Proc Natl Acad Sci U S A. 2011; 108:17510-17515. [PubMed: 21987824]

Ferrucci R, Mameli F, Guidi I, et al. Transcranial direct current stimulation improves recognition memory in Alzheimer disease. Neurology. 2008; 71:493-498. [PubMed: 18525028]

Fletcher PC, Henson RN. Frontal lobes and human memory: insights from functional neuroimaging. Brain. 2001; 124:849-881. [PubMed: 11335690]

Flöel A, Poeppel D, Buffalo EA, et al. Prefrontal cortex asymmetry for memory encoding of words and abstract shapes. Cereb Cortex. 2004; 14:404-409. [PubMed: 15028644]

Flöel A, Suttorp W, Kohl O, et al. Non-invasive brain stimulation improves object-location learning in the elderly. Neurobiol Aging. 2012; 33:1682-1689. [PubMed: 21684040]

Fregni F, Boggio PS, Nitsche M, et al. Anodal transcranial direct current stimulation of prefrontal cortex enhances working memory. Exp Brain Res. 2005; 166:23-30. [PubMed: 15999258]

Freitas C, Mondragón-Llorca H, Pascual-Leone A. Noninvasive brain stimulation in Alzheimer's disease: systematic review and perspectives for the future. Exp Gerontol. 2011a; 46:611-627. [PubMed: 21511025]

Freitas C, Perez J, Knobel M, et al. Changes in cortical plasticity across the lifespan. Front Aging Neurosci. 2011b; 3:5. [PubMed: 21519394]

Gagnon G, Blanchet S, Grondin S, et al. Paired-pulse transcranial magnetic stimulation over the dorsolateral prefrontal cortex interferes with episodic encoding and retrieval for both verbal and non-verbal materials. Brain Res. 2010; 1344:148-158. [PubMed: 20462501]

Gagnon G, Schneider C, Grondin S, et al. Enhancement of episodic memory in young and healthy adults: a paired-pulse TMS study on encoding and retrieval performance. Neurosci Lett. 2011; 488:138-142. [PubMed: 21094215]

Gallate J, Chi R, Ellwood S, et al. Reducing false memories by magnetic pulse stimulation. Neurosci Lett. 2009; 449:151-154. [PubMed: 19022348]

Gazzaley A, Nobre AC. Top-down modulation: bridging selective attention and working memory. Trends Cogn Sci. 2012; 16:129-135. [PubMed: 22209601]

Gialanella B. Aphasia assessment and functional outcome prediction in patients with aphasia after stroke. J Neurol. 2011; 258:343-349. [PubMed: 21181541]

Gladwin TE, den Uyl TE, Fregni FF, et al. Enhancement of selective attention by tDCS: interaction with interference in a Sternberg task. Neurosci Lett. 2012; 512:33-37. [PubMed: 22327036]

Grafman J, Pascual-Leone A, Alway D, et al. Induction of a recall deficit by rapid-rate transcranial magnetic stimulation. Neuroreport. 1994; 5:1157-1160. [PubMed: 8080978]

Haffen E, Chopard G, Pretalli J-B, et al. A case report of daily left prefrontal repetitive transcranial magnetic stimulation (rTMS) as an adjunctive treatment for Alzheimer disease. Brain Stimul. 2012; 5:264-266. [PubMed: 22037125]

Hallett M. Transcranial magnetic stimulation and the human brain. Nature. 2000; 406:147-150. [PubMed: 10910346]

Halsband U, Lange RK. Motor learning in man: a review of functional and clinical studies. J Physiol Paris. 2006; 99:414-424. [PubMed: 16730432]

Hamidi M, Tononi G, Postle BR. Evaluating frontal and parietal contributions to spatial working memory with repetitive transcranial magnetic stimulation. Brain Res. 2008; 1230:202-210. [PubMed: 18662678]

Hamidi M, Tononi G, Postle BR. Evaluating the role of prefrontal and parietal cortices in memoryguided response with repetitive transcranial magnetic stimulation. Neuropsychologia. 2009; 47:295-302. [PubMed: 18822306]

Hamilton R, Messing S, Chatterjee A. Rethinking the thinking cap: ethics of neural enhancement using noninvasive brain stimulation. Neurology. 2011; 76:187-193. [PubMed: 21220723]

Hammer A, Mohammadi B, Schmicker M, et al. Errorless and errorful learning modulated by transcranial direct current stimulation. BMC Neurosci. 2011; 12:72. [PubMed: 21781298]

Hannula DE, Tranel D, Cohen NJ. The long and the short of it: relational memory impairments in amnesia, even at short lags. J Neurosci. 2006; 26:8352-8359. [PubMed: 16899730] 
Hannula H, Neuvonen T, Savolainen P, et al. Increasing top-down suppression from prefrontal cortex facilitates tactile working memory. Neuroimage. 2010; 49:1091-1098. [PubMed: 19643184]

Hartje, W.; Poeck, K. Klinische Neuropsychologie. 5th. Thieme; Stuttgart: 2002.

Haxby JV, Petit L, Ungerleider LG, et al. Distinguishing the functional roles of multiple regions in distributed neural systems for visual working memory. Neuroimage. 2000; 11:145-156. [PubMed: 10679186]

Heimrath K, Sandmann P, Becke A, et al. Behavioral and electrophysiological effects of transcranial direct current stimulation of the parietal cortex in a visuo-spatial working memory task. Front Psychiatry. 2012; 3:56. [PubMed: 22723784]

Herwig U, Abler B, Schönfeldt-Lecuona C, et al. Verbal storage in a premotor-parietal network: evidence from fMRI-guided magnetic stimulation. Neuroimage. 2003; 20:1032-1041. [PubMed: 14568473]

Higo T, Mars RB, Boorman ED, et al. Distributed and causal influence of frontal operculum in task control. Proc Natl Acad Sci U S A. 2011; 108:4230-4235. [PubMed: 21368109]

Horvath JC, Perez JM, Forrow L, et al. Transcranial magnetic stimulation: a historical evaluation and future prognosis of therapeutically relevant ethical concerns. J Med Ethics. 2011; 37:137-143. [PubMed: 21106996]

Huber R, Ghilardi MF, Massimini M, et al. Local sleep and learning. Nature. 2004; 430:78-81. [PubMed: 15184907]

Huber R, Ghilardi MF, Massimini M, et al. Arm immobilization causes cortical plastic changes and locally decreases sleep slow wave activity. Nat Neurosci. 2006; 9:1169-1176. [PubMed: 16936722]

Imm J-H, Kang E, Youn T, et al. Different hemispheric specializations for pitch and audioverbal working memory. Neuroreport. 2008; 19:99-103. [PubMed: 18281901]

Jacobson L, Goren N, Lavidor M, et al. Oppositional transcranial direct current stimulation (tDCS) of parietal substrates of attention during encoding modulates episodic memory. Brain Res. 2012; 1439:66-72. [PubMed: 22265704]

Jaeggi SM, Buschkuehl M, Etienne A, et al. On how high performers keep cool brains in situations of cognitive overload. Cogn Affect Behav Neurosci. 2007; 7:75-89. [PubMed: 17672380]

Jaeggi SM, Buschkuehl M, Jonides J, et al. Improving fluid intelligence with training on working memory. Proc Natl Acad Sci U S A. 2008; 105:6829-6833. [PubMed: 18443283]

James, W. Principles of Psychology. Henry Holt; New York: 1890.

Javadi AH, Walsh V. Transcranial direct current stimulation (tDCS) of the left dorsolateral prefrontal cortex modulates declarative memory. Brain Stimul. 2012; 5:231-241. [PubMed: 21840287]

Javadi AH, Cheng P, Walsh V. Short duration transcranial direct current stimulation (tDCS) modulates verbal memory. Brain Stimul. 2012; 5:468-474. [PubMed: 21962975]

Jo JM, Kim YH, Ko MH, et al. Enhancing the working memory of stroke patients using tDCS. Am J Phys Med Rehabil. 2009; 88:404-409. [PubMed: 19620953]

Jonides J, Lewis RL, Nee DE, et al. The mind and brain of short-term memory. Annu Rev Psychol. 2008; 59:193-224. [PubMed: 17854286]

Kahn I, Pascual-Leone A, Theoret H, et al. Transient disruption of ventrolateral prefrontal cortex during verbal encoding affects subsequent memory performance. J Neurophysiol. 2005; 94:688698. [PubMed: 15758048]

Karabanov A, Jin S-H, Joutsen A, et al. Timing-dependent modulation of the posterior parietal cortexprimary motor cortex pathway by sensorimotor training. J Neurophysiol. 2012; 107:3190-3199. [PubMed: 22442568]

Karmarkar UR, Buonomano DV. Timing in the absence of clocks: encoding time in neural network states. Neuron. 2007; 53:427-438. [PubMed: 17270738]

Karni A, Meyer G, Rey-Hipolito C, et al. The acquisition of skilled motor performance: fast and slow experience-driven changes in primary motor cortex. Proc Natl Acad Sci U S A. 1998; 95:861868. [PubMed: 9448252] 
Kessels RP, d'Alfonso AA, Postma A, et al. Spatial working memory performance after highfrequency repetitive transcranial magnetic stimulation of the left and right posterior parietal cortex in humans. Neurosci Lett. 2000; 287:68-70. [PubMed: 10841993]

Kincses TZ, Antal A, Nitsche MA, et al. Facilitation of probabilistic classification learning by transcranial direct current stimulation of the prefrontal cortex in the human. Neuropsychologia. 2004; 42:113-117. [PubMed: 14615081]

Kirov R, Weiss C, Siebner HR, et al. Slow oscillation electrical brain stimulation during waking promotes EEG theta activity and memory encoding. Proc Natl Acad Sci U S A. 2009; 106:15460-15465. [PubMed: 19706399]

Kirschen MP, Davis-Ratner MS, Jerde TE, et al. Enhancement of phonological memory following transcranial magnetic stimulation (TMS). Behav Neurol. 2006; 17:187-194. [PubMed: 17148839]

Klimesch W. EEG alpha and theta oscillations reflect cognitive and memory performance: a review and analysis. Brain Res Brain Res Rev. 1999; 29:169-195. [PubMed: 10209231]

Koch G, Oliveri M, Torriero S, et al. rTMS evidence of different delay and decision processes in a fronto-parietal neuronal network activated during spatial working memory. Neuroimage. 2005; 24:34-39. [PubMed: 15588594]

Koechlin E, Basso G, Pietrini P, et al. The role of the anterior prefrontal cortex in human cognition. Nature. 1999; 399:148-151. [PubMed: 10335843]

Köhler S, Paus T, Buckner RL, et al. Effects of left inferior prefrontal stimulation on episodic memory formation: a two-stage fMRI-rTMS study. J Cogn Neurosci. 2004; 16:178-188. [PubMed: 15068590]

Korman M, Doyon J, Doljansky J, et al. Daytime sleep condenses the time course of motor memory consolidation. Nat Neurosci. 2007; 10:1206-1213. [PubMed: 17694051]

Krieg SM, Shiban E, Buchmann N, et al. Utility of presurgical navigated transcranial magnetic brain stimulation for the resection of tumors in eloquent motor areas. J Neurosurg. 2012; 116:9941001. [PubMed: 22304452]

Lepore FE. Harvey Cushing, Gordon Holmes, and the neurological lessons of World War I. Arch Neurol. 1994; 51:711-722. [PubMed: 8018046]

Luber B, Kinnunen LH, Rakitin BC, et al. Facilitation of performance in a working memory task with rTMS stimulation of the precuneus: frequency- and time-dependent effects. Brain Res. 2007; 1128:120-129. [PubMed: 17113573]

Luber B, Stanford AD, Bulow P, et al. Remediation of sleep-deprivation-induced working memory impairment with fMRI-guided transcranial magnetic stimulation. Cereb Cortex. 2008; 18:20772085. [PubMed: 18203694]

Luria, AR. The Man With a Shattered World: The History of a Brain Wound. Harvard University Press; Cambridge, MA: 1972.

Machizawa MG, Kalla R, Walsh V, et al. The time course of ventrolateral prefrontal cortex involvement in memory formation. J Neurophysiol. 2010; 103:1569-1579. [PubMed: 20089812]

Manenti R, Cotelli M, Miniussi C. Successful physiological aging and episodic memory: a brain stimulation study. Behav Brain Res. 2011; 216:153-158. [PubMed: 20667492]

Markowitsch HJ, Staniloiu A. The impairment of recollection in functional amnesic states. Cortex. 2013; 49:1494-1510. [PubMed: 22824728]

Marshall L, Mölle M, Hallschmid M, et al. Transcranial direct current stimulation during sleep improves declarative memory. J Neurosci. 2004; 24:9985-9992. [PubMed: 15525784]

Marshall L, Mölle M, Siebner HR, et al. Bifrontal transcranial direct current stimulation slows reaction time in a working memory task. BMC Neurosci. 2005; 6:23. [PubMed: 15819988]

Marshall L, Kirov R, Brade J, et al. Transcranial electrical currents to probe EEG brain rhythms and memory consolidation during sleep in humans. PloS One. 2011; 6:e16905. [PubMed: 21340034]

Martin SJ, Grimwood PD, Morris RG. Synaptic plasticity and memory: an evaluation of the hypothesis. Annu Rev Neurosci. 2000; 23:649-711. [PubMed: 10845078]

McGaugh JL. Memory - a century of consolidation. Science. 2000; 287:248-251. [PubMed: 10634773] 
McNab F, Varrone A, Farde L, et al. Changes in cortical dopamine D1 receptor binding associated with cognitive training. Science. 2009; 323:800-802. [PubMed: 19197069]

Meiron O, Lavidor M. Unilateral prefrontal direct current stimulation effects are modulated by working memory load and gender. Brain Stimul. 2013; 6:440-447. [PubMed: 22743075]

Miller EK, Cohen JD. An integrative theory of prefrontal cortex function. Annu Rev Neurosci. 2001; 24:167-202. [PubMed: 11283309]

Miniussi C, Thut G. Combining TMS and EEG offers new prospects in cognitive neuroscience. Brain Topogr. 2010; 22:249-256. [PubMed: 19241152]

Missonnier P, Leonards U, Gold G, et al. A new electrophysiological index for working memory load in humans. Neuroreport. 2003; 14:1451-1455. [PubMed: 12960762]

Missonnier P, Gold G, Leonards U, et al. Aging and working memory: early deficits in EEG activation of posterior cortical areas. J Neural Transm. 2004; 111:1141-1154. [PubMed: 15338330]

Mitchell KJ, Johnson MK. Source monitoring 15 years later: what have we learned from fMRI about the neural mechanisms of source memory? Psychol Bull. 2009; 135:638-677. [PubMed: 19586165]

Morgan HM, Jackson MC, van Koningsbruggen MG, et al. Frontal and parietal theta burst TMS impairs working memory for visual-spatial conjunctions. Brain Stimul. 2013; 6:122-129. [PubMed: 22483548]

Morrison JH, Baxter MG. The ageing cortical synapse: hallmarks and implications for cognitive decline. Nat Rev Neurosci. 2012; 13:240-250. [PubMed: 22395804]

Moscovitch M, Nadel L, Winocur G, et al. The cognitive neuroscience of remote episodic, semantic and spatial memory. Curr Opin Neurobiol. 2006; 16:179-190. [PubMed: 16564688]

Mottaghy FM, Krause BJ, Kemna LJ, et al. Modulation of the neuronal circuitry subserving working memory in healthy human subjects by repetitive transcranial magnetic stimulation. Neurosci Lett. 2000; 280:167-170. [PubMed: 10675787]

Mottaghy FM, Döring T, Müller-Gärtner H-W, et al. Bilateral parieto-frontal network for verbal working memory: an interference approach using repetitive transcranial magnetic stimulation (rTMS). Eur J Neurosci. 2002a; 16:1627-1632. [PubMed: 12405977]

Mottaghy FM, Gangitano M, Sparing R, et al. Segregation of areas related to visual working memory in the prefrontal cortex revealed by rTMS. Cereb Cortex. 2002b; 12:369-375. [PubMed: 11884352]

Mottaghy FM, Gangitano M, Krause BJ, et al. Chronometry of parietal and prefrontal activations in verbal working memory revealed by transcranial magnetic stimulation. Neuroimage. 2003a; 18:565-575. [PubMed: 12667834]

Mottaghy FM, Pascual-Leone A, Kemna LJ, et al. Modulation of a brain-behavior relationship in verbal working memory by rTMS. Brain Res Cogn Brain Res. 2003b; 15:241-249. [PubMed: 12527098]

Muellbacher W, Ziemann U, Wissel J, et al. Early consolidation in human primary motor cortex. Nature. 2002; 415:640-644. [PubMed: 11807497]

Mull BR, Seyal M. Transcranial magnetic stimulation of left prefrontal cortex impairs working memory. Clin Neurophysiol. 2001; 112:1672-1675. [PubMed: 11514250]

Mulquiney PG, Hoy KE, Daskalakis ZJ, et al. Improving working memory: exploring the effect of transcranial random noise stimulation and transcranial direct current stimulation on the dorsolateral prefrontal cortex. Clin Neurophysiol. 2011; 122:2384-2389. [PubMed: 21665534]

Mylius V, Jung M, Menzler K, et al. Effects of transcranial direct current stimulation on pain perception and working memory. Eur J Pain. 2012; 16:974-982. [PubMed: 22337597]

Nadel L, Samsonovich A, Ryan L, et al. Multiple trace theory of human memory: computational, neuroimaging, and neuropsychological results. Hippocampus. 2000; 10:352-368. [PubMed: 10985275]

Najib, U.; Pascual-Leone, A. Paradoxical functional facilitation with noninvasive brain stimulation. In: Kapur, N.; Pascual-Leone, A.; Ramachandran, V., et al., editors. The Paradoxical Brain. Cambridge University Press; Cambridge: 2011. p. 234-260.

Nitsche MA, Cohen LG, Wassermann EM, et al. Transcranial direct current stimulation: state of the art 2008. Brain Stimul. 2008; 1:206-223. [PubMed: 20633386] 
Noulhiane M, Pouthas V, Hasboun D, et al. Role of the medial temporal lobe in time estimation in the range of minutes. Neuroreport. 2007; 18:1035-1038. [PubMed: 17558291]

Ohn SH, Park C-I, Yoo W-K, et al. Time-dependent effect of transcranial direct current stimulation on the enhancement of working memory. Neuroreport. 2008; 19:43-47. [PubMed: 18281890]

Okuda J, Fujii T, Yamadori A, et al. Participation of the prefrontal cortices in prospective memory: evidence from a PET study in humans. Neurosci Lett. 1998; 253:127-130. [PubMed: 9774166]

Okuda J, Fujii T, Ohtake H, et al. Differential involvement of regions of rostral prefrontal cortex (Brodmann area 10) in time- and event-based prospective memory. Int J Psychophysiol. 2007; 64:233-246. [PubMed: 17126435]

Oliveri M, Turriziani P, Carlesimo GA, et al. Parietofrontal interactions in visual-object and visualspatial working memory: evidence from transcranial magnetic stimulation. Cereb Cortex. 2001; 11:606-618. [PubMed: 11415963]

Olson IR, Moore KS, Stark M, et al. Visual working memory is impaired when the medial temporal lobe is damaged. J Cogn Neurosci. 2006a; 18:1087-1097. [PubMed: 16839283]

Olson IR, Page K, Moore KS, et al. Working memory for conjunctions relies on the medial temporal lobe. J Neurosci. 2006b; 26:4596-4601. [PubMed: 16641239]

Osaka N, Otsuka Y, Hirose N, et al. Transcranial magnetic stimulation (TMS) applied to left dorsolateral prefrontal cortex disrupts verbal working memory performance in humans. Neurosci Lett. 2007; 418:232-235. [PubMed: 17467169]

Paller, KA. Cross-cortical consolidation as the core defect in amnesia: prospects for hypothesis-testing with neuropsychology and neuroimaging. In: Squire, LR.; Schacter, DL., editors. Neuropsychology of Memory. 3rd. Guilford Press; New York: 2002. p. 73-87.

Paller KA, Wagner AD. Observing the transformation of experience into memory. Trends Cogn Sci. 2002; 6:93-102. [PubMed: 15866193]

Pascual-Leone A, Hallett M. Induction of errors in a delayed response task by repetitive transcranial magnetic stimulation of the dorsolateral prefrontal cortex. Neuroreport. 1994; 5:2517-2520. [PubMed: 7696593]

Pascual-Leone A, Gates JR, Dhuna A. Induction of speech arrest and counting errors with rapid-rate transcranial magnetic stimulation. Neurology. 1991; 41:697-702. [PubMed: 2027485]

Pascual-Leone A, Bartres-Faz D, Keenan JP. Transcranial magnetic stimulation: studying the brainbehaviour relationship by induction of "virtual lesions". Philos Trans R Soc Lond B Biol Sci. 1999; 354:1229-1238. [PubMed: 10466148]

Pascual-Leone A, Walsh V, Rothwell J. Transcranial magnetic stimulation in cognitive neuroscience virtual lesion, chronometry, and functional connectivity. Curr Opin Neurobiol. 2000; 10:232237. [PubMed: 10753803]

Pascual-Leone A, Freitas C, Oberman L, et al. Characterizing brain cortical plasticity and network dynamics across the age-span in health and disease with TMS-EEG and TMS-fMRI. Brain Topogr. 2011; 24:302-315. [PubMed: 21842407]

Penolazzi B, Di Domenico A, Marzoli D, et al. Effects of transcranial direct current stimulation on episodic memory related to emotional visual stimuli. PloS One. 2010; 5:e10623. [PubMed: 20498700]

Postle BR, Ferrarelli F, Hamidi M, et al. Repetitive transcranial magnetic stimulation dissociates working memory manipulation from retention functions in the prefrontal, but not posterior parietal, cortex. J Cogn Neurosci. 2006; 18:1712-1722. [PubMed: 17014375]

Preston G, Anderson E, Silva C, et al. Effects of $10 \mathrm{~Hz}$ rTMS on the neural efficiency of working memory. J Cogn Neurosci. 2009; 22:447-456. [PubMed: 19309294]

Rami L, Gironell A, Kulisevsky J, et al. Effects of repetitive transcranial magnetic stimulation on memory subtypes: a controlled study. Neuropsychologia. 2003; 41:1877-1883. [PubMed: 14572521]

Rammsayer TH, Hennig J, Haag A, et al. Effects of noradrenergic activity on temporal information processing in humans. Q J Exp Psychol B. 2001; 54:247-258. [PubMed: 11547514]

Ranganath C, D'Esposito M. Medial temporal lobe activity associated with active maintenance of novel information. Neuron. 2001; 31:865-873. [PubMed: 11567623] 
Rasch B, Büchel C, Gais S, et al. Odor cues during slow-wave sleep prompt declarative memory consolidation. Science. 2007; 315:1426-1429. [PubMed: 17347444]

Reynolds JR, West R, Braver T. Distinct neural circuits support transient and sustained processes in prospective memory and working memory. Cereb Cortex. 2009; 19:1208-1221. [PubMed: 18854581]

Robertson EM. The serial reaction time task: implicit motor skill learning? J Neurosci. 2007; 27:10073-10075. [PubMed: 17881512]

Robertson EM. From creation to consolidation: a novel framework for memory processing. PLoS Biol. 2009; 7:e19. [PubMed: 19175290]

Robertson EM, Cohen DA. Understanding consolidation through the architecture of memories. Neuroscientist. 2006; 12:261-271. [PubMed: 16684970]

Robertson EM, Pascual-Leone A, Miall RC. Current concepts in procedural consolidation. Nat Rev Neurosci. 2004; 5:576-582. [PubMed: 15208699]

Robertson EM, Press DZ, Pascual-Leone A. Off-line learning and the primary motor cortex. J Neurosci. 2005; 25:6372-6378. [PubMed: 16000627]

Rossi S, Cappa SF, Babiloni C, et al. Prefrontal cortex in long-term memory: an "interference" approach using magnetic stimulation. Nat Neurosci. 2001; 4:948-952. [PubMed: 11528428]

Rossi S, Miniussi C, Pasqualetti P, et al. Age-related functional changes of prefrontal cortex in longterm memory: a repetitive transcranial magnetic stimulation study. J Neurosci. 2004; 24:79397944. [PubMed: 15356207]

Rossi S, Pasqualetti P, Zito G, et al. Prefrontal and parietal cortex in human episodic memory: an interference study by repetitive transcranial magnetic stimulation. Eur J Neurosci. 2006; 23:793800. [PubMed: 16487159]

Rossi S, Hallett M, Rossini PM, et al. Safety, ethical considerations, and application guidelines for the use of transcranial magnetic stimulation in clinical practice and research. Clin Neurophysiol. 2009; 120:2008-2039. [PubMed: 19833552]

Rost NS, Smith EE, Chang Y, et al. Prediction of functional outcome in patients with primary intracerebral hemorrhage: the FUNC score. Stroke. 2008; 39:2304-2309. [PubMed: 18556582]

Sandrini M, Cappa SF, Rossi S, et al. The role of prefrontal cortex in verbal episodic memory: rTMS evidence. J Cogn Neurosci. 2003; 15:855-861. [PubMed: 14511538]

Sandrini M, Rossini PM, Miniussi C. Lateralized contribution of prefrontal cortex in controlling taskirrelevant information during verbal and spatial working memory tasks: rTMS evidence. Neuropsychologia. 2008; 46:2056-2063. [PubMed: 18336847]

Sandrini M, Fertonani A, Cohen LG, et al. Double dissociation of working memory load effects induced by bilateral parietal modulation. Neuropsychologia. 2012; 50:396-402. [PubMed: 22223077]

Sauseng P, Klimesch W, Heise KF, et al. Brain oscillatory substrates of visual short-term memory capacity. Curr Biol. 2009; 19:1846-1852. [PubMed: 19913428]

Savolainen P, Carlson S, Boldt R, et al. Facilitation of tactile working memory by top-down suppression from prefrontal to primary somatosensory cortex during sensory interference. Behav Brain Res. 2011; 219:387-390. [PubMed: 21310187]

Scelzo E, Giannicola G, Rosa M, et al. Increased short latency afferent inhibition after anodal transcranial direct current stimulation. Neurosci Lett. 2011; 498:167-170. [PubMed: 21600266]

Schendan HE, Searl MM, Melrose RJ, et al. An FMRI study of the role of the medial temporal lobe in implicit and explicit sequence learning. Neuron. 2003; 37:1013-1025. [PubMed: 12670429]

Schutter DJLG, van Honk J. Increased positive emotional memory after repetitive transcranial magnetic stimulation over the orbitofrontal cortex. J Psychiatry Neurosci. 2006; 31:101-104. [PubMed: 16575425]

Scoville WB, Milner B. Loss of recent memory after bilateral hippocampal lesions. J Neurol Neurosurg Psychiatry. 1957; 20:11-21. [PubMed: 13406589]

Seidler RD, Purushotham A, Kim S-G, et al. Cerebellum activation associated with performance change but not motor learning. Science. 2002; 296:2043-2046. [PubMed: 12065841] 
Shallice T, Warrington EK. Independent functioning of verbal memory stores: a neuropsychological study. Q J Exp Psychol. 1970; 22:261-273. [PubMed: 5431401]

Shimamura AP. Episodic retrieval and the cortical binding of relational activity. Cogn Affect Behav Neurosci. 2011; 11:277-291. [PubMed: 21638193]

Shimamura AP, Wickens TD. Superadditive memory strength for item and source recognition: the role of hierarchical relational binding in the medial temporal lobe. Psychol Rev. 2009; 116:1-19. [PubMed: 19159146]

Sigurdardottir S, Andelic N, Roe C, et al. Cognitive recovery and predictors of functional outcome 1 year after traumatic brain injury. J Int Neuropsychol Soc. 2009; 15:740-750. [PubMed: 19602303]

Silvanto J, Cattaneo Z. Transcranial magnetic stimulation reveals the content of visual short-term memory in the visual cortex. Neuroimage. 2010; 50:1683-1689. [PubMed: 20079448]

Silvanto J, Pascual-Leone A. State-dependency of transcranial magnetic stimulation. Brain Topogr. 2008; 21:1-10. [PubMed: 18791818]

Silvanto J, Pascual-Leone A. Why the assessment of causality in brain-behavior relations requires brain stimulation. J Cogn Neurosci. 2012; 24:775-777. [PubMed: 22264196]

Simons JS, Spiers HJ. Prefrontal and medial temporal lobe interactions in long-term memory. Nat Rev Neurosci. 2003; 4:637-648. [PubMed: 12894239]

Skrdlantová L, Horácek J, Dockery C, et al. The influence of low-frequency left prefrontal repetitive transcranial magnetic stimulation on memory for words but not for faces. Physiol Res. 2005; 54:123-128. [PubMed: 15717850]

Smith EE, Jonides J. Working memory: a view from neuroimaging. Cogn Psychol. 1997; 33:5-42. [PubMed: 9212720]

Smith EE, Jonides J. Storage and executive processes in the frontal lobes. Science. 1999; 283:16571661. [PubMed: 10073923]

Solé-Padullés C, Bartrés-Faz D, Junqué C, et al. Repetitive transcranial magnetic stimulation effects on brain function and cognition among elders with memory dysfunction. A randomized shamcontrolled study. Cereb Cortex. 2006; 16:1487-1493. [PubMed: 16339086]

Soto D, Rotshtein P, Hodsoll J, et al. Common and distinct neural regions for the guidance of selection by visuo-verbal information held in memory: converging evidence from fMRI and rTMS. Hum Brain Mapp. 2012; 33:105-120. [PubMed: 21425391]

Squire, LR. The medial temporal region and memory consolidation: a new hypothesis. In: Weingartner, H.; Parder, E., editors. Memory Consolidation. Erlbaum; Hillsdale, NJ: 1984. p. 185-210.

Squire, LR. Memory and Brain. Oxford University Press; New York: 1987.

Squire LR. Memory systems of the brain: a brief history and current perspective. Neurobiol Learn Mem. 2004; 82:171-177. [PubMed: 15464402]

Squire LR, Zola SM. Episodic memory, semantic memory, and amnesia. Hippocampus. 1998; 8:205211. [PubMed: 9662135]

Sternberg S. High-speed scanning in human memory. Science. 1966; 153:652-654. [PubMed: 5939936]

Teo F, Hoy KE, Daskalakis ZJ, et al. Investigating the role of current strength in tDCS modulation of working memory performance in healthy controls. Front Psychiatry. 2011; 2:45. [PubMed: 21811474]

Thut G, Pascual-Leone A. A review of combined TMS-EEG studies to characterize lasting effects of repetitive TMS and assess their usefulness in cognitive and clinical neuroscience. Brain Topogr. 2010; 22:219-232. [PubMed: 19862614]

Tononi G, Cirelli C. Sleep and synaptic homeostasis: a hypothesis. Brain Res Bull. 2003; 62:143-150. [PubMed: 14638388]

Tononi G, Cirelli C. Sleep function and synaptic homeostasis. Sleep Med Rev. 2006; 10:49-62. [PubMed: 16376591]

Tulving E. Episodic memory: from mind to brain. Annu Rev Psychol. 2002; 53:1-25. [PubMed: 11752477] 
Tulving E, Kapur S, Craik FI, et al. Hemispheric encoding/ retrieval asymmetry in episodic memory: positron emission tomography findings. Proc Natl Acad Sci U S A. 1994; 91:2016-2020. [PubMed: 8134342]

Ungerleider LG, Doyon J, Karni A. Imaging brain plasticity during motor skill learning. Neurobiol Learn Mem. 2002; 78:553-564. [PubMed: 12559834]

van de Ven V, Jacobs C, Sack AT. Topographic contribution of early visual cortex to short-term memory consolidation: a transcranial magnetic stimulation study. J Neurosci. 2012; 32:4-11. [PubMed: 22219265]

Vines BW, Schnider NM, Schlaug G. Testing for causality with transcranial direct current stimulation: pitch memory and the left supramarginal gyrus. Neuroreport. 2006; 17:1047-1050. [PubMed: 16791101]

Wada J, Rasmussen T. Intracarotid injection of sodium amytal for the lateralization of cerebral speech dominance. J Neurosurg. 1960; 106:1117-1133. 1960. [PubMed: 17564192]

Wagle J, Farner L, Flekkoy K, et al. Early post-stroke cognition in stroke rehabilitation patients predicts functional outcome at 13 months. Dement Geriatr Cogn Disord. 2011; 31:379-387. [PubMed: 21720162]

Wagner AD, Shannon BJ, Kahn I, et al. Parietal lobe contributions to episodic memory retrieval. Trends Cogn Sci. 2005; 9:445-453. [PubMed: 16054861]

Wagner T, Valero-Cabre A, Pascual-Leone A. Noninvasive human brain stimulation. Annu Rev Biomed Eng. 2007; 9:527-565. [PubMed: 17444810]

Wagner U, Gais S, Haider H, et al. Sleep inspires insight. Nature. 2004; 427:352-355. [PubMed: 14737168]

Walker MP. A refined model of sleep and the time course of memory formation. Behav Brain Sci. 2005; 28:51-64. [PubMed: 16047457]

Walker MP, Brakefield T, Morgan A, et al. Practice with sleep makes perfect: sleep-dependent motor skill learning. Neuron. 2002; 35:205-211. [PubMed: 12123620]

Walsh, V.; Pascual-Leone, A. Transcranial Magnetic Stimulation: A Neurochronometrics of Mind. MIT Press; Cambridge, MA: 2003.

Watter S, Geffen GM, Geffen LB. The n-back as a dual-task: P300 morphology under divided attention. Psychophysiology. 2001; 38:998-1003. [PubMed: 12240676]

Wheaton LA, Hallett M. Ideomotor apraxia: a review. J Neurol Sci. 2007; 260:1-10. [PubMed: 17507030]

Wheeler ME, Petersen SE, Buckner RL. Memory's echo: vivid remembering reactivates sensoryspecific cortex. Proc Natl Acad Sci U S A. 2000; 97:11125-11129. [PubMed: 11005879]

Wittmann M. The inner experience of time. Philos Trans R Soc Lond B Biol Sci. 2009; 364:19551967. [PubMed: 19487197]

Yamanaka K, Yamagata B, Tomioka H, et al. Transcranial magnetic stimulation of the parietal cortex facilitates spatial working memory: near-infrared spectroscopy study. Cereb Cortex. 2010; 20:1037-1045. [PubMed: 19684247]

Zaehle T, Sandmann P, Thorne JD, et al. Transcranial direct current stimulation of the prefrontal cortex modulates working memory performance: combined behavioural and electrophysiological evidence. BMC Neurosci. 2011; 12:2. [PubMed: 21211016]

Zanto TP, Rubens MT, Thangavel A, et al. Causal role of the prefrontal cortex in top-down modulation of visual processing and working memory. Nat Neurosci. 2011; 14:656-661. [PubMed: 21441920] 


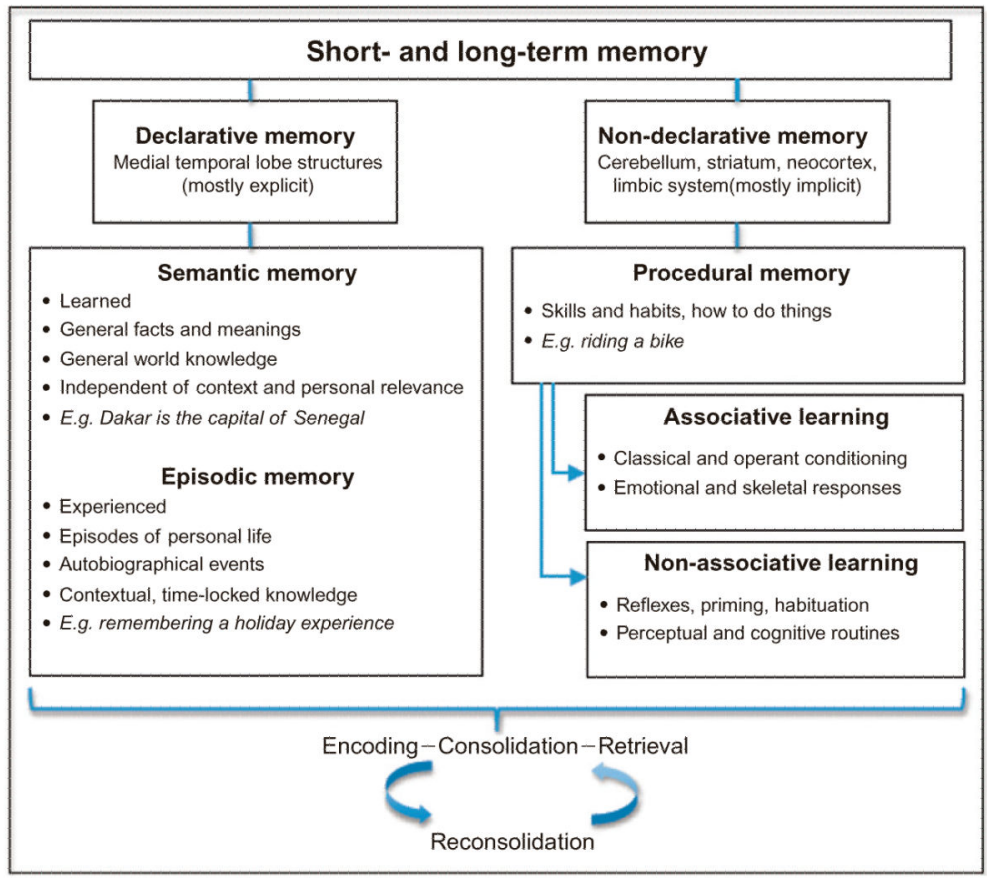

Fig. 55.1.

Classification of different types of memory process. 


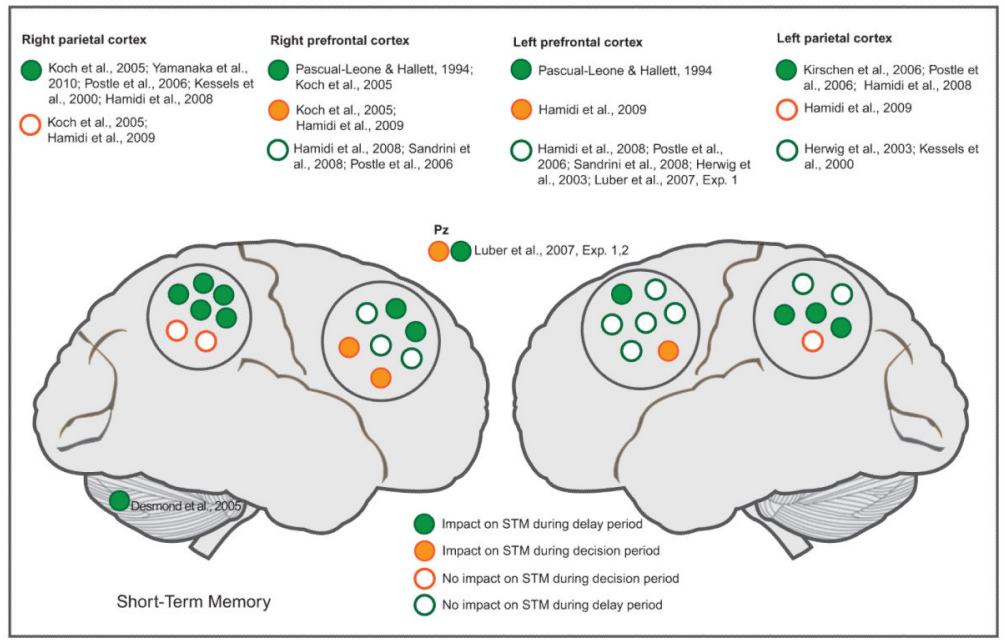

Fig. 55.2.

Schematic summary of findings from studies investigating the impact on short-term memory after stimulation over the left or right prefrontal cortex, parietal areas, or the cerebellum during the delay (green) or the decision period (orange). 


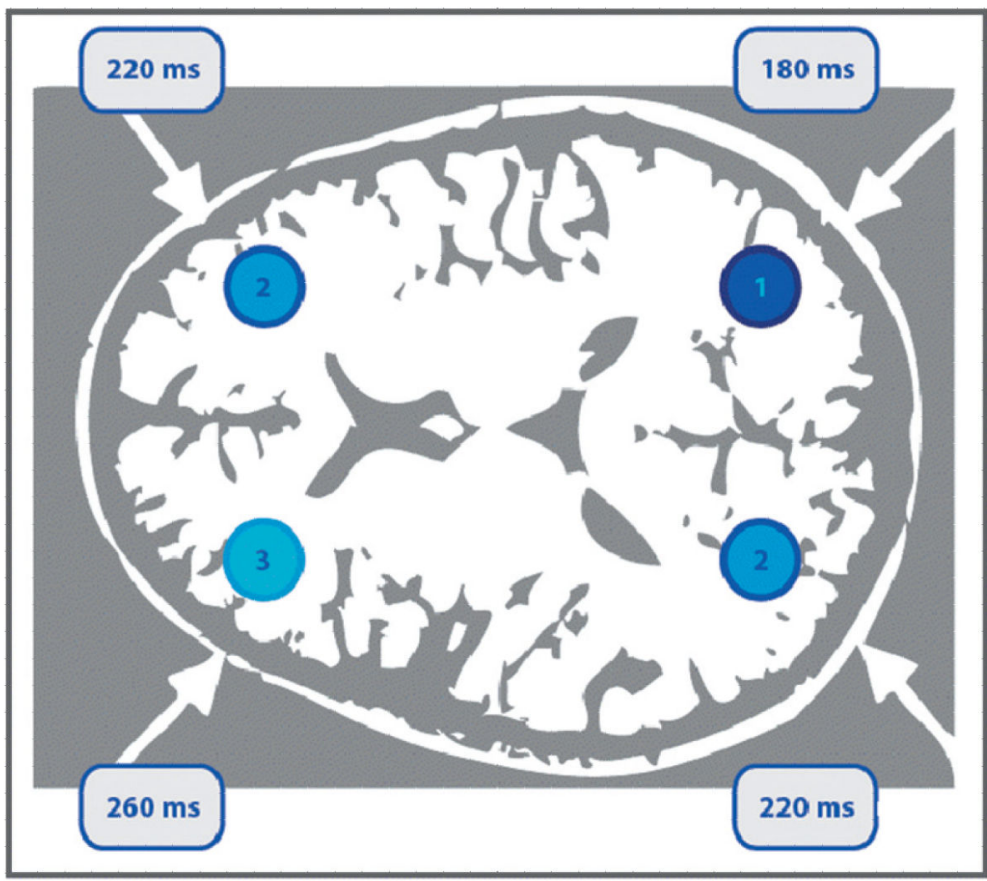

Fig. 55.3.

Accuracy in the 2-back task as a function of the time of transcranial magnetic stimulation (TMS). TMS interference peaked at $180 \mathrm{~ms}$ at the right inferior parietal cortex, at $220 \mathrm{~ms}$ at the left inferior parietal cortex and right middle frontal gyrus (MFG), and at $260 \mathrm{~ms}$ at the left MFG (all $p<0.05$ ). This study illustrates the chronometry of causal contributions of different brain regions to memory processing. (Modified from Mottaghy et al., 2003a, by permission of the authors.) 


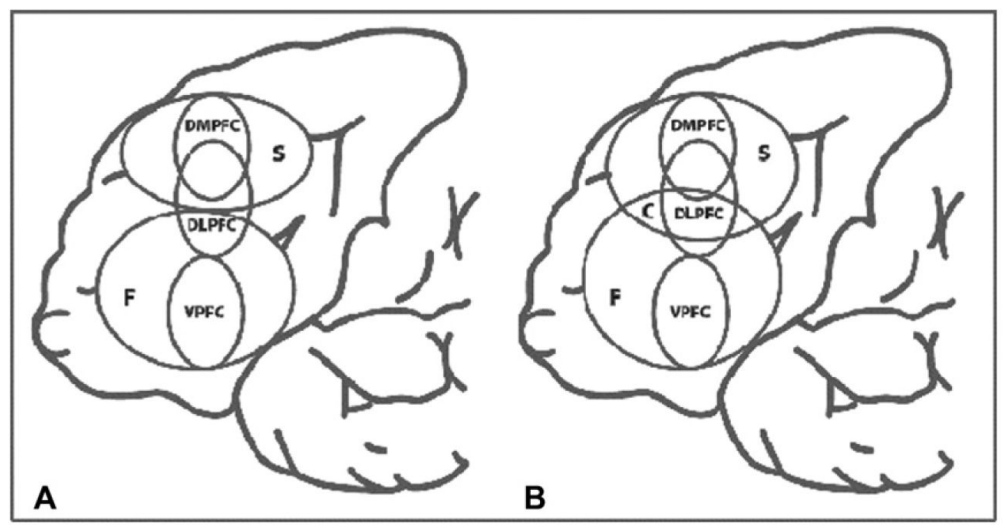

Fig. 55.4.

Study exploring the segregation of memory processes in prefrontal cortex. Two alternative models were proposed based on the data. (A) There might be two different, nonoverlapping, functionally segregated regions within the prefrontal cortex (PFC) that are domain-specific (S, spatial domain; F, face domain). Repetitive transcranial magnetic stimulation (TMS) over the dorsomedial PFC (DMPFC) interferes only with the processing of the spatial information. Dorsolateral PFC (DLPFC) stimulation might have induced overlapping interference of two adjacent domain-specific areas, whereas the ventral PFC (VPFC) led only to interference with the processing of the face stimuli. (B) The DMPFC and the VPFC interference effects can be explained in the same manner as in proposal (A); however, the performance deterioration over the DLPFC in this model might be explained by the interference with information processing of a common module $(\mathrm{C})$ that is employed during both types of stimulus. (Modified from Mottaghy et al., 2002b, by permission of the authors.) 


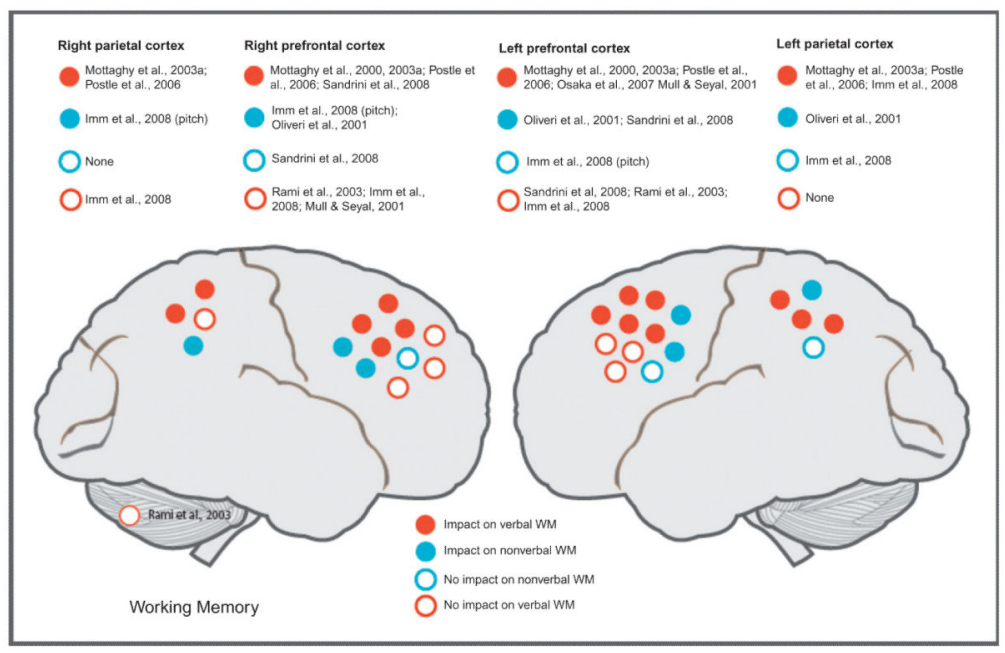

Fig. 55.5.

Schematic summary of findings from studies investigating the impact on verbal (red) or nonverbal (blue) working memory (WM) after stimulation over the left or right prefrontal cortex (PFC), parietal areas, or cerebellum. 


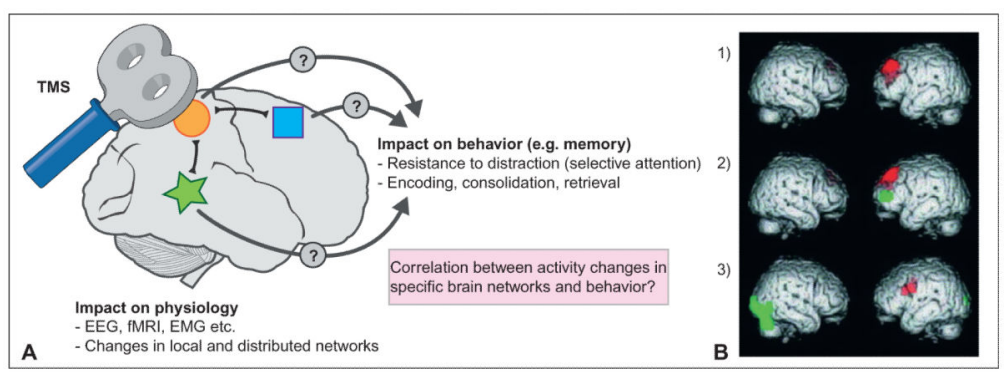

Fig. 55.6.

Transcranial magnetic stimulation-positron emission tomography (TMS-PET) study of the neurobiological substrates of working memory. (A) The impact of TMS on behavior relies on activity changes in local and distributed brain networks. The combination of TMS with brain imaging techniques, such as EEG, fMRI, PET, and EMG, allows us to detect correlations between these activity changes and behavior. Moreover, it allows study of the impact of state dependency on stimulation outcome. (B) Positive (green) and negative (red) correlation between regional cerebral blood flow (rCBF) and performance in the 2-back working memory (WM) task (1) without application of repetitive TMS (rTMS), (2) with rTMS delivered over the left middle frontal gyrus (MFG), and (3) with rTMS applied over the right MFG. While rTMS over the left MFG has a local impact, which is correlated with behavior, rTMS over the right MFG has an impact on a distributed network, including homologous areas. Importantly, also in the case of stimulation over the right MFG, activity changes in the left MFG but not right MFG are correlated with behavioral output. This key finding shows that the effect of TMS can be achieved by a direct effect on underlying areas, but also through trans-synaptic effects (e.g., in homologous areas). The combination of TMS with imaging techniques is crucial in order to identify neural substrates associated with behavioral output. (Modified from Mottaghy et al., 2003b, by permission of the authors.) 
Table 55.1

Synopsis of peer-reviewed, published studies applying noninvasive brain stimulation in the memory domain

\begin{tabular}{|c|c|c|c|c|c|}
\hline Reference & $n$ & Regions stimulated & Stimulation protocol & Task & Results \\
\hline \multicolumn{6}{|c|}{ TMS in short-term memory } \\
\hline $\begin{array}{l}\text { Beckers and } \\
\text { Hömberg } \\
\text { (1991) }\end{array}$ & 24 & $\mathrm{OC}$ & $\begin{array}{l}\text { Various intensities at } \\
40-120 \mathrm{~ms} \text {, during } \\
\text { delay, active/sham }\end{array}$ & $\begin{array}{l}\text { Trigram identification } \\
\text { task and visual DMS }\end{array}$ & $\begin{array}{l}\text { Stim during delay } \\
\text { impaired } \\
\text { identification of } \\
\text { trigrams as } \\
\text { compared to } \\
\text { sham. Stim during } \\
\text { delay } \\
\text { of DMS } \\
\text { decreased memory } \\
\text { scanning } \\
\text { rates. No impact } \\
\text { on accuracy. }\end{array}$ \\
\hline $\begin{array}{l}\text { Kessels et al. } \\
(2000)\end{array}$ & 8 & R/L PPC (P3/P4) & $\begin{array}{l}200 \mathrm{~ms} \text { of } 25 \mathrm{~Hz} \text { rTMS } \\
\text { at } 115 \% \mathrm{rMT}, \\
\text { during } \\
\text { delay, active/sham }\end{array}$ & Spatial DMS & $\begin{array}{l}\text { Stim to right PC } \\
\text { during delay } \\
\text { increased } \\
\text { RT compared to } \\
\text { left stim, but not } \\
\text { sham }(\sim 561 \mathrm{~ms} \\
\text { vs. } \sim 522 \text { and } \\
\sim 540 \mathrm{~ms}) \text {. }\end{array}$ \\
\hline $\begin{array}{l}\text { Mottaghy et al. } \\
\text { (2002b) }\end{array}$ & 8 & $\begin{array}{l}\text { L DMPFC, DLPFC, } \\
\text { VPFC }\end{array}$ & $\begin{array}{l}10 \text { min of } 1 \mathrm{~Hz} \text { rTMS } \\
\text { at } \\
90 \% \text { rMT, } \\
\text { comparison with } \\
\text { baseline }\end{array}$ & $\begin{array}{l}\text { Spatial or face DMS } \\
\text { (objects and faces) }\end{array}$ & $\begin{array}{l}\text { Stim to DMPFC } \\
\text { increased error rate } \\
\text { for } \\
\text { spatial task } \\
\text { compared to } \\
\text { baseline }(2.88 \\
\text { vs. } 1.58) \text {. Stim to } \\
\text { DLPFC increased } \\
\text { error rates for } \\
\text { spatial ( } 4.25 \text { vs. } \\
2.21) \\
\text { and face task } \\
(3.38 \text { vs. } 2.17) \text {. Stim } \\
\text { to } \\
\text { VPFC increased } \\
\text { error rates for face } \\
\text { task ( } 3.63 \text { vs. } \\
1.96) \text {. No impact on } \\
\text { RT. }\end{array}$ \\
\hline $\begin{array}{l}\text { Herwig et al. } \\
\text { (2003) }\end{array}$ & 9 & $\begin{array}{l}\text { L PFC, PMC, PC } \\
\text { (fMRI-guided), } \\
\text { homolog regions } \\
\text { (control) }\end{array}$ & $\begin{array}{c}3 \mathrm{~s} \text { of } 15 \mathrm{~Hz} \text { rTMS at } \\
110 \% \text { rMT, during } \\
\text { delay (second half) }\end{array}$ & $\begin{array}{l}\text { Verbal DMS (1 or } 6 \\
\text { letters) }\end{array}$ & $\begin{array}{l}\text { Stim over left PMC } \\
(\sim 14.3 \text { vs. } 9.5 \%) \text { but } \\
\text { not PC or PFC } \\
\text { increased error rate. } \\
\text { No } \\
\text { impact on RT. }\end{array}$ \\
\hline $\begin{array}{l}\text { Koch et al. } \\
\text { (2005) }\end{array}$ & 9 & $\begin{array}{l}\text { R PPC (P6), } \\
\text { premotor } \\
\text { cortex }(\mathrm{SFG}) \text {, and } \\
\text { DLPFC }(\mathrm{F} 4)\end{array}$ & $\begin{array}{l}300 \mathrm{~ms} \text { of } 25 \mathrm{~Hz} \text { rTMS } \\
\text { at } 110 \% \mathrm{rMT}, \\
\text { during } \\
\text { delay or decision, } \\
\text { active/sham }\end{array}$ & $\begin{array}{l}\text { Matching of spatial } \\
\text { sequences }\end{array}$ & $\begin{array}{l}\text { Stim over PPC } \\
(\sim 29 \%) \text { and DLPFC } \\
\text { ( 22\%) but not } \\
\text { SFG during the } \\
\text { delay } \\
\text { phase impaired } \\
\text { RT. Stim over } \\
\text { DLPFC } \\
\text { during the } \\
\text { decision phase } \\
\text { selectively } \\
\text { impaired RT } \\
(\sim 38 \%) \text {. No impact } \\
\text { on accuracy. }\end{array}$ \\
\hline $\begin{array}{l}\text { Desmond et al. } \\
\text { (2005) }\end{array}$ & 17 & $\mathrm{R}$ superior $\mathrm{Cb}$ & $\begin{array}{l}\text { sp TMS at } 120 \% \text { rMT, } \\
\text { during delay, active/ } \\
\text { non-active trials/ }\end{array}$ & $\begin{array}{l}\text { Verbal DMS and motor } \\
\text { control task }\end{array}$ & $\begin{array}{l}\text { Stim at the } \\
\text { beginning of the } \\
\text { delay phase }\end{array}$ \\
\hline
\end{tabular}




\begin{tabular}{|c|c|c|c|c|c|}
\hline Reference & $n$ & Regions stimulated & Stimulation protocol & Task & Results \\
\hline & & & sham & & $\begin{array}{l}\text { increased RT on } \\
\text { correct trials } \\
\text { compared to non- } \\
\text { active trials, sham, } \\
\text { and motor control } \\
\text { task. No effect on } \\
\text { accuracy. }\end{array}$ \\
\hline $\begin{array}{l}\text { Kirschen et al. } \\
(2006)\end{array}$ & 30 & Left IPL & $\begin{array}{l}3 \mathrm{sp} \text { at } 120 \% \mathrm{rMT}, \\
\text { during delay (at } \\
1,3,5 \mathrm{~s} \text { ), active/sham } \\
\text { control region }\end{array}$ & $\begin{array}{l}\text { Verbal DMS } \\
\text { (phonologically } \\
\text { similar/ dissimilar } \\
\text { pseudo-words and } \\
\text { distractors) }\end{array}$ & $\begin{array}{l}\text { Stim during delay } \\
\text { improved RT for } \\
\text { similar pseudo- } \\
\text { words as compared } \\
\text { to } \\
\text { sham. Accuracy } \\
\text { improved } \\
\text { marginally. } \\
\text { No difference } \\
\text { observed between } \\
\text { TMS } \\
\text { and placebo } \\
\text { scores for dissimilar } \\
\text { pairs. }\end{array}$ \\
\hline $\begin{array}{l}\text { Luber et al. } \\
\text { (2007) }\end{array}$ & 44 & $\begin{array}{l}\text { Exp. 1: Midline PC } \\
\text { (precuneus) or left } \\
\text { DLPFC } \\
\text { Exp. 2: Midline PC } \\
\text { (precuneus) }\end{array}$ & $\begin{array}{l}\text { 100\% rMT, active/ } \\
\text { sham } \\
\text { rTMS } \\
\text { Exp. } 1: 1 \text { or } 5 \mathrm{~Hz}(7 \mathrm{~s}) \\
\text { or } \\
\quad 20 \mathrm{~Hz}(2 \mathrm{~s}) \text {, during } \\
\text { delay } \\
\text { Exp. } 2: 5 \mathrm{~Hz}(7 \mathrm{~s}) \text {, } \\
\quad \text { during delay or } \\
\text { decision }\end{array}$ & $\begin{array}{l}\text { Verbal DMS (1 or } 6 \\
\text { letters) }\end{array}$ & $\begin{array}{l}\text { Exp. 1: Only } 5 \mathrm{~Hz} \\
\text { rTMS over PC but } \\
\text { not } \\
\text { DLPFC during } \\
\text { delay phase } \\
\text { improved } \\
\text { 6-letter RT } \\
\text { compared to sham } \\
\text { (626 vs. } \\
702 \mathrm{~ms}, ~ 11 \%) \\
\text { and 1-letter RT (491 } \\
\text { vs. } \\
542 \mathrm{~ms}, \sim 9 \%) \text {. } \\
\text { Exp. } 2: 5 \mathrm{~Hz} \text { rTMS } \\
\text { over PC during } \\
\text { delay } \\
\text { but not decision } \\
\text { phase improved RT } \\
\text { by } 88 \mathrm{~ms} \text {. 1-letter } \\
\text { accuracy improved } \\
\text { during decision } \\
\text { phase compared to } \\
\text { sham }(\sim 97 \text { vs. } \\
\sim 90, \sim 7 \%) \text {. }\end{array}$ \\
\hline $\begin{array}{l}\text { Hamidi et al. } \\
\text { (2008) }\end{array}$ & $\begin{array}{l}\text { Exp. 1: } 30 \\
\quad \text { Exp. 2: } 24\end{array}$ & $\begin{array}{l}\text { Exp. 1: R/L DLPFC, } \\
\text { SPL, PCG } \\
\text { (control) } \\
\text { Exp. 2: R/L FEF, } \\
\text { IPS, } \\
\quad \text { PCG (control) }\end{array}$ & $\begin{array}{l}3 \mathrm{~s} \text { of } 10 \mathrm{~Hz} \text { rTMS at } \\
110 \% \text { rMT, during } \\
\text { delay, active/control }\end{array}$ & Spatial DMS & $\begin{array}{l}\text { Exp. 1: Stim over } \\
\text { SPL improved RT } \\
\sim 2 \% \\
\text { as compared to } \\
\text { PCG-control } \\
\text { ( 950 ms vs. } \\
\sim 970 \mathrm{ms).} \mathrm{Stim} \mathrm{over} \\
\text { LH } \\
\text { impaired } \\
\text { accuracy more as } \\
\text { stim over } \\
\text { RH (largest effect } \\
\text { over DLPFC). Stim } \\
\text { was more } \\
\text { disruptive if applied } \\
\text { contralaterally to } \\
\text { the visual field } \\
\text { (faster/slower RT } \\
\text { for LH/RH stim). } \\
\text { Exp. 2: Stim } \\
\text { decreased accuracy } \\
\text { overall } \\
\text { and specifically } \\
\text { for contralaterally } \\
\text { presented stimuli. }\end{array}$ \\
\hline
\end{tabular}




\begin{tabular}{|c|c|c|c|c|c|}
\hline Reference & $n$ & Regions stimulated & Stimulation protocol & Task & Results \\
\hline $\begin{array}{l}\text { Luber et al. } \\
(2008)\end{array}$ & $\begin{array}{l}15 \text { (sleep deprived } \\
\text { for } \\
\quad 48 \mathrm{~h} \mathrm{~s} \text { ) }\end{array}$ & $\begin{array}{l}\text { BA } 19 \text { and midline } \\
\text { PC, } \\
\text { BA } 18 \text { (control), } \\
\text { (as } \\
\quad \text { localized in fMRI) }\end{array}$ & $\begin{array}{l}7 \mathrm{~s} \mathrm{of} 5 \mathrm{~Hz} \text { rTMS at } \\
100 \% \mathrm{rMT} \text {, during } \\
\text { delay, active/sham }\end{array}$ & Visual DMS & $\begin{array}{l}\text { Stim to the upper } \\
\text { middle occipital } \\
\text { region } \\
\text { only reduced } \\
\text { sleep-deprivation } \\
\text { induced RT } \\
\text { deficit compared to } \\
\text { sham } \\
\text { ( } 1026 \mathrm{~ms} \text { vs. } \\
1169 \mathrm{~ms}) \text {. No } \\
\text { impact on } \\
\text { accuracy or non- } \\
\text { sleep deprived } \\
\text { subjects (state- } \\
\text { dependency). }\end{array}$ \\
\hline $\begin{array}{l}\text { Hamidi et al. } \\
\text { (2009) }\end{array}$ & 24 & $\begin{array}{l}\text { R/L DLPFC, SPL, } \\
\text { and } \\
\text { PCG (control) }\end{array}$ & $\begin{array}{l}3 \mathrm{~s} \text { of } 10 \mathrm{~Hz} \text { rTMS at } \\
110 \% \text { rMT, during } \\
\text { decision, active/ } \\
\text { control }\end{array}$ & $\begin{array}{l}\text { Spatial DMS } \\
\text { (recognition) and } \\
\text { recall }\end{array}$ & $\begin{array}{l}\text { Recognition: Stim } \\
\text { to right DLPFC } \\
\text { resulted in } \\
\text { accuracy } \\
\text { improvement, } \\
\text { stim to left } \\
\text { DLPFC led to } \\
\text { reduced } \\
\text { accuracy. } \\
\text { Recall: Stim to right } \\
\text { DLPFC resulted in } \\
\text { reduced accuracy. } \\
\text { No impact of stim } \\
\text { over SPL. }\end{array}$ \\
\hline Cattaneo (2009) & $\begin{array}{l}\text { Exp. 1: } 14 \\
\text { Exp. 2: } 11\end{array}$ & $\begin{array}{l}\mathrm{OC}(\mathrm{V} 1, \mathrm{~V} 2) \text { and } \\
\text { vertex }\end{array}$ & $\begin{array}{l}\text { sp TMS at } 65 \% \text { MSO, } \\
\text { at beginning or end } \\
\text { of delay, compared } \\
\text { to baseline }\end{array}$ & $\begin{array}{l}\text { Visual Imagery and } \\
\text { visuospatial STM } \\
\text { Exp. 1: at end of } \\
\text { delay } \\
\text { Exp. 2: at beginning of } \\
\text { delay }\end{array}$ & $\begin{array}{l}\text { Exp. 1: Stim } \\
\text { facilitated both } \\
\text { tasks } \\
\quad \text { compared to } \\
\text { vertex stim and } \\
\text { baseline. } \\
\text { Exp. 2: Stim } \\
\text { impaired STM } \\
\text { compared to } \\
\quad \text { vertex and } \\
\text { baseline but not } \\
\text { visual } \\
\text { imagery. No } \\
\text { impact on accuracy. }\end{array}$ \\
\hline $\begin{array}{l}\text { Preston et al. } \\
(2009)\end{array}$ & 32 & R/L DLPFC (F3/F4) & $\begin{array}{l}55 \text {-s trains of } 10 \mathrm{~Hz} \\
\text { rTMS, ITI } 10 \mathrm{~s} \text {, at } \\
100 \% \text { rMT, offline, } \\
\text { active/sham }\end{array}$ & Verbal DMS & $\begin{array}{l}\text { Stim decreased } \\
\text { correct response RT } \\
\text { in } \\
\text { active }(-21 \%) \\
\text { compared to sham } \\
(+0.3 \%) \text {. No } \\
\text { impact on accuracy. }\end{array}$ \\
\hline $\begin{array}{l}\text { Yamanaka et al. } \\
\text { (2010) }\end{array}$ & 52 & $\mathrm{R} / \mathrm{L}$ PC & $\begin{array}{c}5 \mathrm{~Hz} \mathrm{rTMS} \text { at } 100 \% \\
\text { rMT, during delay } \\
(6 \mathrm{~s}) \text {, active/sham }\end{array}$ & $\begin{array}{l}\text { Spatial DMS and } \\
\text { attentional control } \\
\text { task }\end{array}$ & $\begin{array}{l}\text { Stim over right PC } \\
\text { during delay } \\
\text { improved RT } \\
\sim 7 \% \text { compared to } \\
\text { sham } \\
(\sim 800 \mathrm{~ms} \text { vs. } \\
\sim 865 \mathrm{~ms}) \text {. Increase } \\
\text { of } \\
\text { frontal } \\
\text { oxygenated } \\
\text { hemoglobin } \\
\text { during DMS and } \\
\text { decrease during } \\
\text { control task. }\end{array}$ \\
\hline $\begin{array}{l}\text { Silvanto and } \\
\text { Cattaneo (2010) }\end{array}$ & 12 & $\begin{array}{l}\text { Exp. 1: R/LV5/MT } \\
(2 \text { coils) } \\
\text { Exp. } 2: \mathrm{R} / \mathrm{L} \text { lateral } \\
\text { OC } \\
\text { (2 coils) }\end{array}$ & $\begin{array}{l}\text { sp TMS at } 120 \% \text { PT, at } \\
3 \text { s into delay, } \\
\text { baseline phosphene }\end{array}$ & $\begin{array}{l}\text { Delayed visual motion } \\
\text { discrimination }\end{array}$ & $\begin{array}{l}\text { Exp. 1: Reported } \\
\text { phosphene motion } \\
\text { was } \\
\text { influenced by the } \\
\text { motion component }\end{array}$ \\
\hline
\end{tabular}




\begin{tabular}{|c|c|c|c|c|c|}
\hline Reference & $n$ & Regions stimulated & Stimulation protocol & Task & Results \\
\hline & & & & & $\begin{array}{l}\text { of the memory } \\
\text { item: enhanced } \\
\text { when } \\
\text { direction was the } \\
\text { same as in baseline } \\
\text { phosphene, } \\
\text { weakened if } \\
\text { opposite } \\
\text { direction. } \\
\text { Exp. } 2 \text { : No relation } \\
\text { between task and } \\
\text { phosphenes after } \\
\text { stim of lateral } \\
\text { occipital region. }\end{array}$ \\
\hline $\begin{array}{l}\text { Hannula et al. } \\
\text { (2010) }\end{array}$ & $\begin{array}{l}\text { Exp. 1: } 6 \\
\text { Exp. 3: } 6\end{array}$ & $\begin{array}{l}\text { MFG area with/ } \\
\text { without } \\
\text { S1 connection }\end{array}$ & $\begin{array}{l}\text { sp TMS at } 120 \% \mathrm{rMT} \\
\text { at } 300 \text { or } 1200 \mathrm{~ms} \\
\text { into delay, baseline } \\
\text { control }\end{array}$ & $\begin{array}{l}\text { Tactile STM } \\
\text { (discrimination) } \\
\text { without (Exp. 1) } \\
\text { or with (Exp. 3) } \\
\text { distraction }\end{array}$ & $\begin{array}{l}\text { Exp. 1: Stim } \\
\text { delivered during } \\
\text { early but } \\
\quad \text { not late delay } \\
\text { over MFG regions } \\
\text { with } \\
\quad \text { connection to S1 } \\
\text { decreased RT } \sim 15 \% \\
\quad \text { compared to } \\
\text { baseline }(\sim 730 \mathrm{~ms} \\
\text { vs. } \\
\sim 860 \mathrm{~ms}) \text {. } \\
\text { Exp. 3: Distraction } \\
\text { prolonged mean RT } \\
\text { by } 5 \% \text {. }\end{array}$ \\
\hline $\begin{array}{l}\text { Feredoes et al. } \\
\text { (2011) }\end{array}$ & 16 & $\begin{array}{l}\text { R DLPFC, combined } \\
\text { with fMRI }\end{array}$ & $\begin{array}{l}3 \text { sp TMS at } 110 \% \\
\text { rMT } \\
\text { or } 40 \% \text { rMT } \\
\text { (control), during } \\
\text { delay }\end{array}$ & $\begin{array}{l}\text { Visual DMS (face or } \\
\text { house) with/without } \\
\text { distractor } \\
\text { interference }\end{array}$ & $\begin{array}{l}\text { Stim (time-locked } \\
\text { to distractors) over } \\
\text { DLPFC increased } \\
\text { activation in } \\
\text { posterior areas } \\
\text { (that represented } \\
\text { stimuli but not } \\
\text { distractors) only } \\
\text { when } \\
\text { distractors were } \\
\text { present. }\end{array}$ \\
\hline $\begin{array}{l}\text { Zanto et al. } \\
\text { (2011) }\end{array}$ & 20 & $\begin{array}{l}\text { R IFJ (as localized in } \\
\text { fMRI), combined } \\
\text { with EEG }\end{array}$ & $\begin{array}{l}10 \mathrm{~min} \text { of } 1 \mathrm{~Hz} \text { rTMS } \\
\text { at } \\
120 \% \mathrm{rMT} \text { offline, } \\
\text { active/sham }\end{array}$ & $\begin{array}{l}\text { Visual DMS (motion } \\
\text { direction or } \\
\text { color of dots) }\end{array}$ & $\begin{array}{l}\text { Stim led to a decline } \\
\text { of P1 and accuracy } \\
\text { during the first } \\
\text { half but not second } \\
\text { half of the color } \\
\text { condition, no effects } \\
\text { during motion } \\
\text { condition (P1 } \\
\text { modulation } \\
\text { predicted accuracy } \\
\text { changes). The } \\
\text { magnitude of phase } \\
\text { locking value in } \\
\text { the alpha band (but } \\
\text { not beta or } \\
\text { gamma) decreased } \\
\text { after } \\
\text { rTMS. }\end{array}$ \\
\hline $\begin{array}{l}\text { Higo et al. } \\
(2011) \\
\text { Exp. } 2\end{array}$ & 9 & $\begin{array}{l}\mathrm{L} \mathrm{fO} \text { (as localized } \\
\text { in fMRI in Exp. 1) }\end{array}$ & $\begin{array}{l}15 \text { min } 1 \mathrm{~Hz} \text { rTMS, } \\
\text { offline, adjusted to } \\
\text { RMT, active }\end{array}$ & $\begin{array}{l}\text { Visual delayed } \\
\text { matching to stimulus } \\
\text { class (houses, body } \\
\text { parts, faces) }\end{array}$ & $\begin{array}{l}\text { TMS over fO } \\
\text { disrupted top-down } \\
\text { selective } \\
\text { attentional } \\
\text { modulation in the } \\
\text { occipitotemporal } \\
\text { cortex but did not } \\
\text { alter bottom-up } \\
\text { activation. The fO } \\
\text { may play a role in } \\
\text { regulating activity }\end{array}$ \\
\hline
\end{tabular}




\begin{tabular}{|c|c|c|c|c|c|}
\hline Reference & $n$ & Regions stimulated & Stimulation protocol & Task & Results \\
\hline & & & & & $\begin{array}{l}\text { levels of } \\
\text { representations in } \\
\text { posterior } \\
\quad \text { brain areas. }\end{array}$ \\
\hline $\begin{array}{l}\text { Savolainen et al. } \\
\text { (2011) }\end{array}$ & 12 & $\begin{array}{l}\text { MFG area with/ } \\
\text { without } \\
\text { S1 connection }\end{array}$ & $\begin{array}{l}\text { sp TMS at } 120 \% \text { rMT, } \\
\text { at } 300 \mathrm{~ms} \text { into delay, } \\
\text { baseline control }\end{array}$ & $\begin{array}{l}\text { Tactile STM } \\
\text { (discrimination) with } \\
\text { tactile or visual } \\
\text { distractor }\end{array}$ & $\begin{array}{l}\text { Stim over MFG } \\
\text { region with S1 } \\
\text { connection } \\
\text { followed by tactile } \\
\text { (but not } \\
\text { visual) distractor } \\
\text { decreased RT } \sim 4 \% \\
\text { compared to } \\
\text { baseline ( } \sim 70 \mathrm{~ms} \\
\text { vs. } \\
\sim 800 \mathrm{~ms} \text { ). }\end{array}$ \\
\hline $\begin{array}{l}\text { Soto et al. } \\
\text { (2012) Exp. } 2\end{array}$ & 8 & $\begin{array}{l}\text { L SFG and LOC (as } \\
\text { localized in fMRI } \\
\text { Exp. 1) }\end{array}$ & $\begin{array}{l}15 \mathrm{~min} \text { of } 1 \mathrm{~Hz} \text { rTMS } \\
\text { at } \\
55 \% \text { MSO, offline, } \\
\text { active/sham }\end{array}$ & Visual and verbal DMS & $\begin{array}{l}\text { Stim to left SFG } \\
\text { increased RT for } \\
\text { recognition of } \\
\text { colored shapes } \\
\text { compared to } \\
\text { sham. Stim to the } \\
\text { LOC } \\
\text { increased RT for } \\
\text { recognition of } \\
\text { written words } \\
\text { compared to sham. } \\
\text { No } \\
\text { impact on } \\
\text { accuracy. }\end{array}$ \\
\hline $\begin{array}{l}\text { Morgan et al. } \\
\text { (2013) }\end{array}$ & 20 & R PC, L IFG & $\begin{array}{l}40 \mathrm{~s} \text { train of cTBS at } \\
80 \% \text { aMT, offline, } \\
\text { active/sham }\end{array}$ & $\begin{array}{l}\text { Object color, angle } \\
\text { averaging, and } \\
\text { combined task }\end{array}$ & $\begin{array}{l}\text { Stim to right PC or } \\
\text { left IFG selectively } \\
\text { impaired WM for } \\
\text { the combined task, } \\
\text { but not single } \\
\text { feature tasks as } \\
\text { compared to } \\
\text { sham. }\end{array}$ \\
\hline $\begin{array}{l}\text { van de Ven et } \\
\text { al. (2012) }\end{array}$ & 12 & Lateral OC & $\begin{array}{l}\text { sp TMS at } 110 \% \text { PT at } \\
100,200, \text { or } 400 \mathrm{~ms} \\
\text { into delay, active/ } \\
\text { sham }\end{array}$ & $\begin{array}{l}\text { Modified change } \\
\text { detection task with } \\
\text { low or high memory } \\
\text { loads }\end{array}$ & $\begin{array}{l}\text { Stim delivered at } \\
200 \text { ms into the } \\
\text { delay } \\
\text { phase decreased } \\
\text { accuracy for high } \\
\text { but } \\
\text { not low memory } \\
\text { loads in the } \\
\text { contralateral } \\
\text { visual field } \\
\text { compared to } \\
\text { sham. }\end{array}$ \\
\hline \multicolumn{6}{|c|}{ TMS in working memory and prospective memory } \\
\hline $\begin{array}{l}\text { Mottaghy et al. } \\
(2000)\end{array}$ & 14 & $\begin{array}{l}\text { R/L DLPFC, Fz } \\
\text { (control), } \\
\text { combined } \\
\text { with PET }\end{array}$ & $\begin{array}{r}30 \mathrm{~s} \text { of } 4 \mathrm{~Hz} \text { rTMS at } \\
110 \% \text { rMT, during } \\
\text { task, active/control }\end{array}$ & $\begin{array}{l}\text { Verbal 2-back, 0-back } \\
\text { (control) }\end{array}$ & $\begin{array}{l}\text { Stim over either } \\
\text { R/L DLPFC } \\
\text { reduced } \\
\text { accuracy and } \\
\text { rCBF in the targeted } \\
\text { area as well as } \\
\text { afferent networks } \\
\text { specific to each } \\
\text { hemisphere. Stim to } \\
\text { Fz had no effect } \\
\text { on WM task. } \\
\text { Performance on } \\
\text { the control task was } \\
\text { not affected by } \\
\text { stim. }\end{array}$ \\
\hline $\begin{array}{l}\text { Mull and Seyal } \\
\text { et al. (2001) }\end{array}$ & 7 & R/L DLPFC & $\begin{array}{l}\text { spTMS at } 115 \% \text { rMT, } \\
\text { at } \\
400 \mathrm{~ms} \text { into delay, } \\
\text { active/no TMS }\end{array}$ & Verbal 3-back & $\begin{array}{l}\text { Stim over L DLPFC } \\
\text { increased error rate }\end{array}$ \\
\hline
\end{tabular}




\begin{tabular}{|c|c|c|c|c|c|}
\hline Reference & $n$ & Regions stimulated & Stimulation protocol & Task & Results \\
\hline & & & & & $\begin{array}{l}\text { compared to no } \\
\text { TMS control } \\
(5.4 \%) \text {. } \\
\quad \text { No impact of } \\
\text { stim over R } \\
\text { DLPFC. }\end{array}$ \\
\hline $\begin{array}{l}\text { Oliveri et al. } \\
(2001)\end{array}$ & $\begin{array}{l}35(5 \text { Exp.: 8, 6, 6, } \\
25,6)\end{array}$ & $\begin{array}{l}\text { Exp. series 1: R/L or } \\
\quad \text { bilateral temporal } \\
\text { (T5/T6) and } \\
\text { parietal } \\
\quad \text { (P4/P5) } \\
\text { Exp. series 2: } \\
\text { Bilateral } \\
\quad \text { SFG and DLPFC }\end{array}$ & $\begin{array}{l}\text { Uni- or bilateral } \\
\text { spTMS } \\
\text { at } 130 \% \mathrm{rMT} \text {, at } 300 \\
\text { or } 600 \mathrm{~ms} \text {, active/ } \\
\text { baseline }\end{array}$ & $\begin{array}{l}\text { Spatial 2-back } \\
\text { Visual-object 2-back } \\
\quad \text { (abstract patterns) }\end{array}$ & $\begin{array}{l}\text { Exp. series 1: } \\
\text { Bilateral parietal } \\
\text { stim at } \\
300 \text { ms increased } \\
\text { RT in visuospatial } \\
\text { task compared to } \\
\text { temporal (11\%) and } \\
\text { baseline (20\%). } \\
\text { Bilateral temporal } \\
\text { stim at } 300 \mathrm{~ms} \\
\text { impaired RT in } \\
\text { visual-object } \\
\text { task. No impact on } \\
\text { accuracy. } \\
\text { Exp. series } 2 \text { : } \\
\text { Bilateral stim over } \\
\text { SFG at } \\
600 \text { ms increased } \\
\text { RTs in visuospatial } \\
\text { task compared to } \\
\text { baseline (11\%), } \\
\text { whereas bilateral } \\
\text { stim over DLPFC at } \\
600 \text { ms interfered } \\
\text { in both tasks with } \\
\text { accuracy } \\
\text { (visuospatial: } 10 \% \text {, } \\
\text { visual- } \\
\text { object: } 13 \% \text { ) and } \\
\text { RT (visuospatial: } \\
6 \% \text {, } \\
\text { visual-object: } \\
6 \% \text { ). }\end{array}$ \\
\hline $\begin{array}{l}\text { Sandrini et al. } \\
\text { (2003) }\end{array}$ & 12 & $\mathrm{R} / \mathrm{L}$ DLPFC (F3/F4) & $\begin{array}{l}0.5 \mathrm{~s} \text { of } 20 \mathrm{~Hz} \text { rTMS at } \\
90 \% \text { rMT, during } \\
\text { encoding or } \\
\text { retrieval, } \\
\text { active/ } \\
\text { sham/baseline }\end{array}$ & $\begin{array}{l}\text { Verbal LTM: } \\
\text { Recognition of } \\
\text { unrelated/related } \\
\text { word pairs after } 1 \mathrm{~h}\end{array}$ & $\begin{array}{l}\text { Impaired } \\
\text { recognition } \\
\text { accuracy of } \\
\text { unrelated word } \\
\text { pairs after stim over } \\
\mathrm{R} \\
\text { and L DLPFC } \\
\text { during encoding and } \\
\text { right PFC in } \\
\text { retrieval. No impact } \\
\text { on RT besides } \\
\text { faster RT for } \\
\text { related as } \\
\text { compared to } \\
\text { unrelated } \\
\text { words. }\end{array}$ \\
\hline $\begin{array}{l}\text { Mottaghy et al. } \\
\text { (2003a) }\end{array}$ & 6 & $\begin{array}{l}\text { R/L MFG, inferior } \\
\text { PC }\end{array}$ & $\begin{array}{l}\text { sp TMS at } 120 \% \mathrm{rMT}, \\
\text { at } 140-500 \text { (at } 10 \\
\text { time } \\
\text { points, ISI } 40 \mathrm{~ms} \text { ) } \\
\text { into delay, after } \\
\text { every } 4 \text { th letter, } \\
\text { active/control }\end{array}$ & $\begin{array}{l}\text { Exp. 1: Verbal 2-back } \\
\text { Exp. 2: Choice reaction } \\
\quad \text { (control task) }\end{array}$ & $\begin{array}{l}\text { Impaired accuracy } \\
\text { occurred after stim } \\
\text { of R PC ( }(180 \mathrm{~ms}) \\
\text { of L PC ( } 220 \mathrm{~ms}) \\
\text { and } \\
\text { R MFG }(220 \mathrm{~ms}) \text {, } \\
\text { and L MFG } \\
\text { ( } 260 \mathrm{~ms}) \text {. RT was } \\
\text { impaired only after } \\
\text { L MFG stim ( }(180 \\
\text { ms). No impact on } \\
\text { control task. }\end{array}$ \\
\hline $\begin{array}{l}\text { Mottaghy et al. } \\
\text { (2003b) }\end{array}$ & 14 & R/L DLPFC (F3/F4) & $\begin{array}{l}30 \mathrm{~s} \text { of } 4 \mathrm{~Hz} \text { rTMS at } \\
110 \% \text { rMT, during } \\
\text { task, active/control/ } \\
\text { baseline }\end{array}$ & $\begin{array}{l}\text { Verbal 2-back, 0-back } \\
\quad \text { (control task) }\end{array}$ & $\begin{array}{l}\text { Stim over L DLPFC } \\
\text { led to a shift of } \\
\text { BBR }\end{array}$ \\
\hline
\end{tabular}

Handb Clin Neurol. Author manuscript; available in PMC 2014 December 01. 


\begin{tabular}{|c|c|c|c|c|c|}
\hline Reference & $n$ & Regions stimulated & Stimulation protocol & Task & Results \\
\hline & & & & & $\begin{array}{l}\text { towards the SFG } \\
\text { and to a positive } \\
\text { BBR } \\
\text { in anterior parts } \\
\text { of the SFG. Stim } \\
\text { over } \\
\text { R DLPFC led to a a } \\
\text { shift of the BBR to } \\
\text { left posterior and } \\
\text { inferior IFG. } \\
\text { Baseline } \\
\text { measurements } \\
\text { indicated a } \\
\text { negative BBR in } \\
\text { the left MFG } \\
\text { and no significant } \\
\text { BBR in the } \\
\text { right MFG. }\end{array}$ \\
\hline $\begin{array}{l}\text { Rami et al. } \\
(2003)\end{array}$ & 16 & $\begin{array}{l}\text { HF stim to R/L } \\
\text { DLFPC } \\
\text { and right } \mathrm{Cb}, \mathrm{LF} \\
\text { stim } \\
\text { to L DLPFC }\end{array}$ & $\begin{array}{l}\text { 10-s trains of } 1 \text { or } 5 \mathrm{~Hz} \\
\text { rTMS at } 90 \% \text { rMT, } \\
30 \mathrm{~s} \text { intervals, } \\
\text { during } \\
\text { encoding and } \\
\text { retrieval, active/ } \\
\text { baseline }\end{array}$ & $\begin{array}{l}\text { STM (digits forward), } \\
\text { WM (digits } \\
\text { backward, letter- } \\
\text { number sequencing } \\
\text { WAIS III), episodic } \\
\text { memory (RBMT), } \\
\text { verbal fluency }\end{array}$ & $\begin{array}{l}\text { HF stim over L } \\
\text { DLFPC impaired } \\
\text { verbal } \\
\text { episodic memory } \\
\text { as compared to HF } \\
\text { stim over R } \\
\text { DLPFC, LF stim } \\
\text { over L } \\
\text { DLPFC, and } \\
\text { baseline. }\end{array}$ \\
\hline $\begin{array}{l}\text { Postle et al. } \\
\text { (2006) }\end{array}$ & $\begin{array}{l}\text { R: } 5 \\
\text { L: } 7\end{array}$ & $\begin{array}{l}\text { R/L DLPFC, SPL, } \\
\text { PCG } \\
\text { (control) (as } \\
\text { localized with } \\
\text { fMRI) }\end{array}$ & $\begin{array}{l}6 \mathrm{~s} \text { of } 5 \mathrm{~Hz} \text { rTMS at } \\
100 \% \text { rMT, during } \\
\text { delay, active/control }\end{array}$ & Verbal STM or WM & $\begin{array}{l}\text { Stim over DLPFC } \\
\text { impaired accuracy } \\
\text { of } \\
\text { WM but not STM } \\
\text { compared to } \\
\text { control. Stim } \\
\text { over SPL impaired } \\
\text { accuracy of WM } \\
\text { and STM. No } \\
\text { impact } \\
\text { on RT. }\end{array}$ \\
\hline $\begin{array}{l}\text { Osaka et al. } \\
\text { (2007) }\end{array}$ & 8 & $\begin{array}{l}\text { L DLPFC, Cz } \\
\text { (control) }\end{array}$ & $\begin{array}{l}\text { pp TMS (ISI } 100 \mathrm{~ms} \text { ) } \\
\text { at } \\
.47 \mathrm{~T} \text {, during delay, } \\
\text { active/sham/control }\end{array}$ & $\begin{array}{l}\text { Reading span task } \\
\text { (maintain target } \\
\text { words) }\end{array}$ & $\begin{array}{l}\text { Stim decreased } \\
\text { mean accuracy } \\
\text { compared to } \\
\text { sham or stim over } \\
\mathrm{Cz} \\
(10.9 \% \text { and } \\
7.5 \%) \text {. }\end{array}$ \\
\hline $\begin{array}{l}\text { Sandrini et al. } \\
\text { (2008) }\end{array}$ & $\begin{array}{l}\text { Exp. 1: } 9 \\
\text { Exp. 2: } 14 \\
\text { Exp. 3: } 9\end{array}$ & R/L DLPFC & $\begin{array}{l}0.5 \mathrm{~s} \text { of } 10 \mathrm{~Hz} \text { rTMS at } \\
90 \% \mathrm{rMT} \text {, at end of } \\
\text { delay, active/sham }\end{array}$ & $\begin{array}{l}\text { Exp. 1: combined } \\
\text { verbal/spatial 1-back } \\
\text { Exp. 2: combined } \\
\text { verbal/spatial 2-back } \\
\text { Exp. 3: 2-back with one } \\
\text { domain only }\end{array}$ & $\begin{array}{l}\text { R DLPFC stim } \\
\text { impaired RT in the } \\
\text { verbal } \\
\text { condition ( } 834 \\
\text { ms vs. } \sim 790 \text { and } \\
\sim 803 \mathrm{~ms}) \text {, } \\
\text { whereas L DLPFC } \\
\text { stim } \\
\text { impaired RT in } \\
\text { the spatial condition } \\
\text { compared to } \\
\text { opposite side and } \\
\text { sham } \\
\text { (792 ms vs. } 728 \\
\text { and } 737 \mathrm{~ms}) \text {. No } \\
\text { impact on } \\
\text { accuracy, variation } \\
\text { of only } \\
\text { one domain, or 1- } \\
\text { back task. }\end{array}$ \\
\hline $\begin{array}{l}\text { Imm et al. } \\
(2008)\end{array}$ & 12 & $\begin{array}{l}\mathrm{R} / \mathrm{L} \text { DLPFC }(\mathrm{F} 3 / \mathrm{F} 4) \text {, } \\
\text { inferior PC } \\
(\mathrm{P} 3 / \mathrm{P} 4)\end{array}$ & $\begin{array}{l}\text { sp TMS at } 100 \% \text { rMT, } \\
\text { at } 250,450,650, \text { or } \\
850 \mathrm{~ms} \text { into delay, } \\
\text { active }\end{array}$ & $\begin{array}{l}\text { Audioverbal 2-back } \\
\text { Pitch 2-back }\end{array}$ & $\begin{array}{l}\text { Stim over RH } \\
\text { increased RT in the } \\
\text { pitch }\end{array}$ \\
\hline
\end{tabular}




\begin{tabular}{|c|c|c|c|c|c|}
\hline Reference & $n$ & Regions stimulated & Stimulation protocol & Task & Results \\
\hline & & & & & $\begin{array}{l}\text { 2-back at } 650 \text { and } \\
850 \mathrm{~ms}(724 \text { and } \\
850 \mathrm{~ms} \text { vs. } 656 \\
\mathrm{~ms} \text { ). Stim over P3 } \\
\text { increased RT in } \\
\text { the audioverbal 2- } \\
\text { back at } 450 \mathrm{~ms} \text {. }\end{array}$ \\
\hline $\begin{array}{l}\text { Basso et al. } \\
(2010)\end{array}$ & $\begin{array}{l}\text { Exp. 1: } 27 \\
\text { Exp. 2: } 24 \\
\text { Exp. 3: } 18\end{array}$ & $\begin{array}{l}\text { R/L DLPFC, } \\
\text { interhemispheric } \\
\text { sulcus (control) }\end{array}$ & $\begin{array}{l}\text { spTMS at } 100 \% \text { rMT, } \\
\text { delivered } 300 \mathrm{~ms} \\
\text { into delay, active/ } \\
\text { control }\end{array}$ & $\begin{array}{l}\text { Exp. 1: WM } \\
\text { (medium =3, } \\
\text { high = 5) and lexical } \\
\text { decision (word/ } \\
\text { pseudoword), } \\
\text { prospective } \\
\text { condition (react to } \\
\text { specific words); } \\
\text { Exp. 2: prospective } \\
\text { condition } 1 \text { or } 3 \\
\text { words; Exp. 3: with } \\
\text { TMS }\end{array}$ & $\begin{array}{l}\text { Stim increased error } \\
\text { rates of the PM task } \\
\text { more than the } \\
\text { WM task and } \\
\text { compared } \\
\text { to sham. } \\
\text { Exp. } 1 \text { and 2: } \\
\text { Higher PM demand } \\
\text { affected WM } \\
\text { only at higher loads. } \\
\text { Exp. 3: Stim over } \\
\text { R/L DLPFC } \\
\text { impaired } \\
\text { accuracy of PM } \\
\text { task regardless } \\
\text { of WM load, } \\
\text { while effect on } \\
\text { WM was } \\
\text { marginal. }\end{array}$ \\
\hline $\begin{array}{l}\text { Costa et al. } \\
(2011)\end{array}$ & $\begin{array}{l}\text { Exp. 1: } 8 \\
\text { Exp. 2: } 8\end{array}$ & $\begin{array}{l}\text { Exp. 1: R/L BA } 10 \\
\text { (frontal pole), Cz } \\
\text { (control) } \\
\text { Exp. 2: L BA } 46 \\
\text { (DLPFC), Cz } \\
\text { (control) }\end{array}$ & $\begin{array}{l}20 \mathrm{~s} \text { of cTBS (3-pulse } \\
\text { bursts at } 50 \mathrm{~Hz} \\
\text { every } \\
200 \mathrm{~ms}) \text { at } 80 \% \\
\text { aMT }\end{array}$ & $\begin{array}{l}\text { Verbal forward/ } \\
\text { backward } \\
\text { memorization task } \\
\text { with simultaneous } \\
\text { response to target } \\
\text { word (PM task) }\end{array}$ & $\begin{array}{l}\text { Exp. 1: Stim over } \\
\text { left BA } 10 \\
\text { decreased } \\
\text { accuracy in PM } \\
\text { compared to Cz } \\
\text { stim } \\
\quad(58.6 \% \text { vs. } \\
73.4 \%) \text {. } \\
\text { Exp. } 2 \text { : Stim over } \\
\text { left DLPFC had no } \\
\text { significant effect } \\
\text { on accuracy or RT. }\end{array}$ \\
\hline \multicolumn{6}{|c|}{ TMS in general learning and memory } \\
\hline $\begin{array}{l}\text { Grafman et al. } \\
\text { (1994) }\end{array}$ & 5 & $\begin{array}{l}\text { R/L hemisphere } \\
\text { (F7/F8, } \\
\text { T5/T6, P3/P4, } \\
\text { O1/O2) }\end{array}$ & $\begin{array}{l}5 \mathrm{p} \text { of } 20 \mathrm{~Hz} \text { rTMS at } \\
120 \% \text { rMT, during } \\
\text { encoding (at } 0,250, \\
500,1000 \mathrm{~ms}) \\
\text { active/sham }\end{array}$ & $\begin{array}{l}\text { Verbal memory (word } \\
\text { recall) }\end{array}$ & $\begin{array}{l}\text { Stim over T5, F7, } \\
\text { and F8 at } 0 \text { and } 250 \\
\text { ms } \\
\text { showed highest } \\
\text { impairment of recall } \\
\text { as compared to } \\
\text { sham. Furthermore } \\
\text { stim over T5 and } \\
\text { F7 at } 500 \mathrm{~ms} \\
\text { impaired recall. } \\
\text { Stim over T5 and } \\
\text { F7 } \\
\text { also impaired the } \\
\text { primacy effect. }\end{array}$ \\
\hline $\begin{array}{l}\text { Rossi et al. } \\
\text { (2001) }\end{array}$ & 13 & R/L DLPFC (F3/F4) & $\begin{array}{l}500 \mathrm{~ms} \text { of } 20 \mathrm{~Hz} \text { rTMS } \\
\text { at } 90 \% \text { rMT, during } \\
\text { encoding or } \\
\text { retrieval, active/ } \\
\text { sham/baseline }\end{array}$ & $\begin{array}{l}\text { Visual memory } \\
\text { (indoor/outdoor } \\
\text { images) }\end{array}$ & $\begin{array}{l}\text { Stim over R DLPFC } \\
\text { during retrieval } \\
\text { impaired } \\
\text { accuracy, while } \\
\text { stim over L } \\
\text { DLPFC during } \\
\text { encoding and over } \\
\mathrm{R} \\
\text { DLPFC during } \\
\text { retrieval impaired } \\
\text { discrimination. } \\
\text { No impact of R } \\
\text { DLPFC stim } \\
\text { during encoding and } \\
\mathrm{L} \text { DLPFC stim } \\
\text { during retrieval. }\end{array}$ \\
\hline
\end{tabular}




\begin{tabular}{|c|c|c|c|c|c|}
\hline Reference & $n$ & Regions stimulated & Stimulation protocol & Task & Results \\
\hline $\begin{array}{l}\text { Epstein et al. } \\
(2002)\end{array}$ & 10 & $\begin{array}{l}\text { R/L DLPFC, Cz } \\
\quad \text { (control) }\end{array}$ & $\begin{array}{l}\text { pp TMS (ISI } 60 \mathrm{~ms} \text { ), } \\
120 \% \text { rMT, during } \\
\text { encoding at } 180 \mathrm{~ms}, \\
\text { active/controls } / \mathrm{no} \\
\text { stim }\end{array}$ & $\begin{array}{l}\text { Visual memory } \\
\quad \text { (associate Kanji } \\
\text { words and abstract } \\
\text { patterns) }\end{array}$ & $\begin{array}{l}\text { Stim during } \\
\text { encoding over R } \\
\text { DLPFC } \\
\quad \text { decreased } \\
\text { accuracy compared } \\
\text { to stim } \\
\text { over L DLPFC. } \\
\text { RT was not } \\
\text { measured. }\end{array}$ \\
\hline $\begin{array}{l}\text { Floel et al. } \\
\text { (2004) }\end{array}$ & 15 & $\mathrm{R} / \mathrm{L}$ IFG & $\begin{array}{l}0.5 \mathrm{~s} \text { of } 20 \mathrm{~Hz} \text { rTMS at } \\
90 \% \text { rMT, during } \\
\text { encoding, active/ } \\
\text { sham } / \text { no stim }\end{array}$ & $\begin{array}{l}\text { Verbal (letters) and } \\
\text { nonverbal (abstract } \\
\text { shapes) memory }\end{array}$ & $\begin{array}{l}\text { Stim over L IFG } \\
\text { impaired word } \\
\text { recognition, } \\
\text { while stim over R } \\
\text { IFG } \\
\text { impaired image } \\
\text { recognition, each as } \\
\text { compared to } \\
\text { opposite stim } \\
\text { (words } 20 \% \\
\text { and images 14\%) } \\
\text { or sham (words } \\
24 \% \\
\text { and images 14\%). } \\
\text { No impact on RT. }\end{array}$ \\
\hline $\begin{array}{l}\text { Köhler et al. } \\
\text { (2004) }\end{array}$ & 12 & $\begin{array}{l}\text { L Inferior PFC } \\
\text { (guided } \\
\quad \text { by fMRI) } \\
\mathrm{R} \text { inferior PFC and L } \\
\text { PC } \\
\quad \text { (controls) }\end{array}$ & $\begin{array}{l}5 \mathrm{p} \text { of } 7 \mathrm{~Hz} \text { rTMS at } \\
100 \% \mathrm{rMT} \text {, during } \\
\text { encoding, active/ } \\
\text { control/no stim }\end{array}$ & $\begin{array}{l}\text { During fMRI: } \\
\text { semantic/non- } \\
\text { semantic decisions, } \\
\text { crosshair fixation } \\
\text { During stim: semantic } \\
\text { decisions } \\
\text { After stim: verbal } \\
\text { memory } \\
\text { (recognition) }\end{array}$ & $\begin{array}{l}\text { Stim over L PFC } \\
\text { increased } \\
\text { recognition } \\
\text { accuracy } \\
\text { compared to non- } \\
\text { stim and } \\
\text { control (R PFC, L } \\
\text { PC). No impact on } \\
\text { RT. But, RT for } \\
\text { semantic decisions } \\
\text { made under L } \\
\text { PFC stim was } \\
\text { impaired. }\end{array}$ \\
\hline $\begin{array}{l}\text { Skrdlantov et al. } \\
\text { (2005) }\end{array}$ & 10 & L DLPFC & $\begin{array}{l}0.9 \mathrm{~Hz} \text { rTMS at } 110 \% \\
\text { rMT, during task } \\
\text { (192 p per subtest), } \\
\text { active/sham }\end{array}$ & $\begin{array}{l}\text { Verbal memory (word } \\
\text { recall) Visual } \\
\text { memory (facial } \\
\text { recognition) }\end{array}$ & $\begin{array}{l}\text { Stim over L DLPFC } \\
\text { during task } \\
\text { impaired } \\
\quad \text { free recall of } \\
\text { words but not } \\
\text { recognition of } \\
\text { faces as compared } \\
\text { to } \\
\text { sham. }\end{array}$ \\
\hline $\begin{array}{l}\text { Kahn et al. } \\
\text { (2005) }\end{array}$ & 14 & $\begin{array}{l}\text { R/L posterior } \\
\text { VLPFC, } \\
\quad \text { (guided by fMRI) }\end{array}$ & $\begin{array}{l}\text { spTMS at mean 66\% } \\
\text { MSO, during } \\
\text { encoding (btw 250- } \\
600 \mathrm{~ms} \text { ), active/ } \\
\text { baseline }\end{array}$ & $\begin{array}{l}\text { Verbal memory } \\
\text { (decision if 2/3- } \\
\text { syllable word or } \\
\text { peusdo-word, then } \\
\text { surpise recognition } \\
\text { task with confidence } \\
\text { judgments) }\end{array}$ & $\begin{array}{l}\text { Stim over L VLPFC } \\
\text { impaired word } \\
\text { memory } \\
\text { (confidence), while } \\
\text { stim over } \\
\text { R VLPFC } \\
\text { facilitated word and } \\
\text { pseudo- word } \\
\text { memory } \\
\text { (confidence, } \\
\text { difference } \\
\text { strongest at } 380 \\
\text { ms). } \\
\text { Phonological } \\
\text { decision accuracy } \\
\text { was } \\
\text { facilitated for } \\
\text { words and pseudo- } \\
\text { words after stim } \\
\text { over R VLPFC } \\
\text { (strongest at } 340 \\
\text { ms). }\end{array}$ \\
\hline
\end{tabular}




\begin{tabular}{|c|c|c|c|c|c|}
\hline Reference & $n$ & Regions stimulated & Stimulation protocol & Task & Results \\
\hline $\begin{array}{l}\text { Rossi et al. } \\
(2006)\end{array}$ & 42 & $\begin{array}{l}\text { R/L DLPFC or IPS } \\
\text { (P3/P4) }\end{array}$ & $\begin{array}{l}500 \mathrm{~ms} \text { rTMS at } 20 \mathrm{~Hz} \\
\text { at } 90 \text { or } 120 \% \mathrm{rMT}, \\
\text { during encoding, } \\
\text { active/sham }\end{array}$ & $\begin{array}{l}\text { Visual memory } \\
\text { (indoor/outdoor } \\
\text { images), visuospatial } \\
\text { attention (Posner, } \\
\text { control task) }\end{array}$ & $\begin{array}{l}\text { L DLPFC stim } \\
\text { interfered with } \\
\text { encoding } \\
\text { while R DLPFC } \\
\text { stim interfered with } \\
\text { retrieval. No } \\
\text { impact of stim over } \\
\text { IPS } \\
\text { on encoding or } \\
\text { retrieval even at } \\
\text { higher } \\
\text { intensity. } \\
\text { However, stim over } \\
\text { R IPS } \\
\text { impaired RT in } \\
\text { the attention task. }\end{array}$ \\
\hline $\begin{array}{l}\text { Schutter and } \\
\text { van Honk } \\
\text { (2006) }\end{array}$ & 11 & $\begin{array}{l}\text { L OFC (Fp1), L } \\
\text { DLPFC } \\
\quad \text { (F3) }\end{array}$ & $\begin{array}{l}20 \mathrm{~min} \text { of } 1 \mathrm{~Hz} \text { rTMS } \\
\text { at } \\
80 \% \mathrm{rMT} \text {, offline, } \\
\text { active/sham }\end{array}$ & $\begin{array}{l}\text { Visual memory } \\
\text { (neutral, fearful, and } \\
\text { happy faces) }\end{array}$ & $\begin{array}{l}\text { Stim over L OFC } \\
\text { improved memory } \\
\text { for } \\
\text { happy faces } \\
\text { compared to sham. } \\
\text { Stim } \\
\text { over L DLPFC } \\
\text { improved memory } \\
\text { marginally for } \\
\text { happy faces } \\
\text { compared } \\
\text { to sham. }\end{array}$ \\
\hline $\begin{array}{l}\text { Gallate et al. } \\
\text { (2009) }\end{array}$ & 20 & $\begin{array}{l}\text { L ATL (between } \\
\text { T7/FT7) }\end{array}$ & $\begin{array}{l}10 \mathrm{~min} \text { of } 1 \mathrm{~Hz} \text { rTMS } \\
\text { at } \\
90 \% \mathrm{rMT} \text {, offline, } \\
\text { active/sham }\end{array}$ & $\begin{array}{l}\text { Verbal memory (false } \\
\text { memories) }\end{array}$ & $\begin{array}{l}\text { Stim decreased the } \\
\text { number of false } \\
\text { memories by } \\
36 \% \text { compared to } \\
\text { sham } \\
\text { ( } \sim 3 \text { vs. } \sim 2 \text { errors). }\end{array}$ \\
\hline $\begin{array}{l}\text { Sauseng et al. } \\
\text { (2009) }\end{array}$ & $\begin{array}{l}\text { Exp. 3: } 7 \\
\text { Exp. } 4: 13\end{array}$ & $\begin{array}{l}\text { Exp. 3: R/L PC (P3/ } \\
\text { P4), } \\
\text { Cz (control) } \\
\text { Exp. 4: R/L PC (P3/ } \\
\text { P4), } \\
\text { centroparietal } \\
\text { control }\end{array}$ & $\begin{array}{l}9 \text { pulses of } 10 \mathrm{~Hz} \text { or } 14 \\
\text { pulses of } 15 \mathrm{~Hz} \\
\text { rTMS, at } 110 \% \\
\text { rMT, } \\
\text { during delay, active/ } \\
\text { sham }\end{array}$ & $\begin{array}{l}\text { Visual STM (memorize } \\
\text { color of a square } \\
\text { presented in one but } \\
\text { not other visual } \\
\text { hemifield) }\end{array}$ & $\begin{array}{l}10 \mathrm{~Hz} \text { rTMS to PC } \\
\text { ipsilateral to the } \\
\text { stimulus } \\
\text { improved visual } \\
\text { STM } \\
\text { (Exp. 3/4: } 40 \% \\
\text { less false alarms, } \\
37 \% \\
\text { fewer missed } \\
\text { trials), while } \\
\text { contralateral stim } \\
\text { over PC led to a } \\
\text { decrease. No } \\
\text { effect of } 15 \mathrm{~Hz} \\
\text { rTMS } \\
\text { over PC or } 10 \mathrm{~Hz} \\
\text { rTMS over } \\
\text { centroparietal } \\
\text { sites. }\end{array}$ \\
\hline $\begin{array}{l}\text { Blanchet et al. } \\
\text { (2010) }\end{array}$ & 16 & R/L DLPFC (F3/F4) & $\begin{array}{l}\text { ppTMS, ISI } 3 \mathrm{~ms}, 90 \% \\
\text { rMT, during } \\
\text { encoding or } \\
\text { retrieval, active/ } \\
\text { sham }\end{array}$ & $\begin{array}{l}\text { Verbal (letters) and } \\
\text { nonverbal (shapes) } \\
\text { memory, under full } \\
\text { or divided attention }\end{array}$ & $\begin{array}{l}\text { Stim over L DLPFC } \\
\text { impaired recall as } \\
\text { compared to stim } \\
\text { over R DLPFC } \\
\text { under full } \\
\text { attention encoding } \\
\text { (but not } \\
\text { as compared to } \\
\text { sham). Stim over R } \\
\text { DLPFC impaired } \\
\text { recall as compared } \\
\text { to sham under } \\
\text { divided attention } \\
\text { encoding (but not } \\
\text { as compared to stim } \\
\text { over L DLPFC). }\end{array}$ \\
\hline
\end{tabular}




\begin{tabular}{|c|c|c|c|c|c|}
\hline Reference & $n$ & Regions stimulated & Stimulation protocol & Task & Results \\
\hline $\begin{array}{l}\text { Gagnon et al. } \\
(2010)\end{array}$ & 18 & R/L DLPFC & $\begin{array}{l}\text { ppTMS, ISI } 3 \mathrm{~ms} \text {, at } \\
90 \% \text { rMT, during } \\
\text { encoding or } \\
\text { retrieval, active/ } \\
\text { sham }\end{array}$ & $\begin{array}{l}\text { Verbal (letters) and } \\
\text { nonverbal (abstract } \\
\text { shapes) memory }\end{array}$ & $\begin{array}{l}\text { Stim over L DLPFC } \\
\text { during encoding } \\
\text { decreased DR as } \\
\text { compared to sham } \\
\text { and stim over R } \\
\text { DLPFC. Stim over } \\
\text { the } \\
\text { R DLPFC during } \\
\text { retrieval decreased } \\
\text { DR and hit rate } \\
\text { compared to stim } \\
\text { over } \\
\text { L DLPFC. No } \\
\text { significant } \\
\text { differences } \\
\text { between verbal/ } \\
\text { nonverbal material. }\end{array}$ \\
\hline $\begin{array}{l}\text { Gagnon et al. } \\
\text { (2011) }\end{array}$ & 11 & R/L DLPFC (F3/F4) & $\begin{array}{l}\text { ppTMS, ISI } 15 \mathrm{~ms} \text {, at } \\
\text { 90\% rMT, during } \\
\text { encoding or } \\
\text { retrieval, active/ } \\
\text { sham }\end{array}$ & $\begin{array}{l}\text { Verbal (letters) and } \\
\text { nonverbal (abstract } \\
\text { shapes) memory }\end{array}$ & $\begin{array}{l}\text { Stim over L DLPFC } \\
\text { during encoding } \\
\text { improved RT as } \\
\text { compared to stim } \\
\text { over R DLPFC or } \\
\text { sham. Stim over R } \\
\text { DLPFC during } \\
\text { retrieval improved } \\
\text { RT } \\
\text { as compared to } \\
\text { stim over L DLPFC. } \\
\text { More false alarms } \\
\text { for shapes than for } \\
\text { words occurred } \\
\text { after stim over R } \\
\text { DLPFC or sham. }\end{array}$ \\
\hline $\begin{array}{l}\text { De Weerd et al. } \\
\text { (2012) }\end{array}$ & 13 & $\begin{array}{l}\mathrm{R} \text { OC }(\mathrm{V} 1) \text { to } \\
\text { interfere } \\
\text { with lower-L (but } \\
\text { not } \\
\text { upper-R) quadrant }\end{array}$ & $\begin{array}{l}\text { Priming with } 20 \text { trains } \\
\text { of } 30 \text { pulses at } 6 \mathrm{~Hz} \\
\text { (ITI } 25 \mathrm{~s} \text { ) at } 45 \% \\
\text { MSO, } 6.7 \mathrm{~min} \text { of } \\
1 \mathrm{~Hz} \text { rTMS at } 50 \\
\text { MSO, } 45 \text { min after } \\
\text { session } 1 \text { and } 2, \\
\text { active/no stim }\end{array}$ & $\begin{array}{l}\text { Visual orientation } \\
\text { discrimination (day } \\
\text { 1: lower L quadrant, } \\
\text { upper R quadrant, } \\
\text { day 2: opposite or } \\
\text { vice versa) }\end{array}$ & $\begin{array}{l}\text { Stim delivered } 45 \\
\text { min after the first } \\
\text { and } \\
\text { second training } \\
\text { session to interfere } \\
\text { with lower-L } \\
\text { quadrant strongly } \\
\text { impaired learning } \\
\text { as measured on the } \\
\text { next day. This } \\
\text { interference } \\
\text { occurred } \\
\text { only when } \\
\text { training of the L } \\
\text { visual } \\
\text { field was } \\
\text { followed by training } \\
\text { of the R } \\
\text { visual field } \\
\text { before TMS and not } \\
\text { vice } \\
\text { versa. No } \\
\text { differences between } \\
\text { quadrants at } \\
\text { baseline. }\end{array}$ \\
\hline \multicolumn{6}{|c|}{ tDCS in short-term memory } \\
\hline $\begin{array}{l}\text { Marshall et al. } \\
\text { (2005) }\end{array}$ & 12 & $\begin{array}{l}\text { Bilateral RA/LA or } \\
\text { RC/ } \\
\text { LC DLPFC (F3/ } \\
\text { F4), S }\end{array}$ & $\begin{array}{l}0.26 \mathrm{~mA} \text {, intermittent } \\
\text { on/off } 15 \mathrm{~s} \text { over } \\
15 \text { min, during task, } \\
\text { ref mastoids, active/ } \\
\text { sham }\end{array}$ & $\begin{array}{l}\text { Visual STM (modified } \\
\text { Sternberg) }\end{array}$ & $\begin{array}{l}\text { Bilateral A and C } \\
\text { stim both impaired } \\
\text { RT } \\
\text { as compared to } \\
\text { placebo. No impact } \\
\text { on } \\
\quad \text { accuracy. }\end{array}$ \\
\hline $\begin{array}{l}\text { Ferrucci et al. } \\
\text { (2008) }\end{array}$ & 17 & $\begin{array}{l}\mathrm{A} / \mathrm{C} / \mathrm{S}, \mathrm{R} / \mathrm{L} \mathrm{Cb} \text { and } \\
\mathrm{PFC} \\
\quad \text { (btw Fp1/F3 and } \\
\text { Fp2/F4) }\end{array}$ & $\begin{array}{l}2 \mathrm{~mA}, 15 \text { min, offline, } \\
\text { ref deltoid, active/ } \\
\text { sham }\end{array}$ & $\begin{array}{l}\text { Numerical STM } \\
\quad \text { (modified Sternberg) }\end{array}$ & $\begin{array}{l}\text { C-tDCS over PFC } \\
\text { improved RT } \sim 6 \% \\
\text { compared to } \\
\text { sham }(\sim 625 \mathrm{~ms} \text { vs. }\end{array}$ \\
\hline
\end{tabular}




\begin{tabular}{|c|c|c|c|c|c|}
\hline Reference & $n$ & Regions stimulated & Stimulation protocol & Task & Results \\
\hline & & & & & $\begin{array}{l}\sim 665 \mathrm{~ms}) . \text { No } \\
\text { effect after } \\
\text { A-tDCS. A-tDCS } \\
\text { and C-tDCS } \\
\text { blocked RT } \\
\text { decrease induced } \\
\text { by task repetition. }\end{array}$ \\
\hline $\begin{array}{l}\text { Berryhill et al. } \\
(2010)\end{array}$ & 11 & $\begin{array}{l}\text { A./C/S, R inferior } \\
\text { PC } \\
\quad \text { (P4) }\end{array}$ & $\begin{array}{l}1.5 \mathrm{~mA}, 10 \mathrm{~min} \text {, during } \\
\text { learning, ref left } \\
\text { cheek, active/sham }\end{array}$ & $\begin{array}{l}\text { Visual STM } \\
\text { (recognition and free } \\
\text { recall of objects) }\end{array}$ & $\begin{array}{l}\text { C-tDCS selectively } \\
\text { impaired WM on } \\
\text { recognition tasks } \\
\text { versus anodal and } \\
\text { sham. No impact } \\
\text { on free recall. }\end{array}$ \\
\hline $\begin{array}{l}\text { Gladwin et al. } \\
\text { (2012) }\end{array}$ & 14 & $\mathrm{~A} / \mathrm{S}, \mathrm{L}$ DLPFC & $\begin{array}{l}1 \mathrm{~mA}, 10 \mathrm{~min} \text {, during } \\
\text { task, ref SOA, } \\
\text { active/sham }\end{array}$ & $\begin{array}{l}\text { Verbal STM (modified } \\
\text { Sternberg) }\end{array}$ & $\begin{array}{l}\text { A-tDCS improved } \\
\text { RT when distractor } \\
\text { was present } \\
\text { compared to non- } \\
\text { distractor and } \\
\text { sham conditions. } \\
\text { No } \\
\text { impact on } \\
\text { accuracy. }\end{array}$ \\
\hline $\begin{array}{l}\text { Heimrath et al. } \\
\text { (2012) }\end{array}$ & 12 & $\begin{array}{l}\text { A/C/S, R PC (btw } \\
\text { P8/ } \\
\text { P10), combined } \\
\text { with } \\
\text { EEG }\end{array}$ & $\begin{array}{l}1 \mathrm{~mA}, 30 \mathrm{~min} \text {, offline, } \\
\text { ref btw } \mathrm{P} 7 / \mathrm{P} 9, \\
\text { active/ } \\
\text { sham }\end{array}$ & Spatial DMS & $\begin{array}{l}\text { While A-tDCS over } \\
\text { RH impaired } \\
\text { capacity for } \\
\text { contralateral } \\
\text { stimuli, C } \\
\text {-tDCS improved } \\
\text { it. Both A-tDCS and } \\
\text { C-tDCS affected } \\
\text { capacity for } \\
\text { ipsilateral stimuli } \\
\text { compared to sham. } \\
\text { tDCS altered } \\
\text { ERPs (N2, P2, N3) } \\
\text { and } \\
\text { oscillatory power } \\
\text { in the alpha band at } \\
\text { posterior } \\
\text { electrodes. }\end{array}$ \\
\hline \multicolumn{6}{|c|}{ tDCS in working memory } \\
\hline $\begin{array}{l}\text { Fregni et al. } \\
(2005)\end{array}$ & 15 & $\begin{array}{l}\text { A/C/S, L DLPFC } \\
\text { (F3),A } \\
\text { M1 (control) }\end{array}$ & $\begin{array}{l}1 \mathrm{~mA}, 10 \mathrm{~min} \text {, during } \\
\text { task, ref SOA, } \\
\text { active/sham/M1 }\end{array}$ & $\begin{array}{l}\text { Verbal 3-back } \\
\text { (sequential-letter } \\
\text { task) }\end{array}$ & $\begin{array}{l}\text { A-tDCS over L } \\
\text { DLPFC improved } \\
\text { accuracy by } \\
\sim 10 \%(21.7 \text { vs. } \\
19.8) \text { and } \\
\quad \text { decreased } \\
\text { number of errors by } \\
\sim 28 \% \\
\text { as compared to } \\
\text { sham ( } 4.7 \text { vs. } 6.9) \text {. } \\
\text { No } \\
\text { impact after C- } \\
\text { tDCS over LDLPFC } \\
\text { or } \\
\text { A-tDCS over M1. } \\
\text { No impact on RT. }\end{array}$ \\
\hline $\begin{array}{l}\text { Ohn et al. } \\
(2008)\end{array}$ & 15 & A/S, L DLPFC (F3) & $\begin{array}{l}1 \mathrm{~mA}, 30 \text { min, during, } \\
\text { ref SOA, active/ } \\
\text { sham }\end{array}$ & $\begin{array}{l}\text { Verbal 3-back } \\
\text { (assessed } \\
10,20 \text {, and } 30 \mathrm{~min} \\
\text { into stim, and } 30 \mathrm{~min} \\
\text { after) }\end{array}$ & $\begin{array}{l}\text { A-tDCS improved } \\
\text { accuracy by } 10 \% \text { (at } \\
20 \mathrm{~min} \text { ), } 16 \% \text { (at } \\
30 \mathrm{~min} \text { ), } 14 \% \text { (at } \\
30 \mathrm{~min} \text { after) as } \\
\text { compared to sham. } \\
\text { No impact on } \\
\text { error rates or RT. }\end{array}$ \\
\hline $\begin{array}{l}\text { Mulquiney et al. } \\
\text { (2011) }\end{array}$ & 10 & A, L DLPFC (F3) & $\begin{array}{l}1 \mathrm{~mA}, 10 \mathrm{~min} \text {, during } \\
\text { task, ref SOA active/ } \\
\text { sham/tRNS }\end{array}$ & $\begin{array}{l}\text { Pre and post } \\
\text { stimulation: visual } \\
\text { STM (one card task, } \\
\text { 1-back), WM (2- }\end{array}$ & $\begin{array}{l}\text { A-tDCS decreased } \\
\text { RT in WM (2-back) } \\
\text { for correct } \\
\text { responses by } \sim 2 \%\end{array}$ \\
\hline
\end{tabular}




\begin{tabular}{|c|c|c|c|c|c|}
\hline Reference & $n$ & Regions stimulated & Stimulation protocol & Task & Results \\
\hline & & & & $\begin{array}{l}\text { back) During } \\
\text { stimulation: STM } \\
\text { (Sternberg) }\end{array}$ & $\begin{array}{l}\text { compared to } \\
\text { sham. No impact on } \\
\text { accuracy. No } \\
\text { impact on STM } \\
\text { tasks. }\end{array}$ \\
\hline $\begin{array}{l}\text { Teo et al. } \\
\text { (2011) }\end{array}$ & 12 & A/S, L DLPFC (F3) & $\begin{array}{l}1 \text { or } 2 \mathrm{~mA}, 20 \mathrm{~min} \text {, } \\
\text { during task, ref } \\
\text { SOA, active/sham }\end{array}$ & $\begin{array}{l}\text { Verbal 3-back during } \\
\text { stim, STM } \\
\text { (Sternberg) after } \\
\text { stim }\end{array}$ & $\begin{array}{l}\text { During the final } 5 \\
\text { min of A-tDCS } \\
\text { ( } 2 \mathrm{~mA}) \text { over } \mathrm{L} \\
\text { DLPFC RT } \\
\text { improved } \\
\text { significantly as } \\
\text { compared to sham } \\
(\sim 581 \mathrm{~ms} \text { vs. } \\
\sim 605.25 \text { and } \\
\sim 629.49 \mathrm{~ms}) \text {. No } \\
\text { impact on accuracy. } \\
\text { No impact on } \\
\text { STM after stim. }\end{array}$ \\
\hline $\begin{array}{l}\text { Zaehle et al. } \\
\text { (2011) }\end{array}$ & 16 & $\begin{array}{l}\text { A/C/S, L DLPFC } \\
\text { (F3), } \\
\quad \text { combined with } \\
\text { EEG }\end{array}$ & $\begin{array}{l}1 \mathrm{~mA}, 15 \text { min, offline, } \\
\text { ref mastoid, active/ } \\
\text { sham/control }\end{array}$ & Verbal 2-back (letters) & $\begin{array}{l}\text { A-tDCS improved } \\
\text { RT as compared to } \\
\text { C-tDCS and } \\
\text { resulted in } \\
\text { amplified } \\
\text { oscillatory power } \\
\text { in the theta and } \\
\text { alpha bands } \\
\text { under posterior } \\
\text { electrode } \\
\text { sites. C-tDCS had } \\
\text { opposite effects on } \\
\text { EEG measures. } \\
\text { No impact on } \\
\text { accuracy. }\end{array}$ \\
\hline $\begin{array}{l}\text { Andrews et al. } \\
\text { (2011) }\end{array}$ & 10 & A/S, L DLPFC (F3) & $\begin{array}{l}1 \mathrm{~mA}, 10 \mathrm{~min} \text {, during } \\
\text { task or offline, ref } \\
\mathrm{SOA} \text {, active/sham }\end{array}$ & $\begin{array}{l}\text { During stim: verbal } \\
\text { 2-back followed by } \\
\text { 3-back (letters) } \\
\text { Pre/post stim: STM } \\
\text { (digit span forward) } \\
\text { and WM (digit span } \\
\text { backward) }\end{array}$ & $\begin{array}{l}\text { Online A-tDCS } \\
\text { improved digit span } \\
\text { forward by 5.5\% } \\
\text { as compared to } \\
\text { offline A-tDCS } \\
\text { and sham. No } \\
\text { information } \\
\text { regarding online } \\
\text { task } \\
\text { outcome. }\end{array}$ \\
\hline $\begin{array}{l}\text { Mylius et al. } \\
\text { (2012) }\end{array}$ & 24 & $\begin{array}{l}\mathrm{A} / \mathrm{C} / \mathrm{S}, \mathrm{R} / \mathrm{L} \text { DLPFC } \\
\quad(\mathrm{F} 3 / \mathrm{F} 4)\end{array}$ & $\begin{array}{l}2 \mathrm{~mA}, 20 \mathrm{~min}, 15 \mathrm{~min} \\
\text { before and during } \\
\text { task, ref SOA active/ } \\
\text { sham }\end{array}$ & $\begin{array}{l}\text { Verbal 2-back } \\
\text { Pain percpetion (warm/ } \\
\text { cold) }\end{array}$ & $\begin{array}{l}\text { A-tDCS over R } \\
\text { DLPFC increased } \\
\text { tolerance to heat } \\
\text { pain as compared to } \\
\text { sham. During C- } \\
\text { tDCS over the L } \\
\text { DLPFC there } \\
\text { were fewer outliers } \\
\text { as } \\
\text { compared to } \\
\text { sham. No } \\
\text { significant } \\
\text { differences in } \\
\text { accuracy } \\
\text { (dissociation } \\
\text { of analgesic } \\
\text { effect from } \\
\text { cognitive } \\
\text { function). }\end{array}$ \\
\hline $\begin{array}{l}\text { Sandrini et al. } \\
\text { (2012) }\end{array}$ & 27 & $\begin{array}{l}\text { Bilateral PPC (P3/ } \\
\text { P4), } \\
\text { LAIRC, LC/RA, S }\end{array}$ & $\begin{array}{l}1.5 \mathrm{~mA}, 13 \mathrm{~min}, \\
\text { active/ } \\
\text { sham }\end{array}$ & $\begin{array}{l}\text { Verbal STM (1-back) } \\
\text { and WM (2-back) }\end{array}$ & $\begin{array}{l}\text { 1-back: LA/RC } \\
\text { tDCS abolished } \\
\text { practice- } \\
\quad \text { dependent } \\
\text { improvement in RT } \\
\text { as }\end{array}$ \\
\hline
\end{tabular}

Handb Clin Neurol. Author manuscript; available in PMC 2014 December 01. 


\begin{tabular}{|c|c|c|c|c|c|}
\hline Reference & $n$ & Regions stimulated & Stimulation protocol & Task & Results \\
\hline & & & & & $\begin{array}{l}\text { compared to } \\
\text { sham ( } 9 \% \text { vs. } \\
0.65 \%) .2- \\
\text { back: LC/RA } \\
\text { tDCS abolished } \\
\text { practice- } \\
\text { dependent } \\
\text { improvement in RT } \\
(9.8 \% \\
\text { vs. } 0.45 \%) \text { as } \\
\text { compared to sham. } \\
\text { No } \\
\text { impact on error } \\
\text { rates. }\end{array}$ \\
\hline $\begin{array}{l}\text { Meiron and } \\
\text { Lavidor (2013) }\end{array}$ & 41 & A /S, R/L DLPFC & $\begin{array}{l}2 \mathrm{~mA}, 15 \mathrm{~min} \text {, during } \\
\text { task, ref } \mathrm{Cz} \text {, active/ } \\
\text { sham }\end{array}$ & $\begin{array}{l}\text { Verbal n-back (4 levels } \\
\text { of WM load), during } \\
\text { and after stim }\end{array}$ & $\begin{array}{l}\text { During online } \\
\text { stimulation at } \\
\text { highest WM } \\
\text { loads males } \\
\text { benefited from stim } \\
\text { over } \\
\text { L DLPFC as } \\
\text { compared to sham, } \\
\text { while } \\
\text { females improved } \\
\text { after stim over R } \\
\text { DLPFC. No } \\
\text { impact on RT. } \\
\text { Online } \\
\text { accuracy scores } \\
\text { at the highest WM } \\
\text { level was related } \\
\text { to post-tDCS recall. }\end{array}$ \\
\hline \multicolumn{6}{|c|}{ tDCS in general learning and memory } \\
\hline $\begin{array}{l}\text { Kincses et al. } \\
\text { (2004) }\end{array}$ & 22 & $\begin{array}{l}\mathrm{A} / \mathrm{C} / \mathrm{S}, \mathrm{L} \text { DLPFC } \\
(\mathrm{N}=14) \text { and } \mathrm{VI} \\
(n=8)\end{array}$ & $\begin{array}{l}1 \mathrm{~mA}, 10 \mathrm{~min}, 5 \mathrm{~min} \\
\text { before and during } \\
\text { learning, ref } \mathrm{Cz} \text {, } \\
\text { active/sham, }\end{array}$ & $\begin{array}{l}\text { Probabilistic } \\
\quad \text { classification } \\
\text { learning }\end{array}$ & $\begin{array}{l}\text { A-tDCS over L } \\
\text { DLPFC improved } \\
\text { learning } \\
\text { compared to sham. } \\
\text { No effect } \\
\text { after C-stim or } \\
\text { stim over V1. }\end{array}$ \\
\hline $\begin{array}{l}\text { Marshall et al. } \\
\text { (2004) }\end{array}$ & 30 (males) & $\begin{array}{l}\text { Bilateral RA/LA } \\
\text { DLPFC (F3/F4) }\end{array}$ & $\begin{array}{l}0.26 \mathrm{~mA} / \mathrm{cm}^{2}, \\
\text { intermittent on/off } \\
15 \mathrm{~s} \text { over } 30 \mathrm{~min}, \\
\text { during sleep, active/ } \\
\text { sham }\end{array}$ & $\begin{array}{l}\text { Declarative and } \\
\text { procedural learning } \\
\text { (paired associate } \\
\text { word lists and mirror } \\
\text { tracing), PANAS/ } \\
\text { EWL (mood) }\end{array}$ & $\begin{array}{l}\text { Bilateral anodal } \\
\text { tDCS during sleep } \\
\text { enhanced word } \\
\text { retention compared } \\
\text { to } \\
\text { sham ( } 35.7 \text { vs. } \\
34.5) \text {. No impact } \\
\text { when } \\
\text { applied during } \\
\text { wakefulness and no } \\
\text { impact on } \\
\text { procedural memory. } \\
\text { After } \\
\text { active but not } \\
\text { sham tDCS positive } \\
\text { affect decreased } \\
\text { less and feelings of } \\
\text { depression } \\
\text { decreased. }\end{array}$ \\
\hline $\begin{array}{l}\text { Vines et al. } \\
\text { (2006) }\end{array}$ & 11 & $\begin{array}{l}\text { C/S, L SMG (TP3), } \\
\text { R SMG (control) }\end{array}$ & $\begin{array}{l}1.2 \mathrm{~mA}, 20 \mathrm{~min}, \\
\text { offline, ref SOA, } \\
\text { active/sham/control }\end{array}$ & $\begin{array}{l}\text { Pitch matching ( } 6 / 7 \\
\text { tones) }\end{array}$ & $\begin{array}{l}\text { C-tDCS to L SMG } \\
\text { affected short-term } \\
\text { pitch memory } \\
\text { performance }(9 \%) \\
\text { compared to R } \\
\text { SMG and sham. }\end{array}$ \\
\hline $\begin{array}{l}\text { Elmer et al. } \\
(2009)\end{array}$ & 20 & $\begin{array}{l}\text { A/C/S, R/L DLPFC } \\
\text { (F3/F4) }\end{array}$ & $\begin{array}{l}1.5 \mathrm{~mA}, 5 \mathrm{~min} \text {, during } \\
\text { learning, ref } \\
\text { mastoid, active/ } \\
\text { sham }\end{array}$ & Verbal LTM (VLMT) & $\begin{array}{l}\text { C-tDCS to L } \\
\text { DLPFC decreased } \\
\text { number }\end{array}$ \\
\hline
\end{tabular}




\begin{tabular}{|c|c|c|c|c|c|}
\hline Reference & $n$ & Regions stimulated & Stimulation protocol & Task & Results \\
\hline & & & & & $\begin{array}{l}\text { of words recalled } \\
\text { after } 25 \text { min } \\
\text { compared to } \\
\text { sham }(12 \%) \text {. No } \\
\text { effects } \\
\text { on long-term } \\
\text { retrieval were } \\
\text { found. }\end{array}$ \\
\hline $\begin{array}{l}\text { Boggio et al. } \\
\text { (2009) }\end{array}$ & 30 & $\begin{array}{l}\text { Bilateral ATL (T3/ } \\
\text { T4), } \\
\text { (LA/RC), } \\
\text { unilateral } \\
\text { ATL (LA/RC } \\
\text { enlarged } \\
\text { electrode), S }\end{array}$ & $\begin{array}{l}2 \mathrm{~mA}, 10 \mathrm{~min} \text {, during } \\
\text { encoding and } \\
\text { retrieval, active/ } \\
\text { sham }\end{array}$ & $\begin{array}{l}\text { False memory (within } \\
\text { word categories) }\end{array}$ & $\begin{array}{l}\text { Bilateral and } \\
\text { unilateral tDCS } \\
\text { reduced } \\
\text { false memories } \\
(73 \%) \text { compared to } \\
\text { sham. } \\
\text { Bilateral tDCS } \\
\text { decreased the } \\
\text { number of false } \\
\text { memories compared } \\
\text { to unilateral stim } \\
(\sim 1 \text { vs. } \sim 2 \text { errors }) \\
\text { and compared to } \\
\text { sham }(\sim 1 \text { vs. } \sim 3.7 \\
\text { errors }) .\end{array}$ \\
\hline $\begin{array}{l}\text { Kirov et al. } \\
(2009)\end{array}$ & 28 & $\begin{array}{l}\text { Bilateral RA/LA, } \\
\text { DLPFC (F3/F4) }\end{array}$ & $\begin{array}{l}\text { Five } 5 \text { min epochs of } \\
\text { transcranial slow } \\
\text { oscillation } \\
\text { stimulation (tSOS, } \\
0.75 \mathrm{~Hz} \text { ), } 1 \text { min ISI, } \\
0.517 \mathrm{~mA} / \mathrm{cm}_{2} \text {, ref } \\
\text { mastoid, active/ } \\
\text { sham }\end{array}$ & $\begin{array}{l}\text { Verbal and non-verbal } \\
\text { paired association, } \\
\text { verbal memory } \\
\text { (VLMT), number list } \\
\text { learning, procedural } \\
\text { memory (mirror } \\
\text { tracing, finger } \\
\text { sequence tapping), } \\
\text { control tasks }\end{array}$ & $\begin{array}{l}\text { TSOS during } \\
\text { wakefulness } \\
\text { induced a } \\
\text { local increase in } \\
\text { endogenous EEG } \\
\text { slow oscillations } \\
\text { (0.4-1.2 Hz) and a } \\
\text { widespread } \\
\text { increase in EEG } \\
\text { theta and } \\
\text { beta activity. } \\
\text { TSOS during } \\
\text { learning } \\
\text { improved verbal } \\
\text { encoding, but not } \\
\text { consolidation as } \\
\text { assessed } 7 \mathrm{~h} \text { after } \\
\text { learning. }\end{array}$ \\
\hline $\begin{array}{l}\text { Clark et al. } \\
\text { (2012) }\end{array}$ & $\begin{array}{l}96 \text { (divided in diff. } \\
\text { stim } \\
\text { groups) }\end{array}$ & $\begin{array}{l}\text { Exp. 1-3: A, R } \\
\text { inferior } \\
\quad \text { PFC (F10) } \\
\text { Exp. 4: A, R PC (P4) }\end{array}$ & $\begin{array}{l}0.6 \mathrm{~mA} \text { or } 2 \mathrm{~mA} \text {, } \\
30 \mathrm{~min} \text {, during } \\
\text { learning, ref arm, } \\
\text { active/control } \\
(0.1 \mathrm{~mA})\end{array}$ & $\begin{array}{l}\text { Detection of cues } \\
\text { indicative of covert } \\
\text { threats }\end{array}$ & $\begin{array}{l}\text { Exp. 1-3: A-tDCS } \\
\text { at } 2 \mathrm{~mA} \text { over R } \\
\text { inferior PFC } \\
\text { improved threat } \\
\text { detection sign. } \\
\text { more }(26.6 \%) \text { as } \\
\text { compared to } \\
\text { control (0.1 mA, } \\
14.2 \%) \text {, } \\
\text { while forgetting } \\
\text { rate over } 1 \mathrm{~h} \text { was } \\
\text { similar. } \\
\text { Intermediate current } \\
\text { strength } \\
(0.6 \mathrm{~mA}) \text { was } \\
\text { associated with an } \\
\text { intermediate } \\
\text { improvement } \\
(16.8 \%) \text {. } \\
\text { Exp. } 4: \text { A-tDCS at } 2 \\
\text { mA over R PC } \\
\text { improved } \\
\text { accuracy sign. more } \\
\text { (22.5\%) } \\
\text { as compared to } \\
\text { control (0.1 mA } \\
\text { over F10). }\end{array}$ \\
\hline Chi et al. (2010) & $\begin{array}{l}36 \text { (12 each } \\
\text { condition) }\end{array}$ & $\begin{array}{l}\text { Bilateral ATL, } \\
\text { LA/RC, } \\
\text { RA/LC, S }\end{array}$ & $\begin{array}{l}2 \mathrm{~mA}, 13 \mathrm{~min} \text {, during } \\
\text { task, active/sham }\end{array}$ & $\begin{array}{l}\text { Visual memory } \\
\quad \text { (geometric shapes) }\end{array}$ & $\begin{array}{l}\text { LC/RA-tDCS } \\
\text { resulted in a } \\
\text { improved }\end{array}$ \\
\hline
\end{tabular}




\begin{tabular}{|c|c|c|c|c|c|}
\hline Reference & $n$ & Regions stimulated & Stimulation protocol & Task & Results \\
\hline & & & & & $\begin{array}{l}\text { visual memory } \\
\text { (accuracy) by } 110 \% \\
\text { as } \\
\text { compared to } \\
\text { sham. No change } \\
\text { after } \\
\text { LA/RC-tDCS. }\end{array}$ \\
\hline $\begin{array}{l}\text { Cohen Kadosh } \\
\text { et al. (2010) }\end{array}$ & 15 & $\begin{array}{l}\text { Bilateral PC, } \\
\text { RA/LC, } \\
\text { RC/LA, S }\end{array}$ & $\begin{array}{l}1 \mathrm{~mA}, 20 \text { min, } 6 \text { days, } \\
\text { during learning, } \\
\text { active/sham }\end{array}$ & $\begin{array}{l}\text { Numerical learning } \\
\text { (pseudo-number } \\
\text { paired association), } \\
\text { changes assessed by } \\
\text { numerical tasks } \\
\text { (Stroop, number-to- } \\
\text { space task) }\end{array}$ & $\begin{array}{l}6 \text { days of RA/LC- } \\
\text { tDCS improved RT } \\
\text { in } \\
\text { Stroop compared } \\
\text { to sham. RC/LA- } \\
\text { tDCS impaired } \\
\text { performance } \\
\text { compared to } \\
\text { sham }\end{array}$ \\
\hline $\begin{array}{l}\text { Penolazzi et al. } \\
\text { (2010) }\end{array}$ & 12 & $\begin{array}{l}\text { Bilateral } \\
\text { frontotemporal } \\
\text { stim } \\
\text { between F3/4 } \\
\text { and C3/ 4, } \\
\text { LA/RC, RA/LC }\end{array}$ & $\begin{array}{l}1 \mathrm{~mA}, 20 \text { min, during } \\
\text { encodig, active/ } \\
\text { sham }\end{array}$ & $\begin{array}{l}\text { Visual memory (free } \\
\text { recall of images } \\
\text { differing in affective } \\
\text { arousal and valence) }\end{array}$ & $\begin{array}{l}\text { Bilateral RA/LC- } \\
\text { tDCS improved } \\
\text { recall } \\
\text { of pleasant } \\
\text { images compared to } \\
\text { unpleasant/ } \\
\text { neutral images, } \\
\text { while } \\
\text { bilateral LA/RC- } \\
\text { tDCS improved } \\
\text { recall of } \\
\text { unpleasant images } \\
\text { compared to } \\
\text { pleasant and neutral } \\
\text { images. }\end{array}$ \\
\hline $\begin{array}{l}\text { Javadi et al. } \\
\text { (2012) }\end{array}$ & 13 & $\mathrm{~A} / \mathrm{C}, \mathrm{L}$ DLPFC (F3) & $\begin{array}{l}1.5 \mathrm{~mA}, 1.6 \mathrm{sc} \text {, during } \\
\text { encoding or delay, } \\
\text { ref SOA, active/no } \\
\text { stim }\end{array}$ & Word memorization & $\begin{array}{l}\text { A-tDCS during } \\
\text { encoding improved } \\
\text { accuracy and RT } \\
\text { compared to late } \\
\text { A-tDCS or no } \\
\text { tDCS. C-tDCS } \\
\text { during } \\
\text { encoding } \\
\text { impaired accuracy } \\
\text { and RT } \\
\text { compared to late } \\
\text { C-tDCS or no } \\
\text { tDCS. Stim } \\
\text { during delay had no } \\
\text { effect. }\end{array}$ \\
\hline $\begin{array}{l}\text { Javadi and } \\
\text { Walsh (2012) }\end{array}$ & 32 & $\begin{array}{l}\text { A/C/S, L DLPFC } \\
\text { (F3), } \\
\text { M1 (C3, control) }\end{array}$ & $\begin{array}{l}1.5 \mathrm{~mA}, 20 \mathrm{~s} \mathrm{~A}, 30 \mathrm{~s} \mathrm{C} \text {, } \\
\text { during encoding or } \\
\text { recognition, ref } \\
\text { SOA, } \\
\text { active/sham }\end{array}$ & Word memorization & $\begin{array}{l}\text { During encoding A- } \\
\text { tDCS over DLPFC } \\
\text { improved } \\
\text { accuracy, while C- } \\
\text { tDCS } \\
\text { impaired } \\
\text { accuracy compared } \\
\text { to sham. } \\
\text { M1-tDCS had no } \\
\text { impact. During } \\
\text { recognition C- } \\
\text { tDCS impaired } \\
\text { recognition } \\
\text { compared to sham, } \\
\text { while } \\
\text { A-tDCS showed } \\
\text { a trend towards } \\
\text { improvement. }\end{array}$ \\
\hline $\begin{array}{l}\text { Hammer et al. } \\
\text { (2011) }\end{array}$ & $36(\mathrm{~A} / \mathrm{S}=18, \mathrm{C} / \mathrm{S}=18)$ & $\begin{array}{l}\mathrm{A} / \mathrm{C} / \mathrm{S}, \mathrm{L} \text { DLPFC } \\
\text { (F3) }\end{array}$ & $\begin{array}{l}1 \mathrm{~mA}, 30 \mathrm{~min}, 10 \mathrm{~min} \\
\text { before and during } \\
\text { learning, ref SOA, } \\
\text { active/sham }\end{array}$ & $\begin{array}{l}\text { Errorless/errorfull } \\
\text { learning (word stem } \\
\text { completion) }\end{array}$ & $\begin{array}{l}\text { C-tDCS impaired } \\
\text { encoding and } \\
\text { retrieval } \\
\quad \text { after errorful } \\
\text { learning compared } \\
\text { to }\end{array}$ \\
\hline
\end{tabular}

Handb Clin Neurol. Author manuscript; available in PMC 2014 December 01. 


\begin{tabular}{|c|c|c|c|c|c|}
\hline Reference & $n$ & Regions stimulated & Stimulation protocol & Task & Results \\
\hline & & & & & $\begin{array}{l}\text { errorless learning } \\
\text { and sham. No } \\
\text { impact of anodal } \\
\text { stimulation. }\end{array}$ \\
\hline $\begin{array}{l}\text { Bullard et al. } \\
\text { (2011) }\end{array}$ & $\begin{array}{l}34(\text { control }=14, \\
\text { early }=11, \text { late }= \\
9)\end{array}$ & $\begin{array}{l}\text { A, R Inferior PFC } \\
\text { (F8) }\end{array}$ & $\begin{array}{l}2 \mathrm{~mA}, 30 \mathrm{~min} \text {, early/ } \\
\text { late during learning, } \\
\text { ref arm, active/ } \\
\text { control }(0.1 \mathrm{~mA})\end{array}$ & $\begin{array}{l}\text { Detection of cues } \\
\text { indicative of covert } \\
\text { threats }\end{array}$ & $\begin{array}{l}\text { A-tDCS }(2 \mathrm{~mA}) \\
\text { improved threat } \\
\text { detection } \\
\text { compared to control } \\
(0.1 \mathrm{~mA}) . \text { A- } \\
\text { tDCS was more } \\
\text { effective } \\
\text { when applied } \\
\text { during early } \\
\text { learning. }\end{array}$ \\
\hline $\begin{array}{l}\text { Marshall et al. } \\
\text { (2011) }\end{array}$ & 16 & $\begin{array}{l}\text { Bilateral RA/LA, } \\
\text { DLPFC, }(\mathrm{F} 3, \mathrm{~F} 4)\end{array}$ & $\begin{array}{l}\text { Theta-tDCS at } 5 \mathrm{~Hz} \text {, } \\
0.517 \mathrm{~mA} / \mathrm{cm}^{2}, \\
5 \mathrm{~min}, 1 \mathrm{~min} \text { ISI, } \\
\text { during REM or non- } \\
\text { REM sleep, ref } \\
\text { mastoid, active/ } \\
\text { sham }\end{array}$ & $\begin{array}{l}\text { Verbal paired } \\
\text { association, } \\
\text { procedural memory } \\
\text { (mirror tracing, } \\
\text { finger sequence } \\
\text { tapping), mood } \\
\text { (PANAS) }\end{array}$ & $\begin{array}{l}\text { Theta-tDCS during } \\
\text { non-REM impaired } \\
\text { consolidation of } \\
\text { verbal memory } \\
\text { compared to } \\
\text { sham. No effect on } \\
\text { consolidation in } \\
\text { procedural memory. } \\
\text { Stim during REM } \\
\text { led to an increase of } \\
\text { negative affect. }\end{array}$ \\
\hline $\begin{array}{l}\text { Jacobson et al. } \\
\text { (2012) }\end{array}$ & 24 & $\begin{array}{l}\text { Bilateral L IPS/SPL } \\
\text { (P3), R IPL (P6), } \\
\text { LA/ } \\
\text { RC, RA/LC } \\
\text { (control) }\end{array}$ & $\begin{array}{l}1 \mathrm{~mA}, 10 \mathrm{~min} \text {, active/ } \\
\text { control stim/control } \\
\text { group }\end{array}$ & $\begin{array}{l}\text { Verbal memory } \\
\text { (discrimination of } \\
\text { familiar/unfamiliar } \\
\text { words) }\end{array}$ & $\begin{array}{l}\text { LA/RC-tDCS } \\
\text { improved accuracy, } \\
\text { but } \\
\text { not RT as } \\
\text { compared to control } \\
\text { stim. } \\
\text { No effect after } \\
\text { LC/RA-tDCS. }\end{array}$ \\
\hline \multicolumn{6}{|c|}{ TMS and tDCS in memory studies with elderly subjects } \\
\hline $\begin{array}{l}\text { Rossi et al. } \\
\text { (2004) }\end{array}$ & $66(<45$ and $>50 y)$ & R/L DLPFC (F3/F4) & $\begin{array}{l}500 \mathrm{~ms} \text { of } 20 \mathrm{~Hz} \text { at } \\
90 \% \mathrm{rMT}, \text { during } \\
\text { encoding and } \\
\text { retrieval, active/ } \\
\text { sham/baseline }\end{array}$ & $\begin{array}{l}\text { Visuospatial } \\
\text { memory (old/new } \\
\text { discrimination of } \\
\text { images) }\end{array}$ & $\begin{array}{l}\text { Stim over R DLPFC } \\
\text { in younger subjects } \\
\text { interfered with } \\
\text { retrieval more than } \\
\text { stim over L } \\
\text { DLPFC. This } \\
\text { asymmetrical } \\
\text { effect dissipated } \\
\text { with } \\
\text { age as indicated } \\
\text { by bilateral } \\
\text { interference } \\
\text { effects on } \\
\text { recognition. } \\
\text { Stim of left } \\
\text { DLPFC during } \\
\text { encoding } \\
\text { had a disruptive } \\
\text { effect on all } \\
\text { subjects } \\
\text { which would not } \\
\text { comply with the } \\
\text { HAROLD model. }\end{array}$ \\
\hline $\begin{array}{l}\text { Solé-Padullés et } \\
\text { al. (2006) }\end{array}$ & $\begin{array}{l}39(>50 \text { y with } 1+\mathrm{y} \\
\text { memory } \\
\text { complaints) }\end{array}$ & $\begin{array}{l}\text { Bilateral R/L } \\
\text { DLPFC } \\
\text { combined with } \\
\text { baseline and post- } \\
\text { TMS fMRI }\end{array}$ & $\begin{array}{l}10 \text { trains of } 10 \mathrm{~s} \mathrm{rTMS} \\
\text { at } 5 \mathrm{~Hz} \text {, ITI } 30 \mathrm{~s}, \\
80 \% \mathrm{rMT}, \text { offline, } \\
\text { active/sham }\end{array}$ & Face-name association & $\begin{array}{l}\text { Stim improved } \\
\text { associative memory } \\
\text { compared to } \\
\text { sham (rate of } \\
\text { change: } \\
1.60 \text { vs. }-0.63 \text { ). } \\
\text { TMS led to an } \\
\text { increase } \\
\text { in activation of } \\
\text { the right IFG and } \\
\text { MFG }\end{array}$ \\
\hline
\end{tabular}




\begin{tabular}{|c|c|c|c|c|c|}
\hline Reference & $n$ & Regions stimulated & Stimulation protocol & Task & Results \\
\hline & & & & & $\begin{array}{l}\text { and occipital } \\
\text { areas. }\end{array}$ \\
\hline $\begin{array}{l}\text { Manenti et al. } \\
\text { (2011) }\end{array}$ & $\begin{array}{l}31(60-81 \mathrm{y}), \mathrm{HP} \text { and } \\
\text { LP }\end{array}$ & $\mathrm{R} / \mathrm{L} \mathrm{DLPFC}$ & $\begin{array}{l}450 \mathrm{~ms} \text { of } 20 \mathrm{~Hz} \mathrm{rTMS} \\
\text { (ISI 7-8 s), total of } \\
640 \text { pulses, } 90 \% \\
\text { rMT, during } \\
\text { encoding or } \\
\text { retrieval, active/ } \\
\text { sham/baseline }\end{array}$ & $\begin{array}{l}\text { Verbal memory } \\
\quad \text { (associated/non- } \\
\text { associated word } \\
\text { pairs) }\end{array}$ & $\begin{array}{l}\text { The high- } \\
\text { performing (HP) } \\
\text { group } \\
\text { performed better } \\
\text { in the experimental } \\
\text { task than the low- } \\
\text { performing group } \\
\text { (LP) (92.0\% vs. } \\
\text { 78.9\%). Stim over L } \\
\text { DLPFC affected } \\
\text { accuracy more } \\
\text { during encoding } \\
\text { than during } \\
\text { retrieval, } \\
\text { but only for } \\
\text { unrelated word- } \\
\text { pairs in } \\
\text { the LP group. No } \\
\text { significant } \\
\text { differences in } \\
\text { RT. Asymmetry as } \\
\text { predicted by the } \\
\text { HERA model was } \\
\text { observed only in } \\
\text { LP. }\end{array}$ \\
\hline $\begin{array}{l}\text { Flöel et al. } \\
\text { (2012) }\end{array}$ & $\begin{array}{l}20(50-80 \mathrm{y}, \text { mean } \\
62 \mathrm{y})\end{array}$ & $\mathrm{A}, \mathrm{R}$ TPC & $\begin{array}{l}1 \mathrm{~mA}, 20 \text { min, during } \\
\text { learning, active/ } \\
\text { sham }\end{array}$ & $\begin{array}{l}\text { Object location } \\
\text { learning, immediate } \\
\text { and delayed ( } 1 \text { week } \\
\text { later) free-recall }\end{array}$ & $\begin{array}{l}\text { Anodal stim } \\
\text { improved delayed } \\
\text { correct } \\
\quad \text { free-recall } \\
\text { responses compared } \\
\text { to } \\
\text { sham ( } 24 \% \text { vs. } \\
8.5 \%) \text {, but not } \\
\text { immediate recall } \\
(34 \% \text { vs. } 28.8 \%) \text {. } \\
\text { No } \\
\text { significant } \\
\text { differences in RT. }\end{array}$ \\
\hline \multicolumn{6}{|c|}{ TMS and tDCS in memory studies with Alzheimer's patients } \\
\hline $\begin{array}{l}\text { Cotelli et al. } \\
(2006)\end{array}$ & 15 & $\begin{array}{l}\text { R/L DLPFC (btw } \\
\text { F3/F4 } \\
\text { and F/7/F8), } 1 \\
\text { session }\end{array}$ & $\begin{array}{l}600 \mathrm{~ms} \text { of } 20 \mathrm{~Hz} \text { TMS } \\
\text { at } 90 \% \text { rMT, during } \\
\text { encoding, active/ } \\
\text { sham }\end{array}$ & $\begin{array}{l}\text { Visuoverbal object and } \\
\text { action naming }\end{array}$ & $\begin{array}{l}\text { Stimulation over L } \\
\text { and R DLPFC } \\
\text { improved } \\
\text { accuracy in action } \\
\text { naming } \\
\text { as compared to } \\
\text { sham stimulation. } \\
\text { Object naming } \\
\text { did not improve } \\
\text { significantly. }\end{array}$ \\
\hline $\begin{array}{l}\text { Cotelli et al. } \\
(2008)\end{array}$ & 24 & $\begin{array}{l}\text { R/L DLPFC, } 1 \\
\text { session }\end{array}$ & $\begin{array}{l}500 \mathrm{~ms} \text { of } 20 \mathrm{~Hz} \text { TMS } \\
\text { at } 90 \% \text { rMT, during } \\
\text { encoding, active/ } \\
\text { sham }\end{array}$ & $\begin{array}{l}\text { Visuoverbal object and } \\
\text { action naming }\end{array}$ & $\begin{array}{l}\text { Stimulation over L } \\
\text { and R DLPFC } \\
\text { improved } \\
\text { accuracy in action } \\
\text { naming } \\
\text { but not object } \\
\text { naming as } \\
\text { compared to } \\
\text { sham stimulation } \\
\text { in the mild AD } \\
\text { group. Improved } \\
\text { naming accuracy for } \\
\text { both classes of } \\
\text { stimuli was only } \\
\text { found } \\
\text { in moderate-to- } \\
\text { severely impaired } \\
\text { patients. }\end{array}$ \\
\hline
\end{tabular}




\begin{tabular}{|c|c|c|c|c|c|}
\hline Reference & $n$ & Regions stimulated & Stimulation protocol & Task & Results \\
\hline $\begin{array}{l}\text { Ferrucci et al. } \\
\text { (2008) }\end{array}$ & 10 & $\begin{array}{l}\text { A/C/S, bilateral TPC } \\
(\text { LA/RA, LC/RC, } \\
\text { S), } \\
1 \text { session per } \\
\text { condition }\end{array}$ & $\begin{array}{l}1.5 \mathrm{~mA}, 15 \mathrm{~min}, \\
\text { offline, } \\
\text { active/sham/baseline }\end{array}$ & $\begin{array}{l}\text { Verbal memory and } \\
\text { visual attention }\end{array}$ & $\begin{array}{l}\text { A-tDCS improved } \\
\text { accuracy, while } \\
\text { C-tDCS } \\
\text { decreased } \\
\text { performance as } \\
\text { compared to } \\
\text { baseline. No impact } \\
\text { on } \\
\text { visual attention. }\end{array}$ \\
\hline $\begin{array}{l}\text { Boggio et al. } \\
(2009)\end{array}$ & 10 & $\begin{array}{l}\mathrm{A} / \mathrm{S}, \mathrm{L} \text { DLPFC }(\mathrm{F} 3) \text {, } \\
\mathrm{L} \\
\text { temporal cortex } \\
(\mathrm{T} 7)\end{array}$ & $\begin{array}{c}2 \mathrm{~mA}, 30 \mathrm{~min}, \mathrm{~A} / \mathrm{S} \\
\text { during task, ref } \\
\text { SOA, active/sham }\end{array}$ & $\begin{array}{l}\text { Visual STM, WM } \\
\text { (digit } \\
\text { span backward), } \\
\text { Stroop }\end{array}$ & $\begin{array}{l}\text { Accuracy in visual } \\
\text { memory improved } \\
\text { during A-tDCS } \\
\text { over L DLPFC } \\
(18 \%) \\
\text { and temporal } \\
\text { cortex }(14 \%) \text { as } \\
\text { compared to } \\
\text { sham. No effect on } \\
\text { WM } \\
\text { and Stroop. }\end{array}$ \\
\hline $\begin{array}{l}\text { Cotell et al. } \\
(2011)\end{array}$ & 10 & $\begin{array}{l}\text { L DLPFC, } 20 \\
\text { sessions } \\
\quad \text { without training } \\
\text { vs. } \\
\quad 10 \text { sessions } \\
\text { placebo }\end{array}$ & $\begin{array}{l}25 \mathrm{~min}, 2 \mathrm{~s} \text { of } 20 \mathrm{~Hz} \\
\text { (ITI 28 s) at } 100 \% \\
\text { rMT, offline, } \\
\text { active/sham/baseline }\end{array}$ & $\begin{array}{l}\text { Various tests for } \\
\text { memory, } \\
\text { executive functions, } \\
\text { and } \\
\text { language }\end{array}$ & $\begin{array}{l}\text { Improvement of } \\
\text { auditory sentence } \\
\text { comprehension as } \\
\text { compared to } \\
\text { baseline and } \\
\text { placebo training; no } \\
\text { effect on other } \\
\text { cognitive or } \\
\text { langauge } \\
\text { functions. }\end{array}$ \\
\hline $\begin{array}{l}\text { Bentwich et al. } \\
\text { (2011) }\end{array}$ & 8 & $\begin{array}{l}6 \text { regions, } 3 \text { per day } \\
\text { (Broca, Wernicke, } \\
\text { R } \\
\text { DLPFC and R- } \\
\text { pSAC, } \\
\text { L-pSAC, 1- } \\
\text { DLPFC), } \\
\text { (30 sessions with } \\
\text { training) }\end{array}$ & $\begin{array}{l}20 \text { 2-s trains of } 10 \mathrm{~Hz} \\
\text { per area (=1200 } \\
\text { pulses per day), } 90 \% \\
\text { MT (frontal areas), } \\
110 \% \text { MT (other } \\
\text { areas), active/ } \\
\text { baseline }\end{array}$ & $\begin{array}{l}\text { Training tasks: } \\
\text { attention, memory, } \\
\text { language }\end{array}$ & $\begin{array}{l}\text { ADAS-cog } \\
\text { improved by } \\
\text { approx. } 4 \text { points } \\
\text { after training and } \\
\text { was maintained at } \\
4.5 \text { months } \\
\text { follow-up. CGIC } \\
\text { improved } \\
\text { by } 1.0 \text { and } 1.6 \\
\text { points, respectively. } \\
\text { MMSE, ADAS- } \\
\text { ADL, Hamilton } \\
\text { improved, but not } \\
\text { significantly. No } \\
\text { change in NPI. }\end{array}$ \\
\hline $\begin{array}{l}\text { Boggio et al. } \\
(2012)\end{array}$ & 15 & $\begin{array}{l}\text { A/S, bilateral } \\
\text { (RA/LA) } \\
\text { temporal cortex } \\
\text { (T3/ } \\
\text { T4), } 5 \text { sessions }\end{array}$ & $\begin{array}{l}30 \mathrm{~min}, 2 \mathrm{~mA} \text {, ref } \\
\text { deltoid, offline, } \\
\text { active/sham }\end{array}$ & $\begin{array}{l}\text { Visual STM, } \\
\text { visual attention, } \\
\text { MMSE, } \\
\text { ADAS-Cog }\end{array}$ & $\begin{array}{l}\text { A-tDCS improved } \\
\text { memory } \\
\text { performance } \\
\text { by } 8.99 \% \text { from } \\
\text { baseline compared } \\
\text { to } \\
\text { sham }(-2.62 \%) \text {. } \\
\text { No impact on visual } \\
\text { attention or other } \\
\text { cognitive measures. }\end{array}$ \\
\hline
\end{tabular}




\begin{tabular}{|c|c|c|c|c|}
\hline Reference & $n$ & Regions stimulated & Stimulation protocol & Task \\
\hline $\begin{array}{l}\text { Haffen et al. } \\
\text { (2011) }\end{array}$ & 1 & $\begin{array}{l}\text { L DLPFC, } 10 \\
\text { sessions }\end{array}$ & $\begin{array}{l}20 \mathrm{~min} \text { of } 5 \text {-s trains of } \\
10 \mathrm{~Hz} \text { (ITI } 25 \mathrm{~s} \text { ), } \\
100 \% \text { rMT, offline, } \\
\text { active }\end{array}$ & $\begin{array}{l}\text { Verbal memory } \\
\text { (Memory } \\
\text { Impairment Screen } \\
\text { free and cued recal } \\
\text { Isaacs Set Test, } \\
\text { TMT, picture } \\
\text { naming, copying, } \\
\text { MMSE }\end{array}$ \\
\hline $\begin{array}{l}\text { Ahmed et al. } \\
\text { (2012) }\end{array}$ & 45 & $\begin{array}{l}\mathrm{R} / \mathrm{L} \text { DLPFC, } 5 \\
\text { sessions } \\
\quad \text { without training }\end{array}$ & $\begin{array}{l}\text { Group 1: } \sim 10 \mathrm{~min} \text { of } 5- \\
\mathrm{s} \\
\text { trains of } 20 \mathrm{~Hz} \text { (ITI } \\
25 \mathrm{~s}), 90 \% \mathrm{rMT} \text { per } \\
\text { DLPFC } \\
\text { Group } 2: \sim 16 \mathrm{~min} \text { of } \\
1 \mathrm{~Hz} \text { rTMS, } 100 \% \\
\text { rMT, } \sim 16 \mathrm{~min} \text { per } \\
\text { DLPFC }(2000 \mathrm{p})\end{array}$ & MMSE, IADL, GDS \\
\hline
\end{tabular}

\section{TMS and tDCS in memory studies with Parkinson's patients}

\begin{tabular}{|c|c|c|c|}
\hline $\begin{array}{l}\text { Boggio et al. } \\
(2005)\end{array}$ & $\begin{array}{l}25 \text { (PD \& } \\
\text { depression) }\end{array}$ & $\begin{array}{l}\text { L DLPFC, } 10 \\
\text { sessions } \\
\quad \text { without training }\end{array}$ & $\begin{array}{l}40 \text { trains of } 5 \mathrm{~s} \text { of } \\
15 \mathrm{~Hz}, 110 \% \text { rMT } \\
\text { and fluoxetine } \\
(20 \mathrm{mg} / \text { day }) \text {, offline, } \\
\text { active/sham/baseline }\end{array}$ \\
\hline $\begin{array}{l}\text { Boggio et al. } \\
(2006)\end{array}$ & 18 & $\begin{array}{l}\text { A/S, L DLPFC, M1 } \\
\text { (control), } 1 \\
\text { session } \\
\quad \text { per protocol }\end{array}$ & $\begin{array}{l}20 \mathrm{~min}, 1 \text { or } 2 \mathrm{~mA} \text {, } \\
20 \mathrm{~min} \text {, during task, } \\
\text { ref SOA, active/ } \\
\text { sham/control }\end{array}$ \\
\hline
\end{tabular}

\section{TMS and tDCS in memory studies with stroke patients}

\begin{tabular}{|c|c|c|}
\hline Jo et al. (2009) & $\begin{array}{c}10 \text { (RH stroke), } 1-4 \\
\text { months poststroke }\end{array}$ & $\begin{array}{l}\mathrm{A} / \mathrm{S}, \mathrm{L} \text { DLPFC (F3), } \\
1 \text { to } \\
\text { session per } \\
\text { protocol }\end{array}$ \\
\hline
\end{tabular}

\section{NP (TMT, WCST, Stroop, HVOT, CPM, WM): before treatment, after 2 and 8 weeks}

Verbal 3-back ref SOA, active/

\section{Results}

Stimulation

improved episodic

memory

task performance

and speed

performance.

Improvements were

still seen 1 month

later, however

scores

returned to

baseline by 5

months. ADL

improvements

reported by wife.

Mild to moderate

AD patients $(20 \mathrm{~Hz})$ showed improved

scores on all rating

scales as

compared to the 1-

$\mathrm{Hz}$ and

sham groups.

Although

improvements

were present at 1

month, scores

returned to near

baseline level by

3 months.

Both the fluoxetine and rTMS groups

showed

significant

improvement in

Stroop (colored

words), Hooper, and

WCST

(perseverative

errors), and in

depression rates.

No significant

effects on other

cognitive functions.

Accuracy in 3-back task after

stimulation with

$2 \mathrm{~mA}(20.1 \%)$ as

well

as error

frequency $(35.3 \%)$

improved

significantly

more as compared

to

stim with $1 \mathrm{~mA}$, stim over M1, or

baseline.

A-tDCS improved recognition

accuracy

as compared to sham. No impact on RT.

A, C, S, anodal, cathodal, sham; ADAS-Cog, Alzheimer's Disease Assessment Scale - Cognitive subscale; aMT, active motor threshold; ATL, anterior temporal lobe; BA, Brodmann's area; BBR, brain-behavior relationship; Cb, cerebellum; CGIC, Clinical Global Impression of Change; 
CPM, colored progressive matrices; cTBS, continuous theta-burst stimulation; $\mathrm{Cz}$, vertex; DLPFC, dorsolateral prefrontal cortex; DMS, delayed match-to-sample; DMPFC, dorsomedial prefrontal cortex; DR, discrimination rate; EF, executive functions; ERP, event-related potential; Exp., experiment; FEF, frontal eye fields; FL, frontal lobe; fO, frontal operculum; Fz, frontal midline; GDS, Geriatric Depression Scale; HF, high frequency; HVOT, Hooper Visual Organization Test; IADL, Instrumental Activities of Daily Living; IFG, inferior frontal gyrus; IFJ, inferior frontal junction; IPL, inferior parietal lobule; IPS, intraparietal sulcus; ITI, intertrain interval; L, left; LA/RA, left anodal/right anodal; LC/RC, left cathodal/ right cathodal; LF, low frequency; LH, left hemisphere; LOC, lateral occipital cortex; M1, primary motor cortex; MFG, middle frontal gyrus; MMSE, Mini Mental State Examination; MSO, maximum stimulator output; NP, neuropsychological; NPI, neuropsychiatric inventory; OC, occipital cortex; OFC, orbitofrontal cortex; p, pulse; PANAS, positive and negative symptoms scale; PC, parietal cortex; PCG, postcentral gyrus; PD, Parkinson's disease; PFC, prefrontal cortex; PL, parietal lobule; PM, prospective memory; PMC, premotor cortex; PPC, posterior parietal cortex; ppTMS, paired-pulse transcranial magnetic stimulation; R, right; RBMT, Rivermead Behavioural Memory Test; rCBF, regional cerebral blood flow; ref, reference; RH, right hemisphere; rMT, resting motor threshold; R-pSAC and L-pSAC, right and left parietal somatosensory association cortex; RT, reaction time; rTMS, repetitive transcranial magnetic stimulation; S1, primary somatosensory cortex; SFG, superior frontal gyrus; sign., significant; SMG, supramarginal gyrus; SOA, supraorbital area; sp, single pulse; SPL, superior parietal lobule; stim, stimulation; STM, short-term memory; T, tesla; TL, temporal lobe; TMT, trail making test; TPC, temporoparietal cortex; tRNS, transcranial random noise stimulation; TSOS, transcranial slow oscillation stimulation; VAT, visual attention task; VLPFC, ventrolateral prefrontal cortex; VPFC, ventral prefrontal cortex; VFT, verbal fluency test; VRT, visual recognition task; WAIS, Wechsler Adult Intelligence Scale; WCST, Wisconsin Card Sorting Test; WM, working memory; y, years. 